\title{
The Impact of Consumer Credit Access on Unemployment*
}

\author{
Kyle F. Herkenhoff ${ }^{\dagger}$ \\ UCLA \\ Department of Economics
}

November 22, 2013

\begin{abstract}
Unemployed households' access to unsecured revolving credit (credit cards) nearly quadrupled from about 12 percent to about 45 percent over the last three decades. This paper analyzes how this large increase in revolving credit has impacted the business cycle. The paper develops a general equilibrium business cycle model with search in both the labor market and in the credit market. This generates a very rich and empirically plausible level of heterogeneity in work and credit histories while at the same time permitting a tractable model solution. Calibrating to the observed path of credit use between 1974 and 2012, I find that the large growth in credit access leads to deeper and longer recessions as well as moderately slower recoveries. Relative to an economy with credit fixed at 1970s levels, employment reaches its trough about 1 quarter later and remains depressed by up to .8 percentage points three years after the typical recession in this time period (e.g. employment is depressed by $2.8 \%$ rather than $2 \%$ ). The mechanism is that when borrowing opportunities are easy to find, households optimally search for better-paying but harder-to-find jobs knowing that if the job search fails they can obtain credit to smooth consumption. Despite longer recessions and slower recoveries, increased credit card use enhances welfare by reducing consumption volatility and improving job-match quality.
\end{abstract}

${ }^{*}$ I would like to thank Gary Hansen, Lee Ohanian, and Pierre-Olivier Weill for their guidance and support. I would like to thank Andy Atkeson, Manuel Amador, Yves Balasko, Hugo Hopenhayn, Erik Hurst, Tim Kehoe, Ricardo Lagos, Ellen McGrattan, Seth Neumuller, Guido Menzio, Casey Mulligan, Ana Luisa Pessoa Araujo, Fabrizio Perri, Ed Prescott, Andrea Raffo, Guillaume Rocheteau, Jim Schmitz, and Nancy Stokey for useful comments. This paper was partly written at the Federal Reserve Bank of Minneapolis and the Federal Reserve Bank of St. Louis. I am especially grateful for their hospitality. I also thank the UCLA Ziman Center for Real Estate for funding this research.

†Correspondence: kfh@ucla.edu 


\section{Introduction}

Over the last 30 years, the fraction of unemployed households with access to unsecured revolving credit (e.g. credit cards) nearly quadrupled from $12 \%$ in 1977 to $45 \%$ in 2010 . Such access to credit is quantitatively important for the unemployed. Unemployed households replace 11-18\% of lost income through unsecured borrowing (Sullivan [2008]) while nearly $40 \%$ of households self-report defaulting on non-mortgage payments in response to job loss (Hurd and Rohwedder [2010]). Although a large literature including Ljungqvist and Sargent [1998] examines the impact of unemployment benefit duration and replacement rates on employment incentives and economic recoveries, the macroeconomic effects of credit access on households' job finding behavior remains an open question. In this paper, I theoretically and quantitatively examine how the growth in households' access to credit markets over the last 3 decades has affected the way employment evolves over the business cycle.

Through addressing this question, the paper makes three contributions. Theoretically, it develops a general equilibrium search and matching model with defaultable debt. Quantitatively, it measures the mechanisms through which credit access impacts unemployment over the business cycle, detailing in a series of experiments the crucial role of credit access growth and its impact on employment recoveries from 1974 to 2012. And empirically, it presents aggregate time series for unemployed households' access to credit and use of credit from 1970 onwards.

After calibrating to the observed path of credit use between 1974 and 2012, I find that growth in credit coming out of the 1990, 2001, and 2007 recessions delays the trough of employment by about 1 quarter and generates up to an additional .8 percentage point decline in employment three years after the initial downturn relative to an economy in which credit access is fixed at 1970 s levels. ${ }^{1}$ The mechanism generating this employment slowdown is that growth in credit access coming out of a recession acts as a safety net allowing households to search for better-paying but harder-to-find jobs. The side effects are lower job finding rates and higher unemployment. Nevertheless, because credit access reduces consumption volatility and improves job-match quality, households would be willing to sacrifice .12\% of lifetime consumption in order to be born in an economy with 2010 levels of credit access as opposed to an economy with 1970s levels of credit access. ${ }^{2}$

Underlying these results is a general equilibrium business cycle model in which households search for both jobs and borrowing opportunities. Business cycles are driven by aggregate

\footnotetext{
${ }^{1}$ E.g., employment is depressed by $2.8 \%$ with credit growth rather than $2 \%$ with fixed 1970 s levels of credit three years after the onset of the recession, and the employment trough is reached 5 quarters after the peak rather than 4 quarters after the peak.

${ }^{2}$ While not the focus, this paper has implications for the jobless recovery literature, suggesting that some portion of these slow recoveries may actually be optimal. Concurrent work by Mitman and Rabinovich [2012] finds a large impact of unemployment benefits on recoveries and is the closest study to the present paper (see also Schreft and Singh [2003], Bachmann [2009], Shimer [2010], Jaimovich and Siu [2012], and Berger [2012] among many others).
} 
labor productivity and households choose which jobs to search for, knowing that higher paying jobs take longer to find, especially when labor productivity is depressed (Menzio and Shi $[2010,2011])$. If a household successfully meets a lender in the credit market, it has access to defaultable debt contracts which are priced similar to Eaton and Gersovitz [1981]. On the other side of the market, lenders direct credit offers to households to maximize profits, and so the arrival rate of borrowing opportunities is an equilibrium object that depends on the household's employment status and fluctuates with the aggregate state. ${ }^{3}$ This market structure delivers heterogeneous and endogenously fluctuating access to three insurance channels of unsecured revolving credit: agents can borrow more, roll over prior debts, or default if neither of the prior options are optimal.

To generate the persistent and continual credit expansions observed over the last 3 decades, the model incorporates stochastic, exogenous technological progress in the aggregate efficiency of matching lenders to households. The empirical counterpart of such credit matching efficiency growth is credit scoring, the digitization of the banking sector, and the availability of online loans, among other numerous innovations. ${ }^{4}$ In addition to this exogenous growth in credit, as unemployment durations and default risks endogenously change over the business cycle, lenders expand and restrict the number of credit offers they send, altering household job finding behavior. The general mechanism is that when borrowing opportunities are easy to find, households optimally search for higher-paying but scarcer jobs knowing that if the job search fails they can obtain credit to smooth consumption.

Because the model features directed search in both the labor market and asset market, and since debt contracts are individually priced, I am able to prove that a Recursive Competitive Equilibrium exists with aggregate risk in which the distribution of agents across states does not enter policy functions or prices. In other words, the economy admits a Block Recursive Equilibrium (Menzio and Shi [2010, 2011]).

In the first set of stochastic steady-state experiments, I shut down the exogenous credit matching efficiency growth, and I show that business cycle dynamics across economies with constant but differing levels of credit access are nearly identical. This is because greater credit access produces two offsetting effects. The first of which is a pure self-insurance effect. In the short run, holding the wealth distribution constant, greater credit access allows households to be more selective with the jobs they take. The second effect is an offsetting wealth distribution effect. In the long run with greater credit access, households save less and borrow more. As they deplete their savings, the ability of households to self-insure actually returns to its pre-credit expansion levels. But, it is precisely this ability to self-insure which determines

\footnotetext{
${ }^{3}$ By using directed search in the consumer credit market, this paper relates to the market microstructure of consumer credit markets. Related work by Drozd and Nosal [2008] and Drozd and Serrano-Padial [2012] study a consumer credit market with similar features to Burdett and Judd [1983]. Work by Wasmer and Weil [2000], Petrosky-Nadeau [2009], and Petrosky-Nadeau and Wasmer [2013] find important interactions between random search in the labor market and random search in the credit market for firms.

${ }^{4}$ See Mester [1997] for more on credit scoring and the decline in time to process loans, and see Berger et al. [1995] for more on the digitization of banking.
} 
how employment evolves during a recession. As a result, business cycles which occur close to credit expansions, before the offsetting wealth adjustment occurs, are fundamentally different from business cycles which occur during periods of constant credit.

The main experiment is then to feed actual labor productivity residuals into two identical economies from 1974-2012, except one economy receives increases in the credit matching efficiency calibrated to observed credit use among the unemployed while the other economy has credit matching efficiency remain at 1970s levels, and to then compare employment recoveries along the transition path. Following the 1990, 2001, and 2007 recessions, growth in access to unsecured revolving credit generates up to an additional .8 percentage point decline in employment 12 quarters after the initial onset of these recessions compared to an economy that has 1970s levels of credit access. ${ }^{5}$ These estimates of employment effects from credit growth straddle those of the 2008 unemployment benefit extensions (Rothstein [2011] and Hagedorn et al. [2013]). Compared to the economy with 1970s levels of credit access, allowing for credit growth brings employment deviations $24 \%, 48 \%$, and $15 \%$ closer to the data three years after the initial onset of the 1990, 2001, and 2007 recessions, respectively.

There are several testable implications of the theory. The model is consistent with the precipitous reduction in liquid asset holdings by households over the 1974-2012 time period, the trend rise in defaults per capita over that same time period, and the long run decline in consumption volatility relative to income volatility. The model's self-insurance mechanism also produces a long run rise in unemployment durations that is broadly consistent with the aggregate data (Abraham and Shimer [2001] and Mukoyama and Şahin [2009]). Using the new 2007-2009 Survey of Consumer Finances (SCF) panel, I also provide suggestive evidence that the model's self-insurance mechanism is consistent with micro data by showing that credit access is significantly and positively correlated with individual unemployment durations. Among credit applicants, those who were denied credit had unemployment durations that were 6 weeks shorter, on average. However the inherent endogeneity, time aggregation bias, and lack of business cycle variation in the data require the use of a structural model to properly answer the question posed in this paper.

While much is known both theoretically and empirically about the way unemployment insurance and saving decisions impact employment incentives (inter alia Mortensen [1976], Katz and Meyer [1990], Hansen and İmrohoroğlu [1992], Hopenhayn and Nicolini [1997], Ljungqvist and Sargent [1998], and Acemoglu and Shimer [1998]), only recently has the profession considered the way labor markets are affected by other private consumption smoothing mechanisms such as home equity loans (Hurst and Stafford [2004]), default arrangements (Athreya and Simpson [2006], Han and Li [2007], Gordon [2011], Herkenhoff and Ohanian [2012], Herkenhoff [2012], Chen [2012] and Dobbie and Song [2013]), and mortgage modifications (Mulligan [2008, 2012] and Herkenhoff and Ohanian [2011]). The present paper contributes to this research agenda by explicitly modeling and measuring the interaction

\footnotetext{
${ }^{5}$ Jappelli and Pagano [1994] find that loose consumer credit limits may harm economic growth, and Calvo et al. [2006] finds that there can be strong recoveries without private credit expansions.
} 
between access to credit markets and household job search behavior over the business cycle.

Several other studies including Crossley and Low [2005], Athreya and Simpson [2006], Rendon [2006], and Guerrieri and Lorenzoni [2011] have looked at the role borrowing constraints play in models with partial equilibrium labor markets and found significant interactions between borrowing constraints and labor supply, while general equilibrium work by Krusell et al. [2010] and Nakajima [2012] find moderate effects of saving on labor markets. ${ }^{6}$ Concurrent work by Bethune et al. [2013] provides a steady state general equilibrium analysis of the way consumer credit affects labor markets through firm productivity. The present paper departs from theirs as their model shuts off the insurance channel of unsecured credit by assuming households cannot carry debts between periods, households do not make job search decisions in their model, and their analysis is not concerned with business cycles.

The paper proceeds as follows. Section 2 presents evidence of unsecured credit use by the unemployed, Section 3 outlines the model, Section 4 describes the steady state calibration, Section 5 provides steady state results, Section 6 analyzes the non-linear impulse responses of the model near steady state, Section 7 explains the transition path calibration, Section 8 includes the transition path results, and Section 9 concludes.

\section{Credit and Unemployment in the Data}

Section 2.1 presents time series of access to credit by the unemployed, showing that access more than doubled between 1983 and 1992 and more than tripled between 1977 and 1992. Section 2.2 describes existing evidence of credit use among the unemployed. Section 2.3 analyzes the correlation between credit access and time spent unemployed, framing the inherent endogeneity and data limitations associated with any reduced form answer to the main question.

\subsection{Unemployed Access to Credit 1970-2012}

In this section I present new time series for credit access and credit use based on the Survey of Consumer Finances from 1983 to 2010 and its predecessor, the Survey of Consumer Credit, from 1970 to 1977. Figure 1 depicts the unsecured revolving credit access rates among all households as well as among the unemployed. Unsecured revolving credit is taken to be the fraction of households with bankcards that have a revolving feature (when I refer to credit cards, I am referring to bankcards). Between 1983 and 1992, unsecured revolving credit access rates among the unemployed doubled. Among all households including those without credit access, Figure 2 shows that the fraction of unemployed households carrying positive balances also doubled between 1983 and 1992. Figure 3 plots the ratio of revolving credit balance to monthly income (measured as an average over the prior year) for the sample

\footnotetext{
${ }^{6}$ In one extension Nakajima [2012] modifies his model to allow for borrowing. He finds that allowing for borrowing has little impact on aggregates largely because the calibration produces near-zero borrowing in equilibrium and by assumption households do not make job search decisions.
} 
of borrowers with positive balances. These borrowers carried revolving balances of roughly 100\% of their prior monthly wages in 1991 and 200\% of their prior monthly wages by 2001 . Figure 4 shows the average nominal balance for those with positive balances, the numerator of Figure 3. The main takeaway from these pictures is that revolving credit access and use grew enormously during the 1980s, not just for the employed but also for the unemployed.

Figure 1: Fraction of Population with Access to Credit

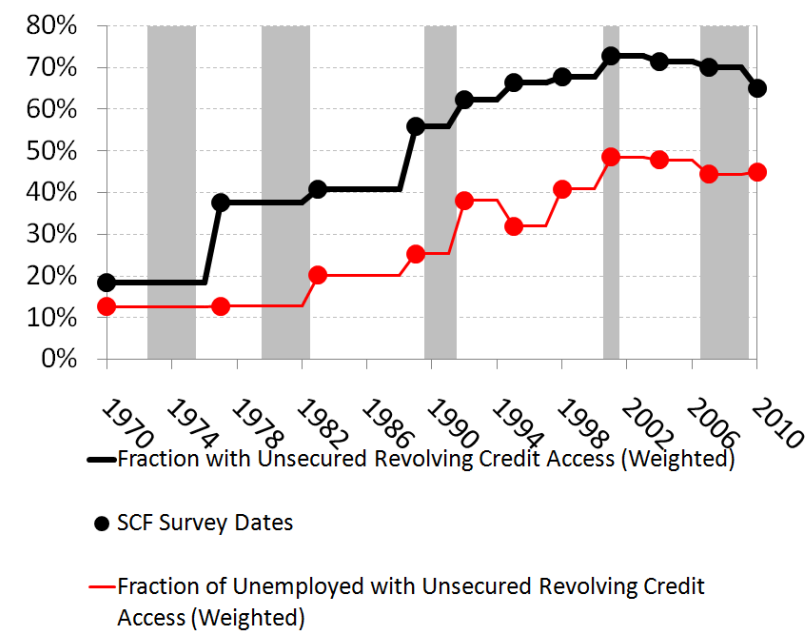

Figure 3: Revolving Credit to Monthly Income Ratios, Conditional on Holding a Positive Balance

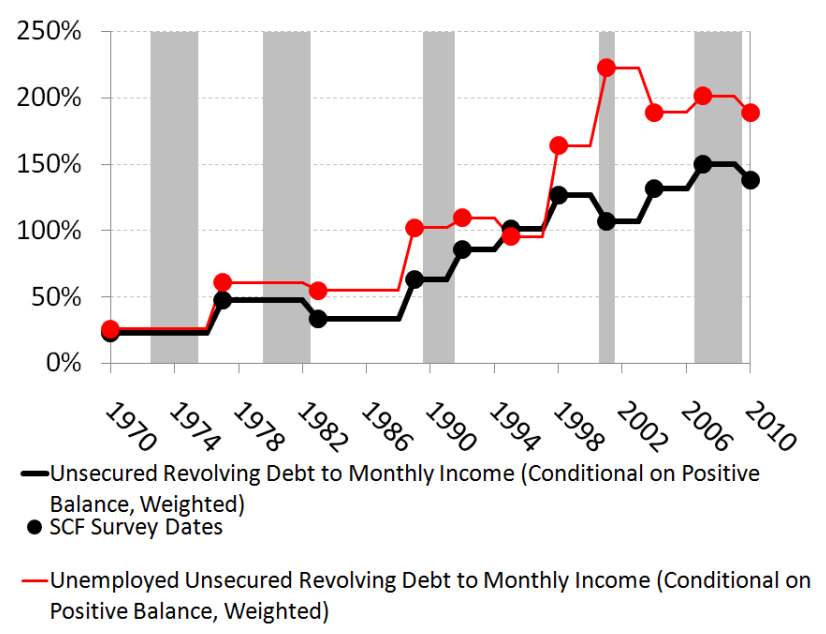

Figure 2: Fraction of Population Carrying Positive Balances

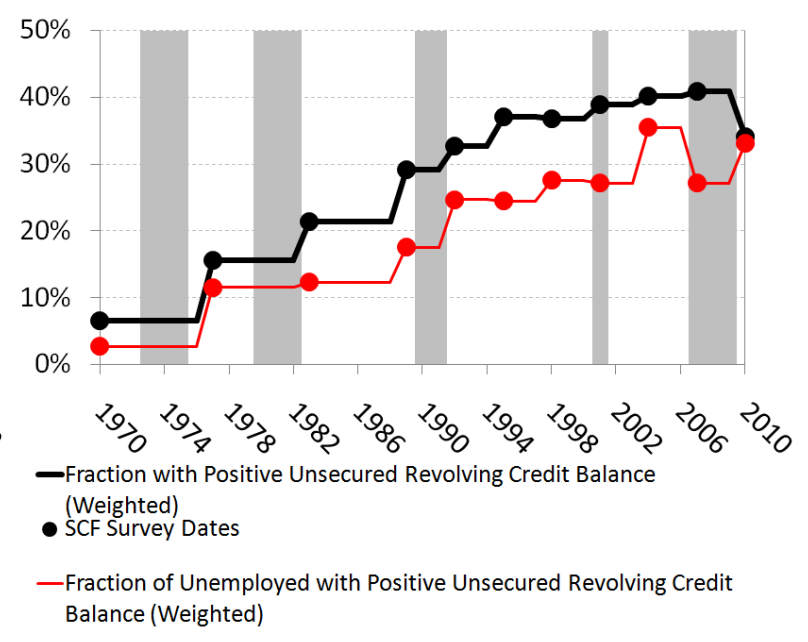

Figure 4: Average Nominal Balance, Conditional on Holding a Positive Balance

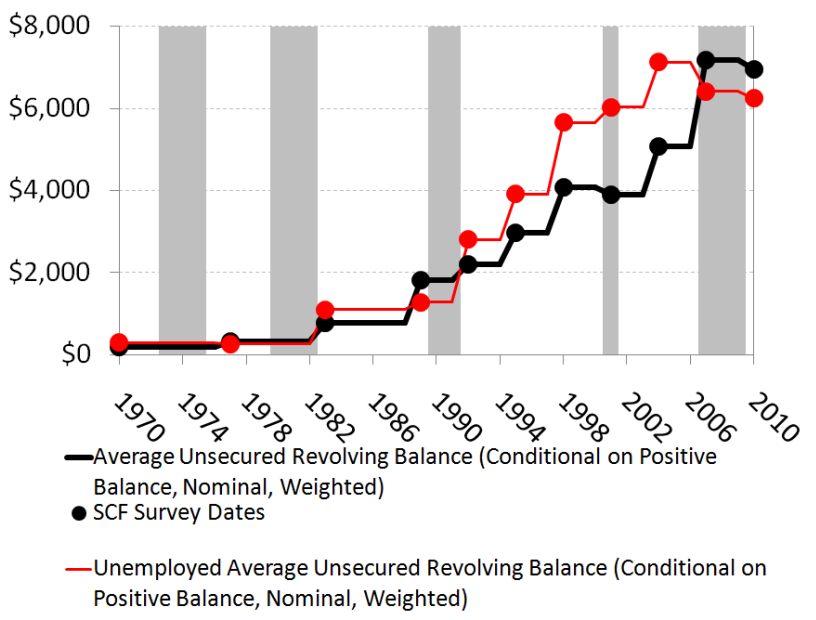

To gauge the degree of total available self-insurance, in the online appendix, I establish two more facts from the SCF: (i) the mean ratio of the unused credit limit to annual gross 
income grew from $12 \%$ in 1989 to $34 \%$ in 2007, and (ii) the mean ratio of liquid assets plus unused credit to income also grew from $79 \%$ in 1989 to $93 \%$ in $2007 .{ }^{7}$

\subsection{Existing Evidence of Credit Use Among the Unemployed}

Evidence that the unemployed borrow to replace income is provided by Sullivan [2008] and Hurd and Rohwedder [2010]. Using an indirect approach, Sullivan [2008] finds that unemployed households with low assets increase unsecured debt by 11-18 cents per dollar of lost income (this effect holds in both the Panel Study of Income Dynamics and Survey of Income and Program Participation). Using a more direct approach, Hurd and Rohwedder [2010] find that $18 \%$ of unemployed households self-report using unsecured credit to replace lost income. Hurd and Rohwedder [2010] also find that at least 36\% of households self-report at least some degree of non-mortgage default in response to job loss. Their study is based on the 2009 RAND American Life Panel. ${ }^{8}$

\subsection{Credit Supply and Time Spent Unemployed}

While recent work by Chetty [2008] has shown that access to liquid assets in the form of severance payments increases unemployment durations significantly, there is limited evidence regarding credit access and time spent unemployed. In this section, I show that being denied credit is associated with a $38.4 \%$ reduction in the reported time spent unemployed for the subsample of 2007-2009 SCF panel heads, detailed below. While this is suggestive evidence of the mechanism being studied, the inherent endogeneity of the credit denial regressor motivates the structural model of Section 3.

Before the more formal analysis that follows, Table 1 illustrates the unemployment durations of working age heads who are labor force participants, reported a positive unemployment duration over the prior year, and applied for at least 1 loan during the 2007-2009 time period. ${ }^{9}$ These restrictions yield a sample of 95 individuals (see Table 2 for summary statistics). The average time spent out of work between 2008 and 2009 was 17 weeks for those who were denied credit between 2007 and 2009, versus 23.3 weeks for those who obtained credit, i.e. those who were denied credit had a 6.3 -week shorter average time unemployed. ${ }^{10}$ This

\footnotetext{
${ }^{7}$ Since 1989, the SCF collected credit limit information.

${ }^{8}$ In my online appendix, I show that $16 \%$ of all unemployed households (both with and without credit access) have less liquid assets than their monthly credit card balance, and defaulters have unsecured revolving debt to monthly income ratios in excess of $200 \%$. Evidence of search in credit markets including inquiries and denials is also in the online appendix.

${ }^{9}$ I use the 2007-2009 SCF Panel since it has the least aggregation bias regarding credit denial. The survey asks respondents about credit denial between 2007 and 2009 (other SCF surveys use 5 year windows) and total time spent out of work during the 12 months prior to the 2009 survey date. There is still time aggregation bias since the date of loan application and date of unemployment spell (as well as the length of any single unemployment spell) are unknown, and so the statistics reported are interpreted as correlations.

${ }^{10}$ It is also important to note that $49.1 \%$ of those who reported a positive unemployment duration during
} 
Table 1: Weeks Spent Unemployed and Credit Denial Status, Basic Tabulations (2009, SCF)

\begin{tabular}{|c|c|c|c|c|c|c|}
\hline & $\begin{array}{l}\text { Mean } \\
\text { (Wtd.) }\end{array}$ & Mean & Std. & Min & $\operatorname{Max}$ & Obs. \\
\hline Weeks Unemployed During '08-'09 if Denied During '07-'09 & 17.0 & 17.3 & 14.4 & 1 & 52 & 40 \\
\hline Weeks Unemployed During '08-'09 if Not Denied During '07-'09 & 23.3 & 23.4 & 16.6 & 2 & 52 & 55 \\
\hline Weeks Unemployed During '06-'07 if Denied During '02-'07 & 16.2 & 16 & 13.8 & 1 & 52 & 38 \\
\hline Weeks Unemployed During '06-'07 if Not Denied During '02-'07 & 18.8 & 19.7 & 18.1 & 1 & 52 & 42 \\
\hline
\end{tabular}

Table 2: Weeks Spent Unemployed and Credit Denial Status, Summary Statistics (2009, $\mathrm{SCF}$ )

\begin{tabular}{|c|c|c|c|c|c|}
\hline Variable & Mean & Std. & Variable & Mean & Std. \\
\hline Log Weeks Unemployed over Prior Year & 2.67 & 0.96 & Credit Utilization Rate 2009 & 0.25 & 0.43 \\
\hline Strict Credit Denial 2009 (d) & 0.42 & 0.50 & College Degree $(\mathrm{d})$ & 0.20 & 0.40 \\
\hline Total Income in 2006 ( $\$$ ten thousands) & 5.32 & 13.89 & Male (d) & 0.74 & 0.44 \\
\hline Liquid Assets to Income Ratio 2009 & 0.26 & 1.15 & Married (d) & 0.45 & 0.50 \\
\hline Illiquid Assets to Income Ratio 2009 & 1.20 & 5.90 & Age & 39.58 & 11.07 \\
\hline Unsecured Debt to Income Ratio 2009 & 0.10 & 0.41 & Race (d) & 0.27 & 0.45 \\
\hline Observations & 95 & & & & \\
\hline
\end{tabular}

correlation persists in the more formal analysis below once I control for observables. The same correlation pattern also holds true among mortgagors (in fact the correlation is even stronger) and also in previous time periods which are subject to much more time aggregation bias.

Wages, education, and other demographics may play an important role in understanding this negative correlation between weeks spent unemployed and credit denial. Low wage workers are more likely to be denied credit, and, as we know from Autor and Dorn [2009] and Jaimovich and Siu [2012] among others, the labor market has polarized and low wage workers have more job opportunities than before (thus lower durations). I correct for this observed heterogeneity by including controls for prior income during 2006, as well as basic demographic and balance sheet controls. ${ }^{11}$

2008-2009 applied for credit whereas 53.6\% of the employed applied for credit. Thus, the correlation is not simply driven by the fact that employed persons apply more often and are thus denied more often.

${ }^{11}$ There is also an important role for unobserved heterogeneity as there may be 'bad types' who are denied 
Table 3: Weeks Spent Unemployed Between 2008-2009 and Credit Denial Between 2007-2009. Dependent Variable is Log of Weeks Spent Unemployed Between 2008-2009, (2007-2009 SCF)

\begin{tabular}{|c|c|c|c|c|}
\hline & $(1)$ & $(2)$ & $(3)$ & $(4)$ \\
\hline Credit Denial 2009 (d) & $\begin{array}{c}-0.415^{* *} \\
(0.202)\end{array}$ & $\begin{array}{c}-0.412^{*} \\
(0.210)\end{array}$ & $\begin{array}{c}-0.394^{*} \\
(0.212)\end{array}$ & $\begin{array}{c}-0.384^{*} \\
(0.215)\end{array}$ \\
\hline Total Income in 2006 ( $\$$ ten thousands) & & $\begin{array}{c}0.00209 \\
(0.00325)\end{array}$ & $\begin{array}{c}0.00388 \\
(0.00295)\end{array}$ & $\begin{array}{c}0.00351 \\
(0.00300)\end{array}$ \\
\hline Liquid Assets to Income Ratio 2009 & & & $\begin{array}{c}0.137^{* * *} \\
(0.0348)\end{array}$ & $\begin{array}{c}0.131^{* * *} \\
(0.0358)\end{array}$ \\
\hline Illiquid Assets to Income Ratio 2009 & & & $\begin{array}{c}0.0204^{* * *} \\
(0.00696)\end{array}$ & $\begin{array}{c}0.0200^{* * *} \\
(0.00691)\end{array}$ \\
\hline Unsecured Debt to Income Ratio 2009 & & & $\begin{array}{c}0.00637 \\
(0.148)\end{array}$ & $\begin{array}{c}0.0588 \\
(0.164)\end{array}$ \\
\hline Credit Utilization Rate 2009 & & & & $\begin{array}{l}-0.175 \\
(0.232)\end{array}$ \\
\hline Demographic Controls & No & No & Yes & Yes \\
\hline Observations & 95 & 95 & 95 & 95 \\
\hline R-squared & 0.046 & 0.077 & 0.123 & 0.129 \\
\hline \multicolumn{5}{|c|}{$\begin{array}{l}\text { Notes. Robust Standard Errors in parentheses. Asterisk legend: } * * * \mathrm{p}<0.01,{ }^{* *} \mathrm{p}<0.05,{ }^{*} \mathrm{p}<0.1 \\
2009 \mathrm{SCF} \text { non-mortgagor working-age heads who are labor force participants, reported a positive } \\
\text { number of weeks spent unemployed over the prior } 12 \text { months, and sent at least one loan applicatior } \\
\text { between the } 2007 \text { and } 2009 \text { survey dates. Demographic controls include, age, race, sex, marital status } \\
\text { and education. OLS coefficients reported in columns }(1)-(4) \text {. Dependent variable is the log of week } \\
\text { spent out of work over the prior } 12 \text { months to the } 2009 \text { survey date. Observations are unweighted. }\end{array}$} \\
\hline
\end{tabular}

Table 3 reports OLS coefficients from a regression of the log number of weeks spent unemployed between 2008 and 2009 on the credit denial status measured between 2007 and 2009. Column (1), which has no controls, shows that being denied credit between 2007 and 2009 is associated with a $41.5 \%$ reduction in the reported time spent unemployed between 2008 and 2009. The correlation is essentially unchanged in column (2) after including total 2006 income, in levels, as a proxy for prior wages. Including controls for age, marital status, sex, and education as well as balance sheet controls for liquid assets and illiquid assets does not significantly alter the result as shown in Column (3). ${ }^{12}$ Finally, as Column (4) demonstrates, credit utilization rates are not driving the correlation. Column (4) shows that being denied credit between 2007 and 2009 is associated with a $38.4 \%$ reduction in the reported time spent unemployed between 2008 and 2009. While this is suggestive of the static mechanism, the inherent endogeneity, time aggregation bias, and lack of business cycle variation make such estimates difficult to interpret. Therefore, I will turn to a structural model.

credit and have trouble finding jobs. This would bias the coefficient on credit denial toward zero.

${ }^{12}$ While not reported here, including unemployment benefits, another extremely endogenous covariate, does not alter the reported relationship. 


\section{Model}

The model features labor productivity-driven business cycles with directed search and matching in both the labor market and defaultable debt market. Households direct their search among wage submarkets, and once matched with a firm, wages are fixed until there is an exogenous separation (Appendix C allows for on-the-job-search). Firms operate a constant returns to scale technology which converts one indivisible unit of labor into final consumption goods, where the amount of final consumption goods produced depends solely on aggregate labor productivity.

Households also search for lenders. Once matched with a lender, households can borrow using one-period, non-contingent, and non-enforceable loans. Taking into account default risk, these loans are priced individually along the intensive margin as in Eaton and Gersovitz [1981] and Chatterjee et al. [2007]. On the other side of the credit market, lenders observe the state space of households and then direct credit offers toward households to maximize expected profits. Consequently, the household's employment status and prior financial position endogenously determine access to credit.

To generate the large and persistent increases in credit access observed from 1970 to 2012 , I allow for technological progress in the efficiency of matching households to lenders. As I will explain in detail below, growth in credit access is crucial for understanding business cycles over the 1970-2012 time period. When credit expands coming out of a recession, households optimally choose to look for scarcer jobs in high-wage submarkets, understanding that if their job search fails they can easily obtain credit to smooth consumption.

To obtain analytical results and clarify the economic mechanism at play, I start with a model in which all lending relationships last one period. In the calibrated model, however, I consider multi period lending relationships to establish better contact with the data. In a separate extension in Appendix C, I also consider the role of on-the-job-search.

\subsection{Household Problem}

Time is discrete and runs forever. As in Menzio et al. [2012], there are $T \geq 2$ overlapping generations of risk averse households that face both idiosyncratic and aggregate risk. Each household lives $T$ periods deterministically and discounts the future at a constant rate $\beta \in$ $(0,1)$. Every period households first participate in an asset market where they search for borrowing opportunities and make asset accumulation and default decisions. After the asset market closes, households enter the labor market where they make job search decisions.

Similar to Dubey et al. [1990, 2005] and Zame [1993], consumers maximize the present discounted value of preferences over non-durable consumption $(c)$ and leisure $(\eta)$ net of any utility penalties of default, $x(D)$, where $D$ is the fraction of debt defaulted upon. ${ }^{13}$ I assume

\footnotetext{
${ }^{13}$ Unlike bankruptcy which is acyclical, Herkenhoff [2012] uses Equifax data to show that default (defined
} 
that labor is indivisible so that employed households consume their entire time endowment of leisure, and preferences are separable between consumption and leisure. The utility function of the employed is $u(c)-x(D)$ and the utility function of the unemployed is $u(c)+\eta-x(D)$ so that the interpretation of $\eta$ is as a flow utility of leisure. Let $t$ be age and $t_{0}$ index birth cohort, and let $h_{t, t_{0}+t}$ equal one if the agent is employed. Then $c_{t, t_{0}+t}, \eta \cdot\left(1-h_{t, t_{0}+t}\right)$, and $D_{t, t_{0}+t}$ respectively denote the consumption, leisure, and default outcomes of an age $t$ agent at date $t_{0}+t$. The goal of a newly born in cohort $t_{0}$ is to maximize

$$
E_{t_{0}}\left[\sum_{t=1}^{T} \beta^{t}\left(u\left(c_{t, t_{0}+t}\right)+\eta \cdot\left(1-h_{t, t_{0}+t}\right)-x\left(D_{t, t_{0}+t}\right)\right)\right] .
$$

Anticipating the recursive nature of the problem below, I will drop the age and time subscripts from variables and only retain the age subscript $t$ for the value function.

A household's state vector consists of their current employment status $e \in\{W, U\}$ where $e=W$ if employed and $e=U$ if unemployed, their credit access status $a \in\{C, N\}$ where $\mathrm{a}=C$ indicates the individual has credit access and is synonymous with being matched to a lender and $\mathrm{a}=N$ indicates no credit access, their current wage $w \in \mathcal{W} \equiv[\underline{w}, \bar{w}] \subseteq \mathbb{R}_{+}$ if employed or unemployment benefits $z \in \mathcal{Z} \equiv[\gamma \underline{w}, \gamma \bar{w}] \subseteq \mathbb{R}_{+}$where $\gamma \in(0,1)$ is the replacement rate if unemployed, their net assets $b \in \mathcal{B} \equiv[\underline{b}, \bar{b}] \subseteq \mathbb{R}$, their age $t \in \mathbb{N}_{T} \equiv$ $\{1, \ldots, T\}$, and the aggregate state $\Omega .{ }^{14}$

The aggregate state $\Omega$ includes three components. The first component is aggregate productivity $y \in \mathcal{Y}$, the second component is the aggregate credit matching efficiency $A \in \mathcal{A}$, and the third component is an infinite dimensional object $\mu$ which summarizes the distribution of households across all state variables, i.e. $\mu:\{W, U\} \times\{C, N\} \times \mathcal{W} \cup \mathcal{Z} \times \mathcal{B} \times \mathbb{N}_{T} \rightarrow[0,1]$. Let $\mu^{\prime}=\Phi\left(\Omega, A^{\prime}, y^{\prime}\right)$ be the law of motion for the distribution.

At the start of every period, households wait passively to match with lenders. I will refer to this as search in the classic Mortensen and Pissarides [1994] sense. Similar to Mortensen and Pissarides [1994] in which firms post vacancies to attract employees, in the present model, lenders send credit offers to attract borrowers. Similar to the way a job vacancy is filled by a household in Mortensen and Pissarides [1994], in the present paper, if a credit offer successfully reaches a household, a match is struck between the lender and household I call this obtaining credit access. The terms of the loan are then determined by bargaining.

As is standard in the literature $b^{\prime}$ is net assets. If $b^{\prime}>0$ the agent is saving and if $b^{\prime}<0$ the agent is borrowing. If the agent is matched with a lender and opts to borrow, then $b^{\prime}<0$ indicates the face value of the loan, $q$ is the discount on the face value (which I will

to be $90+$ days late) is approximately a continuous choice (i.e. consumers default on 2 or 3 out of 6 credit lines), is highly procyclical, and occurs 6x more frequently than bankruptcy. Herkenhoff [2012] also shows that nearly $30 \%$ of delinquent credit lines end up in collection, indefinitely, and Furletti [2003] documents that banks sell defaulting non-bankrupt accounts to collection agencies for 5 cents per 1 dollar.

${ }^{14}$ The set of operating wage submarkets is an equilibrium object. The bounds $[\underline{w}, \bar{w}]$ are non-binding but used in the existence proofs. 
also call the bond price), and thus households receive $-q \times b^{\prime}$ units of the numeraire (the final consumption good) in exchange for their non-enforceable promise to repay $-b^{\prime}$ units of the final consumption good tomorrow. The discount on the bonds $q$, in equilibrium, is a function of the state space of the household; for example, if today's aggregate state is $\Omega$, the resulting bond price for an age $t$ unemployed household $(U)$ with unemployment benefits $z$ who is requesting a loan of size $b^{\prime}$ is $q_{U, t}\left(z, b^{\prime} ; \Omega\right)$. In general, the discount on the face value of the loan is greater than the riskless discount $q_{U, t}\left(z, b^{\prime} ; \Omega\right) \leq \frac{1}{1+r_{f}}$ and will vary individually depending on the household's individual default risk (Section 3.2 provides more details about lenders). If the household saves $b^{\prime}>0$ then the household must pay $\frac{1}{1+r_{f}} \times b^{\prime}$ units of the final consumption good today in order to receive $b^{\prime}$ units of the final consumption good tomorrow. To unify notation, $q_{U, t}\left(z, b^{\prime} ; \Omega\right)=\frac{1}{1+r_{f}}$ if $b^{\prime}>0$ and the household saves.

Because I assume that lenders can direct their search toward households, the probability a household receives a credit offer is a function of the state space of the household. I define $A \psi\left(\theta_{U, t}^{C}(z, b ; \Omega)\right)$ to be the probability that an age $t$ unemployed $(U)$ household with net assets $b$ and unemployment benefit income $z$ in aggregate state $\Omega$ meets a lender. I define $\theta_{U, t}^{C}(z, b ; \Omega)$ to be the corresponding credit submarket tightness (lender to household ratio) among all such households looking for credit; Section 3.2 will explain the credit market in more detail. Let $U_{t}^{C}(z, b ; \Omega)$ be the value function of an unemployed household matched with a lender and $U_{t}^{N}(z, b ; \Omega)$ be the value function of an unemployed household without credit access. Using this notation, the Bellman equation for an unemployed agent looking for a lender, $U_{t}(z, b ; \Omega)$, is

$$
\begin{gathered}
U_{t}(z, b ; \Omega)=\underbrace{A \psi\left(\theta_{U, t}^{C}(z, b ; \Omega)\right)}_{\text {Find Lender }} U_{t}^{C}(z, b ; \Omega)+\left(1-A \psi\left(\theta_{U, t}^{C}(z, b ; \Omega)\right)\right) U_{t}^{N}(z, b ; \Omega) \quad \forall t \leq T \\
U_{T+1}(z, b ; \Omega)=0 .
\end{gathered}
$$

In the current section, matches between households and lenders are destroyed at the end of every period. Households then re-match at the beginning of the period with a new lender. Later on, I allow for long term relationships with lenders.

After the asset market closes, the aggregate state is realized, and then unemployed agents enter the labor market where they look for jobs paying $\tilde{w} \in \mathcal{W}$. Each submarket is indexed by a wage and age pair $(\tilde{w}, t)$ and $p\left(\theta_{t}^{L}\left(\tilde{w} ; \Omega^{\prime}\right)\right)$ is the probability of successfully matching to an employer paying $\tilde{w}$. In this section the wage is fixed over the duration of the employment relationship, but this is relaxed in Appendix $\mathrm{C}$ when on-the-job-search is allowed. The function $\theta_{t}^{L}\left(\tilde{w} ; \Omega^{\prime}\right)$ is the submarket tightness (job vacancy to unemployment ratio) for an age $t$ agent looking for jobs paying $\tilde{w}$ given the aggregate state $\Omega^{\prime}$. If an agent successfully matches with an employer paying $\tilde{w}$ their continuation value is given by $W_{t+1}\left(\tilde{w}, b^{\prime} ; \Omega^{\prime}\right)$. Section 3.3 will explain the labor market in more detail.

The unemployed receive a separable flow utility $\eta$ from leisure by assumption. For those with access to credit, their choice set for assets includes loans, i.e. their asset choice is 
unrestricted $b^{\prime} \in \mathcal{B}$. Thus, the problem solved by an age $t$ unemployed agent $(U)$ with credit access $(C)$, unemployment benefits $z$, net assets $b$ in aggregate state $\Omega$ is

$$
\begin{aligned}
U_{t}^{C}(z, b ; \Omega)=\max _{b^{\prime} \in \mathcal{B}, D \in[0,1]} u(c)-x(D)+\eta+\beta \mathbb{E}\left[\max _{\tilde{w} \in \mathcal{W}} p\left(\theta_{t+1}^{L}\left(\tilde{w} ; \Omega^{\prime}\right)\right) W_{t+1}\left(\tilde{w}, b^{\prime} ; \Omega^{\prime}\right)\right. & \left.+\left(1-p\left(\theta_{t+1}^{L}\left(\tilde{w} ; \Omega^{\prime}\right)\right)\right) U_{t+1}\left(z, b^{\prime} ; \Omega^{\prime}\right)\right] \forall t \leq T \\
& +(1 \leq t)=0
\end{aligned}
$$

subject to the budget constraint,

$$
c+q_{U, t}\left(z, b^{\prime} ; \Omega\right) b^{\prime} \leq z+(1-D) b,
$$

and taking as given the law of motion for the aggregate state,

$$
\begin{aligned}
\Omega^{\prime} & =\left(\mu^{\prime}, A^{\prime}, y^{\prime}\right) \\
\mu^{\prime} & =\Phi\left(\Omega, A^{\prime}, y^{\prime}\right) \\
y^{\prime} & \sim F\left(y^{\prime} \mid y\right) \\
A^{\prime} & \sim G\left(A^{\prime} \mid A\right) .
\end{aligned}
$$

For those who are unemployed $(\mathrm{U})$ without access to credit $(\mathrm{N})$, the problem is similar except the household's asset choice $b^{\prime}$ is restricted to be positive, $b^{\prime} \geq 0$,

$$
\begin{aligned}
U_{t}^{N}(z, b ; \Omega)=\max _{b^{\prime} \geq 0, D \in[0,1]} u(c)-x(D)+\eta+\beta \mathbb{E}\left[\max _{\tilde{w} \in \mathcal{W}} p\left(\theta_{t+1}^{L}\left(\tilde{w} ; \Omega^{\prime}\right)\right) W_{t+1}\left(\tilde{w}, b^{\prime} ; \Omega^{\prime}\right)\right. & \left.+\left(1-p\left(\theta_{t+1}^{L}\left(\tilde{w} ; \Omega^{\prime}\right)\right)\right) U_{t+1}\left(z, b^{\prime} ; \Omega^{\prime}\right)\right] \quad \forall t \leq T \\
& \quad(1 \leq T)=0
\end{aligned}
$$

subject to the budget constraint

$$
c+\frac{1}{1+r_{f}} b^{\prime} \leq z+(1-D) b
$$

and taking as given the aggregate law of motion (1).

Employed agents in this economy face a similar credit constraint to unemployed agents. At the start of the period, employed agents are able to obtain access to credit markets with probability $A \psi\left(\theta_{W, t}^{C}(w, b ; \Omega)\right)$ which depends on the vector of household attributes. Let $W_{t}^{C}(w, b ; \Omega)$ be the value function for an employed agent that successfully matches with a lender, and $W_{t}^{N}(w, b ; \Omega)$ be the value function for an employed agent that is unable to match with a lender. Using this notation, the Bellman equation for an employed household looking for credit, $W_{t}(w, b ; \Omega)$, is

$$
W_{t}(w, b ; \Omega)=A \psi\left(\theta_{W, t}^{C}(w, b ; \Omega)\right) W_{t}^{C}(w, b ; \Omega)+\left(1-A \psi\left(\theta_{W, t}^{C}(w, b ; \Omega)\right)\right) W_{t}^{N}(w, b ; \Omega) \quad \forall t \leq T
$$




$$
W_{T+1}(w, b ; \Omega)=0 .
$$

Let $\delta_{t+1}(w ; y)$ be the state contingent job separation rate. ${ }^{15}$ Also let $q_{W, t}\left(w, b^{\prime} ; \Omega\right)$ be the bond price for an employed household. Since the model will be calibrated at a quarterly frequency, it is important to allow workers to immediately search for a job following a separation. Therefore, the problem solved by an age $t$ employed agent (W) with credit access $(\mathrm{C})$, wage $w$, and net assets $b$ in aggregate state $\Omega$ is given by

$$
\begin{aligned}
W_{t}^{C}(w, b ; \Omega) & =\max _{b^{\prime} \in \mathcal{B}, D \in[0,1]} u(c)-x(D)+\beta \mathbb{E}\left[\left(1-\delta_{t+1}\left(w ; y^{\prime}\right)\right) W_{t+1}\left(w, b^{\prime} ; \Omega^{\prime}\right)\right. \\
& \left.+\delta_{t+1}\left(w ; y^{\prime}\right) \max _{\tilde{w} \in \mathcal{W}}\left\{p\left(\theta_{t+1}^{L}\left(\tilde{w} ; \Omega^{\prime}\right)\right) W_{t+1}\left(\tilde{w}, b^{\prime} ; \Omega^{\prime}\right)+\left(1-p\left(\theta_{t+1}^{L}\left(\tilde{w} ; \Omega^{\prime}\right)\right)\right) U_{t+1}\left(\gamma w, b^{\prime} ; \Omega^{\prime}\right)\right\}\right]
\end{aligned}
$$

subject to the budget constraint,

$$
c+q_{W, t}\left(w, b^{\prime} ; \Omega\right) b^{\prime} \leq w+(1-D) b .
$$

and taking as given the aggregate law of motion (1).

For those who are employed (W) and without access to credit (N), they face the same problem except their asset choice is restricted to be positive, $b^{\prime} \geq 0$,

$$
\begin{aligned}
W_{t}^{N}(w, b ; \Omega) & =\max _{b^{\prime} \geq 0, D \in[0,1]} u(c)-x(D)+\beta \mathbb{E}\left[\left(1-\delta_{t+1}\left(w ; y^{\prime}\right)\right) W_{t+1}\left(w, b^{\prime} ; \Omega^{\prime}\right)\right. \\
& \left.+\delta_{t+1}\left(w ; y^{\prime}\right) \max _{\tilde{w} \in \mathcal{W}}\left\{p\left(\theta_{t+1}^{L}\left(\tilde{w} ; \Omega^{\prime}\right)\right) W_{t+1}\left(\tilde{w}, b^{\prime} ; \Omega^{\prime}\right)+\left(1-p\left(\theta_{t+1}^{L}\left(\tilde{w} ; \Omega^{\prime}\right)\right)\right) U_{t+1}\left(\gamma w, b^{\prime} ; \Omega^{\prime}\right)\right\}\right]
\end{aligned}
$$

subject to the budget constraint

$$
c+\frac{1}{1+r_{f}} b^{\prime} \leq w+(1-D) b
$$

and taking as given the aggregate law of motion (1).

\subsection{Saving Institutions and Lending Institutions}

There is a loanable funds market with a unit measure of risk neutral saving institutions and a unit measure of risk neutral lending institutions. Saving institutions are competitive and face a frictionless market where they accept deposits each period. These institutions have access to a risk-free technology that yields $r_{f}$ on deposits. With free entry, the yield on savings offered to consumers is this risk free rate $r_{f}$. Lending institutions on the other hand must look for agents who want to borrow. Lenders send out one-period credit offers to potential borrowers based on the borrower's characteristics. Each set of characteristics is a different submarket. The cost of sending a credit offer is $\kappa_{C}$.

\footnotetext{
${ }^{15}$ The state contingency of the separation rate is used in the existence proof to bound the firm continuation value away from zero, but will be set to a constant for computations.
} 
It is important to note that a credit offer is an invitation to bargain. If a lender successfully meets a households who wants to borrow, the lender and household Nash bargain over the bond price schedule $q_{e, t}\left(w, b^{\prime} ; \Omega\right)$ which is a function of loan size $b^{\prime}$, employment status $e$, wage $w$ if employed or unemployment benefits $z$ if unemployed, and the aggregate state $\Omega$. I assume households have a bargaining weight of unity, i.e. households make take-it-orleave-it bond price proposals. As is, this assumption leaves lenders with no incentives to enter the lending market. To generate incentives for lenders to send credit offers, I assume that lenders are guaranteed a proportional minimum servicing fee $\tau$ which is based on the loan size. Consumers then bargain over the bond schedule taking as given the proportional minimum servicing fee $\tau .{ }^{16}$ Let $b_{e, t}{ }^{*}(w, b ; \Omega)$ be the present bond policy of the household and $D_{e^{\prime}, t+1}^{a^{\prime}}\left(w^{\prime}, \hat{b} ; \Omega^{\prime}\right)$ be the future default decision of the household which depends on tomorrow's employment $e^{\prime}$, access to credit $a^{\prime}$, age $t+1$, wage $w^{\prime}$ (which takes into account the risk the household loses its job), loan size $\hat{b}$, and the aggregate state $\Omega^{\prime}$. With this notation, the expected profits accruing to a matched lender, $Q_{t}(e, w, b ; \Omega)$, are given by,

$Q_{t}(e, w, b ; \Omega)=q_{e, t}(w, \hat{b} ; \Omega) \hat{b}-\frac{1}{1+r_{f}} \mathbb{E}\left[\left(1-D_{e^{\prime}, t+1}^{a^{\prime}}\left(w^{\prime}, \hat{b} ; \Omega^{\prime}\right)\right) \cdot \hat{b}\right] \forall e \in\{W, U\}, b \in \mathcal{B}, \hat{b}=b_{e, t}^{*}(w, b ; \Omega)$

To ensure an expected minimum servicing fee of $\tau$ on the resources lent, the expected yield on the loan must be $\left(1+r_{f}+\tau\right)$ :

$$
\left(1+r_{f}+\tau\right) \leq \frac{\mathbb{E}\left[\left(1-D_{e^{\prime}, t+1}^{a^{\prime}}\left(w^{\prime}, \hat{b} ; \Omega^{\prime}\right)\right) \cdot \hat{b}\right]}{q_{e, t}(w, \hat{b} ; \Omega) \hat{b}} \forall e \in\{W, U\}, \hat{b} \in \mathcal{B}_{-}
$$

Thus the general menu of prices across loans as well as savings contracts is given below (note, the price is indexed by employment status $e \in\{W, U\})$ :

$$
q_{e, t}(w, \hat{b} ; \Omega)= \begin{cases}\frac{\mathbb{E}\left[\left(1-D_{e^{\prime}, t+1}^{a^{\prime}}\left(w^{\prime}, \hat{b} ; \Omega^{\prime}\right)\right)\right]}{\left(1+r_{f}+\tau\right)}, & \hat{b} \in \mathcal{B}_{-} \\ \frac{1}{\left(1+r_{f}\right)}, & \hat{b} \in \mathcal{B}_{+}\end{cases}
$$

Define $A \cdot M_{C}\left(u_{c}(\mathbf{x}), v_{c}(\mathbf{x})\right)$ to be the constant returns to scale matching function in credit submarket $\mathbf{x}$, where $u_{c}(\mathbf{x})$ is the number of households searching for credit with state vector $\mathbf{x}, v_{c}(\mathbf{x})$ is the number of credit offers sent to such households, and $A$ is the aggregate credit matching efficiency. Then, the credit-filling rate, which is the probability a lender matches with a household, is given by,

$$
A \cdot \phi\left(\theta_{e, t}^{C}(w, b ; \Omega)\right)=\frac{A \cdot M_{C}\left(u_{c, t}(e, w, b ; \Omega), v_{c, t}(e, w, b ; \Omega)\right)}{v_{c, t}(e, w, b ; \Omega)}
$$

\footnotetext{
${ }^{16}$ This could be endogenized as a choice by the household but at the expense of tractability. In the model, $\tau$ covers the credit offer cost and yields an incentive for lending institutions to look for potential borrowers. In the literature, imposing this wedge $\tau$ is common; see Livshits et al. [2007] for an example. From a theoretical perspective, the ex-post bargaining over the bond price makes lender's profit expectations independent of the distribution of households across states. If a lender simply posted a spread, they would have to forecast the statespace of households who would arrive at their door to form profit expectations.
} 
And the credit-finding rate, which is the probability a household meets a lender, is given by,

$$
A \cdot \psi\left(\theta_{e, t}^{C}(w, b ; \Omega)\right)=\frac{A \cdot M_{C}\left(u_{c, t}(e, w, b ; \Omega), v_{c, t}(e, w, b ; \Omega)\right)}{u_{c, t}(e, w, b ; \Omega)}
$$

The free entry condition for lenders will bind for every submarket of consumers that takes loans:

$$
\kappa_{C}=A \cdot \phi\left(\theta_{e, t}^{C}(w, b ; \Omega)\right) Q_{t}(e, w, b ; \Omega)
$$

The free entry condition can be inverted to obtain the equilibrium tightness in the credit market, $\theta_{e, t}^{C}(w, b ; \Omega)$, which can then be used to recover the credit-finding rate of the household.

\subsection{Firms}

As in Moen [1997], Menzio and Shi [2009, 2010], Karahan and Rhee [2011], and Menzio et al. [2012], I assume that firms post fixed wage contracts and there is free entry of firms. In particular, firms post vacancies in certain submarkets that are indexed by wage $w \in \mathcal{W} \subset$ $\mathbb{R}_{++}$and age $t$ (this setup is most similar to Menzio et al. [2012]). The posted wage $w$ is fixed once an employee is found. ${ }^{17}$ The submarket tightness is given by $\theta_{t}^{L}(w ; \Omega)=\frac{v_{t}(w ; \Omega)}{u_{t}(w ; \Omega)}$ where $v_{t}(w ; \Omega)$ is the number of vacancies posted in the $(w, t)$ submarket and $u_{t}(w ; \Omega)$ is the number of unemployed households in that submarket. ${ }^{18}$ The constant returns to scale of the matching function $M(u, v)$ will guarantee that the ratio of unemployed persons to vacancies is all that matters for determining job finding rates. Let the vacancy filling rate be given by $f\left(\theta_{t}^{L}(w ; \Omega)\right)=\frac{M\left(u_{t}(w ; \Omega), v_{t}(w ; \Omega)\right)}{v_{t}(w ; \Omega)}$ and let the job finding rate be given by $p\left(\theta_{t}^{L}(w ; \Omega)\right)=$ $\frac{M\left(u_{t}(w ; \Omega), v_{t}(w ; \Omega)\right)}{u_{t}(w ; \Omega)}$. The value to a firm of posting a vacancy in submarket $(w, t)$ is given below:

$$
V_{t}(w ; \Omega)=-\kappa_{L}+f\left(\theta_{t}^{L}(w ; \Omega)\right) J_{t}(w ; \Omega)
$$

With free entry it must be the case that profits are competed away. Substituting, the free entry condition is given below:

$$
\kappa_{L}=f\left(\theta_{t}^{L}(w ; \Omega)\right) J_{t}(w ; \Omega) \text { if } \theta(w ; \Omega)>0
$$

The equilibrium market tightness in the labor market, $\theta_{t}^{L}(w ; \Omega)$, can be obtained by inverting the free entry condition and then be used to recover the job finding rate of households.

To characterize $J_{t}(w ; \Omega)$, I assume that firms operate a linear technology and are subject to an exogenous job destruction rate $\delta_{t+1}\left(w ; y^{\prime}\right)$ that is state dependent. The firm value of an

\footnotetext{
${ }^{17}$ Appendix $\mathrm{C}$ allows for on the job search.

${ }^{18}$ Off equilibrium path markets will have a tightness of 0 which can be justified as the limit of a sequential game in which workers tremble as in Menzio and Shi [2011].
} 
ongoing match to a worker of age $t$ being paid wage $w$ in aggregate state $\Omega$ is given below: ${ }^{19}$

$$
\begin{gathered}
J_{t}(w ; \Omega)=y-w+\beta \mathbb{E}_{\Omega^{\prime}}\left[\left(1-\delta_{t+1}\left(w ; y^{\prime}\right)\right) J_{t+1}\left(w ; \Omega^{\prime}\right)\right] \forall t \leq T \\
J_{T+1}(w ; \Omega)=0
\end{gathered}
$$

where the aggregate law of motion for $\Omega^{\prime}$ given by (1) is taken as given.

\subsection{Timing}

The timing of the model is outlined below:

(1) Asset Market Opens: (i) Search and Matching in Asset Market, (ii) Default Decision and Asset Accumulation Decision;

(2) Aggregate Risk Resolved, Age Advances;

(3) Labor Market Opens: (i) Job Destruction, then (ii) Search and Matching in Labor Market.

\subsection{Equilibrium}

Definition of a Recursive Competitive Equilibrium: A recursive competitive equilibrium for this economy is a list of household policy functions for assets $\left\{b_{e, a, t}^{* *}(w, b ; \Omega)\right\}_{e=W, U \quad a=C, N \quad t \in \mathbb{N}_{T}}$, wage search decisions $\left\{\tilde{w}_{a, t}^{*}(w, b ; \Omega)\right\}_{a=C, N} t \in \mathbb{N}_{T}$, and the fraction of debt to default upon $\left\{D_{e, t}^{*, a}(w, b ; \Omega)\right\}_{e=W, U} a=C, N \quad t \in \mathbb{N}_{T}$, a bond price $\left\{q_{e, t}(w, b ; \Omega)\right\}_{e=W, U} t \in \mathbb{N}_{T}$, a labor market tightness function $\left\{\theta_{t}^{L}(w ; \Omega)\right\}_{t \in \mathbb{N}_{T}}$, a credit market tightness function $\left\{\theta_{e, t}^{C}(w, b ; \Omega)\right\}_{e=W, U} t \in \mathbb{N}_{T}$, distributions for the aggregate shocks $\left(F\right.$ and $G$ ), and an aggregate law of motion $\Omega^{\prime}=$ $\left(\Phi\left(\Omega, A^{\prime}, y^{\prime}\right), A^{\prime}, y^{\prime}\right)$, such that:

i. Given the prices, shock processes, and the aggregate law of motion, the household's policy functions solve their respective dynamic programming problems.

ii. The labor market tightness is consistent with free entry equation (4).

iii. The credit market tightness is consistent with free entry equation (3) .

iv. Debt is priced consistent with households making take-it-or-leave-it proposals according to equation (2).

\footnotetext{
${ }^{19}$ Notice that the expectation $\mathbb{E}_{\Omega^{\prime}}$ is over the aggregate state vector which includes the distribution of people across states (I will omit the subscript from now on)
} 
v. The law of motion of the aggregate state is consistent with household policy functions.

In order to solve the problem numerically, I will focus on a subset of competitive equilibria called Block Recursive Equilibria (see Menzio and Shi [2009], Menzio and Shi [2010], and Menzio et al. [2012] for more). A block recursive competitive equilibrium is a recursive competitive equilibrium in which the resulting decision rules and prices do not depend on the aggregate distribution of agents across states (i.e $\mu$ is not a state variable for the household, lending institutions, saving institutions, or firms). Under relatively innocuous assumptions, a Block Recursive equilibrium exists.

\subsection{Theoretical Characterization}

I will first start with characterizing the optimal default rule and bond price, two ingredients that are essential to understand the model's insurance mechanisms.

Lemma 3.1. Under the Inada conditions outlined in assumption A.ii (see Appendix A.1), for initial debt levels such that $b \in \mathcal{B}$ and $b<0$, (1) the optimal choice of $D$ is continuously differentiable over the set $[\underline{b}, \epsilon]$ for arbitrarily small $\epsilon<0$, (2) the fraction of debt defaulted upon is monotone increasing in the initial debt position $|b|, b<0$ and (3) the fraction of debt defaulted upon is monotone decreasing in subsequent resources borrowed $\left|q_{e, t}\left(w, b^{\prime} ; \Omega\right) b^{\prime}\right|$, $b^{\prime}<0$ across all ages.

The well-behaved intratemporal utility penalty of default is the key ingredient to obtain differentiability of the bond price. Why is the first claim of Lemma 3.1 important? If $\tau$ were set to zero, the bond price would be differentiable everywhere, and the model could be linearized and then potentially estimated. The second claim of Lemma 3.1 says that if $b<0$ and households begin the period with greater indebtedness (i.e. $b$ is slightly more negative) they will default on a larger fraction of that debt position. The third claim says that the fraction of debt defaulted upon is weakly increasing in the subsequent amount of resources borrowed. Thus, if the household has access to more credit in the present period, then the household will repay more of its prior debts that are due in the present period. Each of these results are intuitive and will be crucial to understanding the way bond prices reflect credit conditions as explained below.

As described in Corollary 3.2, since the bond price is an affine function of the household's default policy function, it inherits many properties.

Corollary 3.2. Under the Inada conditions outlined in assumption A.ii (see Appendix A.1), for initial debt levels such that $b \in \mathcal{B}$ and $b<0$, (1) the equilibrium bond price is continuously differentiable over the interval $[\underline{b}, \epsilon], \epsilon<0$, (2) the equilibrium bond price is monotone decreasing in resources lent and (3) the equilibrium bond price is monotone increasing in subsequent resources borrowed across all ages. 
Corollary 3.2 is important for understanding the model's intertemporal mechanics. The cost of funds today is impacted by access to funds tomorrow. Namely, if aggregate credit conditions are expected to be tight tomorrow, resources today will be lent at a higher premium, further limiting the availability of self-insurance. The opposite holds true in a credit boom where expected easy credit tomorrow results in cheap self-insurance today. This cheap self-insurance is what ultimately changes job search decisions as shown in Corollary 3.6.

I follow a similar strategy of Menzio et al. [2012] to prove the existence of a Block Recursive Equilibrium for the T-span economy. The basic strategy is to show that age $T$ terminal prices and value functions are independent of the distribution and then use backward induction to show that the remaining value functions are independent of the distribution. I deviate in some regards to Menzio et al. [2012] since, in my model, the welfare theorems break down and it does not suffice to simply solve the social planner's problem.

Proposition 3.3. Under the boundedness conditions and Inada conditions outlined in assumptions A.i-A.ii (see Appendix A.1), a Block Recursive Equilibrium exists for the T-span economy.

This is a computationally useful proposition since it states that solutions exist in which agents do not need to forecast the law of motion for the aggregate state. Is this without loss of generality? Lemma 3.4 shows that for certain functional forms, only one Recursive Competitive Equilibrium exists and it is Block Recursive.

Lemma 3.4. Suppose that $x(0)=0$ and $x(D) \rightarrow \infty \forall D>0, M(u, v)=\min \{u, v\}$ and $M_{C}\left(u_{C}, v_{C}\right)=v_{C}^{\alpha_{C}} u_{C}^{1-\alpha_{C}}$ with $\alpha_{C} \rightarrow 0$ (i.e. constant arrival rate of credit offers). Under assumptions A.i-A.ii there exists a unique Competitive Equilibrium that is also Block Recursive.

To motivate an alternative existence proof for Block Recursivity which does not rely on Schauder's fixed point theorem, I ask the question, does a Block Recursive Equilibrium exist for a version of my economy with infinitely lived agents? Under mild assumptions, the answer is yes. I adapt the 'limit of finite horizon economies' proof strategy popularized by Balasko and Shell [1980], Aiyagari [1988], and Levine [1989] among others to a setting in which I extend the lifespan in a finitely lived economy to infinity.

Proposition 3.5. Under assumptions A.i-A.ii (see Appendix A.1) and B.i-B.iii (see Appendix A.3), there exists an equilibrium sequence of prices for an infinitely lived agent economy where the equilibrium sequence of prices is independent of the distribution across states.

Proposition 3.5 is useful if one wants to drop the dimensionality of the problem and drop $t \in \mathbb{N}_{T}$ as a state variable. The only potential drawback is that the limiting set may potentially include non-stationary equilibria. In practice however, it is simple to check numerically that the limiting set contains at least one recursive equilibrium. 
Ultimately, the assumptions of Lemma 3.4 allow one to characterize the mechanism at the heart of the model - when credit access increases agents optimally search for better-paying but scarcer jobs. 20

Corollary 3.6. Under the assumptions of Lemma 3.4, the wage policy function of the household is increasing in credit access.

The intuition behind Corollary 3.6 is that credit access acts as a safety net allowing the unemployed to search for better-paying but harder-to-find jobs, knowing that if the job search fails they can obtain credit to smooth consumption. This lowers the aggregate job finding rate, ceteris paribus. In the long run, however, households ultimately save less which tends to raise the aggregate job finding rate. The experiments designed below measure these competing effects over the business cycle (see Section 6.2).

\subsection{Computational Extension: Long Lived Credit Relationships with Semi-Endogenous Default Punishments}

In this section, I allow households to match with lenders for more than one period in order to make better contact with data. While the problem of the firm remains unchanged, both the household and lender problems undergo several modifications.

With long term lending relationships, lenders are forward looking and therefore understand that households who will not necessarily borrow today may borrow in the future. Therefore all households receive credit offers and enter into matches which will persist even though the household does not immediately borrow.

It also becomes possible to punish households not only using a direct utility penalty function but also by excluding the household from borrowing in the period of default and destroying their existing match. The time it takes for the household to then regain credit access is an endogenous outcome.

\subsubsection{Long Lived Credit Relationships: Households}

Matches with lenders occur exactly as before, except once a household matches with a lender, the household remains matched to the lender until the household defaults or the match is destroyed exogenously (the exogenous breakup rate is given by $\bar{s}$ ). Let $s(D)$ describe the credit relationship breakup probability which is assumed to be contingent on the default choice $D$ :

$$
s(D)= \begin{cases}1 & \text { if } D>\underline{D} \\ \bar{s} & \text { if } D=\underline{D}\end{cases}
$$

\footnotetext{
${ }^{20}$ Computationally, Corollary 3.6 holds for every set of functional forms and parameters tested by the author.
} 
In this scenario, credit access $a \in\{C, N\}$ is a persistent state. The problem now solved by an unemployed agent $(U)$ with credit access $(C)$ is given by,

$$
\begin{aligned}
& U_{t}^{C}(z, b ; \Omega)=\max _{b^{\prime} \in \mathcal{B}, D \in[0,1]} u(c)-x(D)+\eta \\
& +(1-s(D)) \cdot \beta \mathbb{E}\left[\max _{\tilde{w} \in \mathcal{W}} p\left(\theta_{t+1}^{L}\left(\tilde{w} ; \Omega^{\prime}\right)\right) W_{t+1}^{C}\left(\tilde{w}, b^{\prime} ; \Omega^{\prime}\right)+\left(1-p\left(\theta_{t+1}^{L}\left(\tilde{w} ; \Omega^{\prime}\right)\right)\right) U_{t+1}^{C}\left(z, b^{\prime} ; \Omega^{\prime}\right)\right] \\
& \underbrace{+\quad s(D)}_{\text {Lose Credit }} \cdot \beta \mathbb{E}\left[\max _{\tilde{w} \in \mathcal{W}} p\left(\theta_{t+1}^{L}\left(\tilde{w} ; \Omega^{\prime}\right)\right) W_{t+1}\left(\tilde{w}, b^{\prime} ; \Omega^{\prime}\right)+\left(1-p\left(\theta_{t+1}^{L}\left(\tilde{w} ; \Omega^{\prime}\right)\right)\right) U_{t+1}\left(z, b^{\prime} ; \Omega^{\prime}\right)\right] \quad \forall t \leq T \\
& U_{T+1}^{C}(z, b ; \Omega)=0
\end{aligned}
$$

such that the law of motion for aggregates (1) is taken as given and the budget constraint is satisfied,

$$
c+q_{U, t}\left(z, b^{\prime}, D ; \Omega\right) b^{\prime} \leq z+(1-D) b .
$$

Notice that the bond price $q_{U, t}\left(z, b^{\prime}, D ; \Omega\right)$ now depends on the default decision. I assume that if the household defaults, no loanable funds will be made available to the household. This type of 'universal default rule' is discussed in more in Appendix B.

Universal Default Assumption: Default results in the immediate severance of all lending relationships.

In the case of a default, the household is excluded for an endogenous number of periods. The household's state vector pins down the subsequent credit-finding rate and ultimately determines when access is regranted; when lenders determine whether to lend to households, they take into account future default risk. This endogenous reaccess time is what I call a 'semi-endogenous' default punishment.

The only other household value function that changes is for an employed (W) household with credit access $(\mathrm{C})$ :

$$
\begin{aligned}
& \begin{array}{r}
W_{t}^{C}(w, b ; \Omega)= \\
\begin{array}{r}
\max _{b^{\prime} \in \mathcal{B}, D \in[0,1]} u(c)-x(D) \\
+(1-s(D)) \cdot \beta \mathbb{E}\left[\left(1-\delta_{t+1}\left(w ; y^{\prime}\right)\right) W_{t+1}^{C}\left(w, b^{\prime} ; \Omega^{\prime}\right)+\delta_{t+1}\left(w ; y^{\prime}\right)\left\{\max _{\tilde{w} \in \mathcal{W}} p\left(\theta_{t+1}^{L}\left(\tilde{w} ; \Omega^{\prime}\right)\right) W_{t+1}^{C}\left(\tilde{w}, b^{\prime} ; \Omega^{\prime}\right)\right.\right. \\
\left.\left.+\left(1-p\left(\theta_{t+1}^{L}\left(\tilde{w} ; \Omega^{\prime}\right)\right)\right) U_{t+1}^{C}\left(\gamma w, b^{\prime} ; \Omega^{\prime}\right)\right\}\right]
\end{array} \\
\underbrace{+\quad s(D)}_{\text {Lose Credit }} \cdot \beta \mathbb{E}\left[\left(1-\delta_{t+1}\left(w ; y^{\prime}\right)\right) W_{t+1}\left(w, b^{\prime} ; \Omega^{\prime}\right)+\delta_{t+1}\left(w ; y^{\prime}\right)\left\{\max _{\tilde{w} \in \mathcal{W}} p\left(\theta_{t+1}^{L}\left(\tilde{w} ; \Omega^{\prime}\right)\right) W_{t+1}\left(\tilde{w}, b^{\prime} ; \Omega^{\prime}\right)\right.\right. \\
\left.\left.+\left(1-p\left(\theta_{t+1}^{L}\left(\tilde{w} ; \Omega^{\prime}\right)\right)\right) U_{t+1}\left(\gamma w, b^{\prime} ; \Omega^{\prime}\right)\right\}\right]
\end{array}
\end{aligned}
$$

such that the law of motion for aggregates (1) is taken as given and the budget constraint is satisfied,

$$
c+q_{W, t}\left(w, b^{\prime}, D ; \Omega\right) b^{\prime} \leq w+(1-D) b
$$




\subsubsection{Long Lived Credit Relationships: Lending Institutions}

When there are long lived credit relationships, the lender's problem is no longer static and must be solved via dynamic programming. The resulting bond price and lender profit function are included in Appendix B.

\section{Stochastic Steady State Calibration}

I will first consider a stochastic steady state to illustrate the model's mechanism. Then I argue that in order to understand the 1974-2012 time period, one must consider an environment in which credit is continually and persistently expanding as opposed to a steady state experiment.

Stochastic steady state means that aggregate labor productivity still fluctuates but that aggregate credit matching efficiency is constant forever. The period is set to one quarter. I calibrate the aggregate labor productivity process to match the Bureau of Labor Statistic's output per worker in the non-farm business sector. The series is logged and band pass filtered to obtain deviations from trend with periods between 6 and 32 quarters. Aggregate productivity deviations are assumed to fluctuate over time according to an $\mathrm{AR}(1)$ process:

$$
\ln \left(y^{\prime}\right)=\rho \ln (y)+\epsilon_{1} \text { s.t. } \epsilon_{1} \sim N\left(0, \sigma_{e}^{2}\right)
$$

Estimation yields $\rho=0.8961$ and $\sigma_{e}=0.0055$, and the process is discretized using Rouwenhurst's method.

The benefit replacement rate is set to $50 \%(\gamma=.5)$ which is in line with OECD estimates of the replacement rate for the United States. For this numeric exercise, I set the job destruction rate to a constant $10 \%$ per quarter as in Shimer [2005], and so $\delta_{t+1}\left(w ; y^{\prime}\right)=.1$ across all states. The labor vacancy posting cost $\kappa_{L}$ is chosen to target a mean unemployment rate of $5.6 \%$ which is the average postwar BLS unemployment rate. For the labor market matching function, I follow Haan et al. [1997] and use a constant returns to scale matching function that yields well-defined job finding probabilities:

$$
M(u, v)=\frac{u \cdot v}{\left(u^{\zeta}+v^{\zeta}\right)^{1 / \zeta}} \in[0,1)
$$

The matching elasticity parameter is chosen to be $\zeta=1.6$ as in Schaal [2012].

The aggregate credit matching efficiency $A_{2010}$ is chosen to match the fraction of unemployed households with positive balances in the 2010 SCF. The household discount factor is set to $\beta=.98$, and the risk free rate is set to $4 \%$ as in Livshits et al. [2007]. The model closely replicates the left tail of the liquid wealth distribution for the employed and unemployed (see Table 6). I use aggregate data on credit card offers in combination with Survey of Consumer 
Finance application rates and denial rates to estimate a credit matching elasticity parameter of $\zeta_{C}=.37$ assuming the matching function is also the same as Haan et al. [1997]: ${ }^{21}$

$$
M_{C}\left(u_{c}, v_{c}\right)=\frac{u_{c} \cdot v_{c}}{\left(u_{c}^{\zeta_{C}}+v_{c}^{\zeta_{C}}\right)^{1 / \zeta_{C}}} \in[0,1)
$$

The proportional minimum servicing fee is set to $\tau=8 \%$ based on the spread between the risk free rate in the model and the average real credit card interest rate from 1974-2011 which was $12.02 \% .^{22}$

Using Equifax data, the exogenous credit separation rate $\bar{s}$ is chosen in order to match the probability of obtaining a new credit line among credit inquirers. The model equivalent of credit inquirers are those agents with non-zero credit-finding rates. This yields $\bar{s}=.25$ which yields an average credit relationship duration of roughly 1 year. Following an analogous strategy to Shimer [2005], I normalize the credit entry costs $\kappa_{C}=1.75 e^{-6}$ such that the implied average credit market tightness lies in the interval $[127.1,206.1] .{ }^{23}$

Preferences are given below (let $\mathrm{h}=1$ for employed persons and $\mathrm{h}=0$ otherwise):

$$
u(c)+\eta(1-h)-x(D) \equiv \frac{c^{1-\sigma}-1}{1-\sigma}+\eta(1-h)-\kappa_{D} \cdot \frac{D}{1-D+\epsilon}
$$

I set the risk aversion parameter to a standard value, $\sigma=2$. The functional form of $x(D)$ is one of many that satisfies the necessary inada conditions (assumption A.ii). ${ }^{24} \mathrm{I}$ set $\kappa_{D}$ to match the average fraction of balances involved in a default episode (see Table 5 below). ${ }^{25}$ To guarantee boundedness of returns, I take $\epsilon$ to be an arbitrarily small finite number. In terms of the flow utility of leisure, I follow most of the quantitative search and matching literature by setting $\eta$ to target a labor market moment. I choose $\eta$ to match the autocorrelation of unemployment since the flow utility of leisure determines unemployed households' willingness to remain out of work. The life span is set to $T=120$ quarters (30 years), and newly born agents are born unemployed, with zero assets, and the highest possible unemployment benefits.

Table 4 summarizes the model's calibrated parameters. Table 5 summarizes the model's fit relative to the targeted moments. And Table 6 summarizes the liquid wealth distribution in both the model and the data.

\footnotetext{
${ }^{21}$ See Appendix E for more details. I use non-linear least squares to estimate the elasticity parameter.

${ }^{22}$ This is an upper bound on the over-head costs since this includes a default risk component. The results are unchanged for lower values of $\tau$. Interest rate data come from the Board of Govenors and inflation data come from the BLS.

${ }^{23}$ The credit market tightness measure is available from 1995 to 2007 and is constructed as the ratio of credit card mail volume (Synovate) to credit card applicants (SCF).

${ }^{24}$ I have found that the functional form is unimportant for the main quantitative results.

${ }^{25}$ In the past, utility penalties have been calibrated to levels of asset exemption across states as in Araujo and Funchal [2006].
} 
Table 4: Summary of Parameters, 2010 Stochastic Steady State Calibration

\begin{tabular}{lll}
\hline Parameter & Value & Description \\
\hline Pre-Calibrated: & & \\
$\beta$ & 0.98 & Quarterly Discount Factor (Implied Annual Rate 8\%) \\
$r_{f}$ & 0.04 & Annualized Risk Free Rate \\
$\tau$ & 0.08 & Annualized Proportional Servicing Fee \\
$\delta$ & 0.1 & Quarterly Job Destruction Rate \\
$\rho$ & 0.8961 & Auto Correlation of Labor Productivity \\
$\sigma_{\epsilon}$ & 0.0055 & Standard Deviation of Labor Productivity \\
$\gamma$ & 0.5 & Benefit Replacement Rate \\
$\zeta$ & 1.6 & Labor Match Elasticity \\
$\zeta_{C}$ & 0.37 & Credit Match Elasticity \\
$\kappa_{C}$ & $1.75 e^{-6}$ & Credit Vacancy Cost \\
$\sigma$ & 2 & Risk Aversion \\
$T$ & 120 & Lifespan in Quarters \\
Calibrated: & & \\
$\kappa_{L}$ & 0.02 & Labor Vacancy Posting Cost \\
$\eta$ & 0.58 & Flow Utility of Leisure \\
$A_{2010}$ & 0.374 & Credit Matching Efficiency \\
$\bar{s}$ & 0.25 & Exogenous Separation Rate \\
$\kappa_{D}$ & 2.3 & Disutility of Default \\
\hline
\end{tabular}

Table 5: Simulated Moments, 2010 Stochastic Steady State Calibration

\begin{tabular}{ccccc}
\hline Parameter & Target & Model & Data & Source \\
\hline$\kappa_{L}$ & Unemployment Rate & $5.59 \%$ & $5.60 \%$ & BLS (1948-2007) \\
$\eta$ & Autocorrelation of Unemployment & 0.953 & 0.94 & Shimer (2005) \\
$A_{2010}$ & Fraction of Unemployed Borrowing & 0.332 & 0.331 & SCF (2010) \\
$\bar{s}$ & Approval Rate & $23 \%$ & $25 \%$ & Equifax (1999-2011) \\
$\kappa_{D}$ & Default Fraction & $24 \%$ & $27 \%$ & Equifax (1999-2011) \\
\hline
\end{tabular}

\section{Stochastic Steady State Comparison, 1977 vs. 2010}

I begin the analysis by considering the stochastic steady state of two economies with different levels of credit access. Holding all other parameters fixed, I calibrate the 1977 steady state by setting $A_{1977}$ to match the fraction of unemployed households with positive balances in 1977.

Table 7 illustrates the stochastic steady state results. The model predicts that the un- 
Table 6: 2010 Stochastic Steady State Wealth Distribution

\begin{tabular}{|c|c|c|c|c|}
\hline \multicolumn{5}{|c|}{ Ratio of Liquid Wealth to Annual Income } \\
\hline & \multicolumn{2}{|c|}{ All Households } & \multicolumn{2}{|c|}{$\begin{array}{l}\text { Unemployed } \\
\text { Households }\end{array}$} \\
\hline & $\underline{\text { Model }}$ & Data & Model & Data \\
\hline p10 & $\overline{0.01}$ & $\overline{-0.06}$ & $\overline{-0.10}$ & $\overline{-0.08}$ \\
\hline p25 & 0.04 & 0.00 & -0.05 & 0.00 \\
\hline p50 & 0.06 & 0.03 & 0.00 & 0.00 \\
\hline p75 & 0.10 & 0.21 & 0.10 & 0.04 \\
\hline p90 & 0.18 & 1.41 & 0.20 & 0.29 \\
\hline Mean & 0.08 & 0.51 & 0.03 & 0.23 \\
\hline
\end{tabular}

employment rate is .34 percentage points higher in the economy with credit access. The mechanism driving this difference is that credit acts as a safety net allowing households to search for better-paying and harder-to-find jobs. The increased availability of credit lowers the job finding rate by 1 percentage point and doubles the fraction of households with liquid assets to annual gross income less than 1\%. In the data, the fraction of households with liquid assets to annual gross income less than 1\% went from $18 \%$ in 1977 to $38 \%$ in 2010. To check the mechanism is providing a degree of insurance consistent with the data, I report the quarterly debt to income ratios of unemployed borrowers along with the mean unemployment duration. On average households who do not immediately find a new job upon being laid-off are out of a job for roughly 1.3 quarters. Combining this with the fact that the average debt to income ratio of the unemployed is $36 \%$, it is possible to calculate that unemployed borrowers in the model replace approximately $18 \%$ of their lost income in the 2010 steady state $(D T I * \gamma=.36 * .5=18 \%)$ which is in line with what Sullivan [2008] finds.

The annual default rate in the model increases enormously from $.004 \%$ to $.015 \%$ between 1977 and 2010. The model's concept of default is quite different from bankruptcy, but the bankruptcy series is the only proxy for consumer default spanning the relevant time period. The bankruptcy rate increased from .1\% of the working age population per annum in 1977 to $.7 \%$ of the working age population per annum in 2010 . While the trend is correct, the model's level of defaults is quite low compared to the data. The approval rate is also much higher in the 2010 stochastic steady state, but there is no data counterpart available in 1977.

The observed income process is also affected by credit access. Table 8 shows the model's annual log income processes, estimated as an AR(1), versus the data. The model's income process in both steady states is more persistent than the data due to the fixed wage contracts, but there are occasionally large income swings when agents lose their jobs. The volatility of the income process is actually greater in the economy with increased credit access since agents take larger risks in the labor market (looking for harder-to-find, better-paying jobs) 
and the income distribution fans out. But, as I will discuss in Section 8.3, consumption volatility is lower in the economy with greater credit access.

To calculate the welfare gains in the model, I follow Lucas [1987] and consider the fraction of ex-ante lifetime consumption a newly born agent living in an economy with 1977 levels of credit access would give up in order to be a newly born in the economy with 2010 levels of credit access. The results show that it is welfare improving to have more credit even though the unemployment rate increases. Table 9 shows that a newly born agent in the 1977 steady state would sacrifice $.12 \%$ of expected lifetime consumption in order to be a newly born agent in the 2010 steady state.

Table 7: Stochastic Steady State Comparison

\begin{tabular}{lrrr}
\hline & $\mathbf{2 0 1 0}$ & $\mathbf{1 9 7 7}$ & Ratio (2010/1977) \\
\hline Fraction of Unemployed Borrowing (Target) & 0.33 & 0.12 & 2.78 \\
& & & \\
Unemployment Rate & $5.59 \%$ & $5.25 \%$ & 1.07 \\
LQTI< 1\% & $8.92 \%$ & $4.78 \%$ & 1.87 \\
Job Finding Rate & 0.65 & 0.66 & 0.98 \\
Average Credit Approval Rate & 0.23 & 0.05 & 4.45 \\
Annualized Default Rate (Post) & $0.015 \%$ & $0.004 \%$ & 3.88 \\
DTI Unemployed Borrowers & 0.36 & 0.32 & 1.12 \\
Mean Unemployment Duration in Years & 0.388 & 0.379 & 1.024 \\
\hline
\end{tabular}

Table 8: Income Process, Log Annual Income

\begin{tabular}{lll}
\hline \multicolumn{3}{c}{ Income Process } \\
\hline & \multicolumn{3}{c}{ Data Corr. } & Std. Dev \\
Storesletten et al. [2004] & 0.95 & 0.12 \\
& & \multicolumn{2}{c}{$\stackrel{\text { Model }}{ }$} \\
& Auto Corr. & Std. Dev \\
2010 Stochastic Steady State & 0.997 & 0.106 \\
1977 Stochastic Steady State & 0.997 & 0.102 \\
\hline
\end{tabular}

Table 9: Stochastic Steady State Welfare Analysis

\begin{tabular}{lrrr}
\hline & $\mathbf{2 0 1 0}$ & $\mathbf{1 9 7 7}$ & Ratio (2010/1970) \\
\hline Ex-Ante Expected Utility of Newly Born & -0.40 & -0.45 & 0.90 \\
\hline Fraction of Lifetime Consumption Willing to & $0.12 \%$ & & \\
Forego to Move from 1977 to 2010 SS & & & \\
\hline
\end{tabular}




\section{Understanding How Credit Access Changes Business Cycles: Impulse Response Experiments}

To answer the question of how credit access has changed the way employment responds to downturns, the simplest experiment is to compare business cycle recoveries across the 2010 stochastic steady state and 1977 stochastic steady state. Such a steady state experiment yields inconclusive differences in the business cycle behavior of employment. I first explain why that is the case in a series of experiments, and then I argue that in order to understand the 1974-2012 time period, one must consider an environment in which credit is continually and persistently expanding as opposed to a steady state experiment.

In general, greater credit access has two effects. The first of which is a pure self-insurance effect. Holding the wealth distribution constant, greater credit access allows households to be more selective with the jobs they take. The second effect is a wealth distribution effect. In the long run with greater credit access, households save less and borrow more. Such a leftward shift in the wealth distribution increases the job finding rate; a household with a previous debt position or little savings will find a job much faster than a similar household with a larger savings buffer. The experiments I run in this section are designed to illustrate these two forces and how they operate over the business cycle. The experiments have the following setup:

i. Consider 2 economies in good times with productivity $1.5 \%$ above trend.

ii. Both economies endure the same temporary productivity drop (productivity is $1.5 \%$ below trend for 3 quarters).

iii. One economy has a credit expansion while the other does not. I model a credit expansion as a change in the credit matching efficiency from $A_{1977}$ to $\widehat{A}$ where I will consider several different values of $\widehat{A}$ (a more disciplined data exercise will follow in Section 7 ).

iv. I assess two timing assumptions:

A. The credit expansion occurs immediately after the recession

B. The credit expansion occurs 5 years before the recession (and so the economies are approximately in their respective steady states when the recession occurs)

I assume that all agents have the same beliefs about transitions over $\left[A_{1977}, \hat{A}\right]$ given by

$$
P_{A}=\left[\begin{array}{cc}
0.975 & 0.025 \\
0 & 1
\end{array}\right]
$$




\subsection{Credit Expands After Recession: Self-Insurance Effect}

To isolate the self-insurance effect, consider first the case in which credit expands immediately following a recession. ${ }^{26}$ Figure 5 illustrates the productivity decline and the various values of $\widehat{A}$ fed into the model (to give these credit expansions context, I have enclosed in parentheses the increase in the fraction of unemployed households borrowing before the recession compared to 2 years after the recession). The blue heavy-dashed middle line corresponding to a $7.09 \%$ increase in borrowing is closest to the data in terms of actual observed credit expansions (a more disciplined data exercise will follow in Section 7). Figure 6 shows that the unemployment rate is greater in the economy with the credit expansion and takes significantly longer to reach pre-recession levels compared to the world in which credit access is fixed at $A_{1977}$. Figure 7 shows that the job finding rate falls significantly during the recession and takes longer to recover to pre-recession levels in the economy with increased credit access; the slowdown in job finding is driven by a rise in reservation wages as illustrated in Figure $8{ }^{27}$ While this experiment shuts down immediate shifts in the wealth distribution, in the long run all households eventually lower their liquid asset positions as shown in Figure 9 .

In Figure 10, the blue heavy-dashed line plots the difference in unemployment rates between the economy with a credit expansion (the $7.09 \%$ increase in borrowing) versus the economy with fixed credit over a longer period of time. Figure 10 shows that the peak difference in unemployment rates between the economies reaches nearly $\frac{1}{2} \%$ three quarters after the expansion. In the long run the difference in the unemployment rates actually becomes negative indicating a higher unemployment rate in the economy with fixed accessultimately households save less and the wealth distribution effect wins when the economy suffers no further productivity shocks.

\subsubsection{The Interaction Between Labor Productivity and Credit Matching Effi- ciency}

To understand how the productivity shock interacts with the increase in credit matching efficiency, the line with circular markers in Figure 10 corresponds to the difference in unemployment rates between the economy with growing credit access and the economy with fixed access when the only shock allowed is the credit matching efficiency increase (i.e. productivity is set to $1.5 \%$ above trend forever and the size of the credit shock $\widehat{A}$ is the same as that of the heavy-dashed blue line with a $7.09 \%$ borrowing increase). The large mass of unemployed households at the end of the recession uses the new credit to look for higher paying jobs; in a world with no credit expansion, there are simply fewer households that use credit. This interaction between the productivity shock and credit matching efficiency shock results in an additional increase in the unemployment rate of .2\%.

\footnotetext{
${ }^{26}$ This experiment is particularly relevant for the transition results in Section 7 .

${ }^{27}$ The reservation wage is defined in this context as the wage-submarket in which the households searches
} 

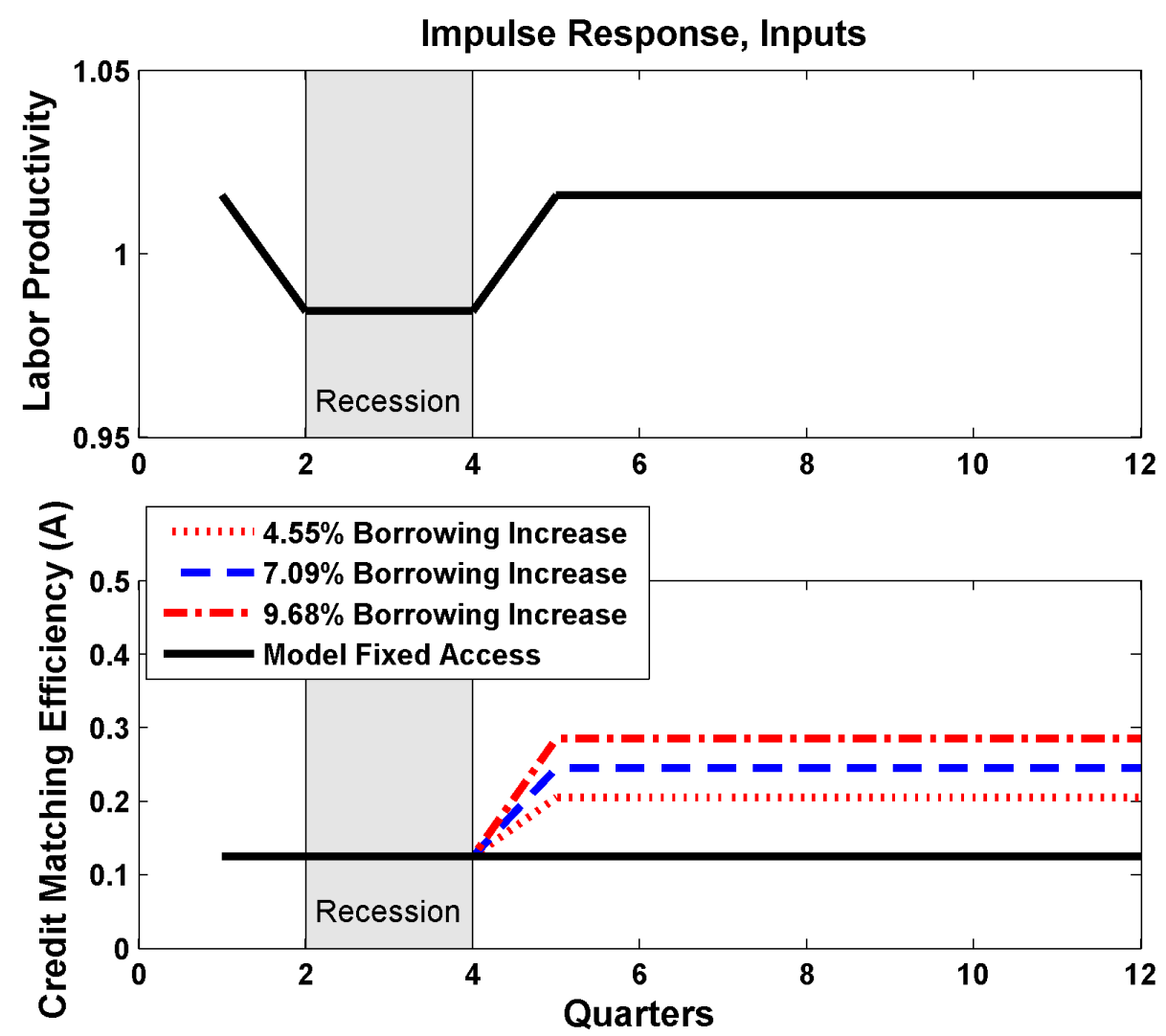

Figure 6: Credit Expansion After Recession: Unemployment Rate

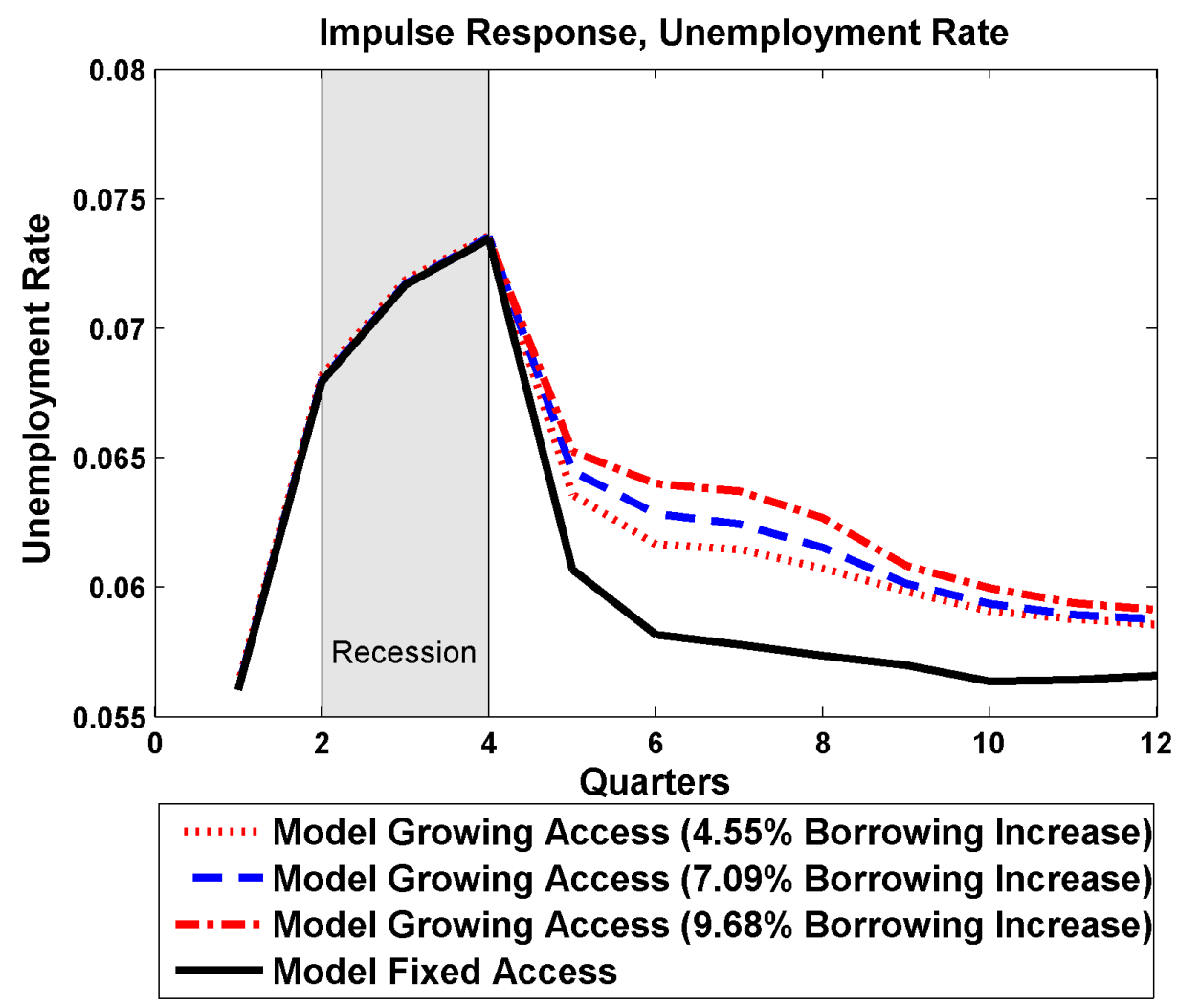


Figure 7: Credit Expansion After Recession: Job Finding Rate

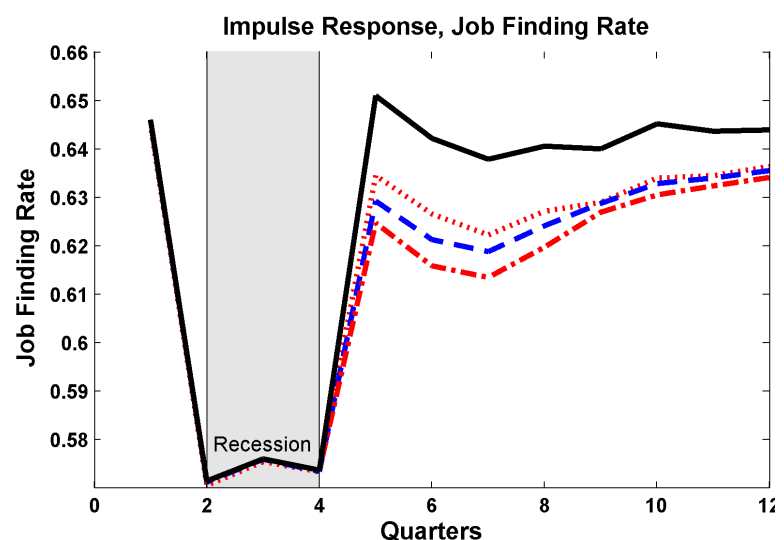

…... Model Growing Access (4.55\% Borrowing Increase) - - Model Growing Access (7.09\% Borrowing Increase) - . - Model Growing Access (9.68\% Borrowing Increase) Model Fixed Access
Figure 8: Credit Expansion After Recession: Reservation Wages

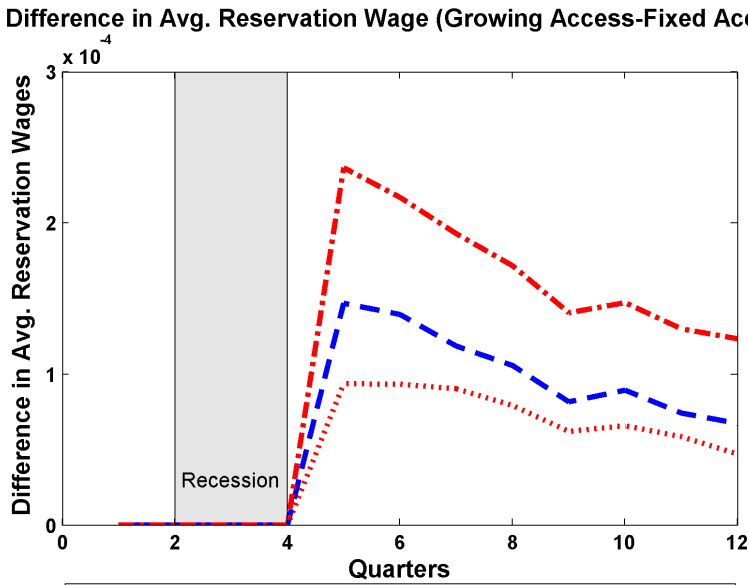

' $\cdots \cdots$ Model Growing Access (4.55\% Borrowing Increase) - - Model Growing Access (7.09\% Borrowing Increase) - . - Model Growing Access (9.68\% Borrowing Increase)
Figure 9: Credit Expansion After Recession: Fraction of the Population with a Liquid Asset to Annual Gross Income Ratio $<1 \%($ LQTI $<1 \%)$

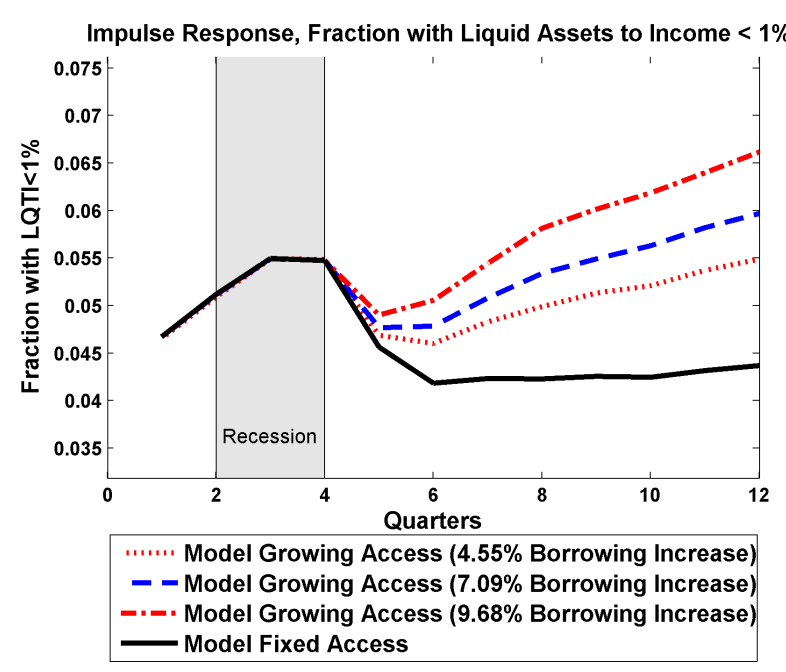

Figure 10: Difference in Unemployment Rates (UR with Expansion Minus UR with Fixed Access)

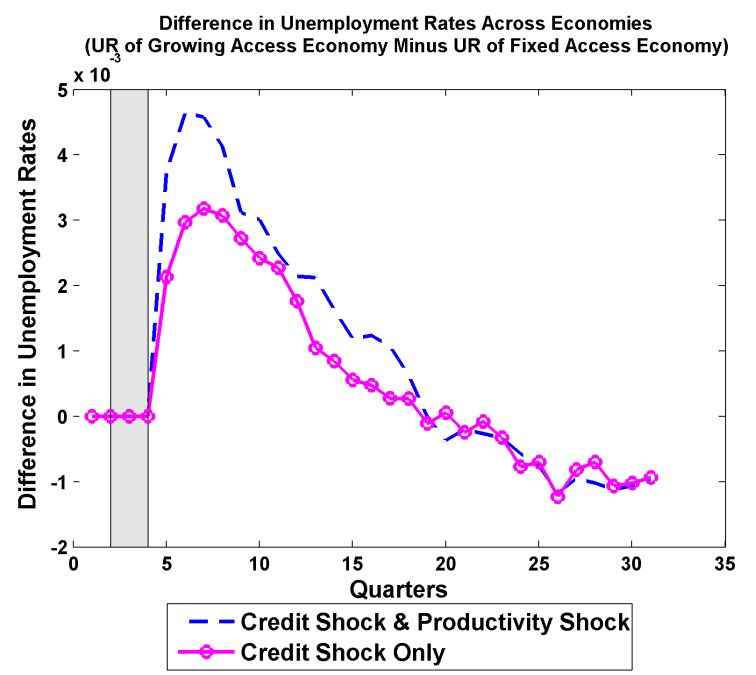




\subsection{Credit Expands Before Recession: Wealth Distribution Effect}

Figure 11 shows the inputs for the experiment in which credit expands 5 years before the recession (all of the shocks are the same size as in Section 6.1, and the borrowing increase is still measured 2 years after the initial shock). The two economies are close to their respective steady states when the business cycle occurs. Figure 12 shows that it is difficult to determine which economy has a stronger recovery since the percentage change in employment is quite similar across these economies (this is also reflected in the job finding rates of Figure 13). Employment in the economy in which credit expands remains everywhere below employment in the economy with fixed credit access; however, in first-differences the change in employment as productivity recovers is larger in the economy with the credit expansion.

What matters most for understanding why these two economies respond to business cycles so similarly is that the wealth distribution shifts prior to the business cycle (see Figure 14). By the time of the recession, households have reduced their liquid asset holdings in the economy for which credit access expands (this is the wealth-distribution effect). Thus, even though there is greater credit access, total liquid resources available for self-insurance (unused credit plus liquid assets) actually returns to pre-credit expansion levels. More formally, to measure total liquid resources available for self-insurance, the dashed line with circular markers in Figure 15 plots aggregate liquid assets plus aggregate unused credit per capita for the economy with an $8.47 \%$ borrowing increase (this image is zoomed-out to show the entire sample period). ${ }^{28}$ This figure shows that by the time of the recession, the economy with the credit expansion actually has slightly less total liquid resources available to households. This reversal is due to the fact that some households were actually constrained prior to the credit expansion. It is precisely because these two economies enter the recession with similar degrees of total liquid resources available for self-insurance that the employment dynamics across these two economies closely track each other.

Prima facie, the two business cycles are quite similar. However, two additional forces operate during the recession, the strength of which depends on the composition of borrowers and savers in an economy: (i) credit approval rates fall for households who enter the credit market with moderately negative net worth (whose default risks increase), and (ii) credit approval rates increase for relatively high net worth households (who are now more likely to be out of a job for multiple periods and thus start borrowing). This asymmetric change in the safety net is shown through the credit approval rates across asset positions in Table 10. The subgroups with initial negative net worth are forced to find jobs quickly since its less likely they can roll over their debts, while the subgroups with positive net worth are able to obtain more borrowing opportunities and thus take longer to find jobs. To show the aggregate impact of these approval rate fluctuations, Figure 16 plots the difference in liquid assets plus unused credit across the two economies (i.e. the difference between the circularly

\footnotetext{
${ }^{28}$ Let $b_{-, \text {avg }}$ be the average amount of debt among borrowers. Unused credit among non-borrowers with state space $\mathbf{x}$ is calculated as $\psi\left(\theta_{c}(\mathbf{x})\right) \cdot\left|b_{-, a v g}\right|$. Unused credit among borrowers is calculated as $\left|\min \left\{b_{-, a v g}-b, 0\right\}\right|$.
} 
marked dashed curve and solid hash marked curve in Figure 15). Figure 16 shows that total available resources for self-insurance expands relatively more in the economy with the credit expansion during the initial phase of the recession but contracts as households begin to repay the interest on their loans. This temporary expansion, in combination with a differing composition of households across assets, is the main reason why there is any divergence in employment dynamics across the two economies. To better understand why these business cycles are so similar, the following section methodically isolates changes in the composition of borrowers and savers over the business cycle.

\subsubsection{Isolating the Wealth Effect}

This section isolates the wealth distribution effect and its impact on the business cycle. Figure 17, which is just the blue heavy-dashed line corresponding to the $8.47 \%$ borrowing increase in Figure 13, plots the job finding rate when both the wealth distribution and self-insurance effects are allowed to adjust prior to the business cycle as well as during the business cycle. While the two job finding rates start at the same pre-recession level, the job finding rates diverge briefly in the recession only to return to nearly identical levels in the recovery.

To isolate the wealth distribution effect, I freeze the pre-credit expansion wealth distribution and look at only the movements in the job finding rate attributable to the self-insurance effect. I simulate an economy in which credit expands (using the $8.47 \%$ borrowing increase) to obtain a vector of job finding rates for households by assets $\left\{j f_{1}^{A}(t), j f_{2}^{A}(t), \ldots\right\}_{t}$ and a vector describing the fraction of households in each asset interval $\left\{f_{1}^{A}(t), f_{2}^{A}(t), \ldots\right\}_{t}$ for each date of the simulation $t$. I repeat the same exercise in the economy with fixed credit access to obtain vectors $\left\{j f_{1}^{N}(t), j f_{2}^{N}(t), \ldots\right\}_{t}$ and $\left\{f_{1}^{N}(t), f_{2}^{N}(t), \ldots\right\}_{t}$ such that the superscripted $N$ indicates fixed credit access. The job finding rates in Figure 18 are calculated as

$$
\overline{j f}(t)^{A}=\sum_{i} f_{i}^{A}(t) \times j f_{i}^{A}(t)
$$

in the case when credit expands and

$$
\overline{j f}(t)^{N}=\sum_{i} f_{i}^{N}(t) \times j f_{i}^{N}(t)
$$

in the case when credit is fixed.

To isolate the wealth distribution effect, I calculate counterfactual job finding rates $\overline{j f}(t)_{N o \text { Wealth }}^{A}$ and $\overline{j f}(t)_{\text {No Wealth }}^{N}$ by holding the wealth distribution constant but letting the asset-specific job finding rates vary over time:

$$
\overline{j f}(t)_{N o \text { Wealth }}^{A}=\sum_{i} f_{i}^{A}(\mathbf{1}) \times j f_{i}^{A}(t)
$$




$$
\overline{j f}(t)_{\text {No Wealth }}^{N}=\sum_{i} f_{i}^{N}(\mathbf{1}) \times j f_{i}^{N}(t)
$$

Figure 18 plots $\overline{j f}(t)_{\text {No Wealth }}^{A}$ and $\overline{j f}(t)_{\text {No Wealth }}^{N}$. There is a difference in job finding rates prior to the recession since the wealth distribution is methodically blocked from adjusting in the preceding 5 years. Without the wealth distribution effect, the self-insurance effect is the only effect present. During a recession the self-insurance effect becomes disproportionately more important for households since unemployment durations increase. Given any initial asset position, the likelihood increases of remaining unemployed long enough that borrowing becomes optimal. As result, the job finding rate of the economy with the credit expansion drops by more in a recession as compared to the economy with fixed access. If the wealth distribution were able to freely move, households in the economy with greater credit access would borrow and then have to repay those loans during the recovery. However, since this mitigating channel is shutdown by fixing the wealth distribution, there is actually a large and persistent difference in job finding rates between the two economies during the recovery. Consequently, without the wealth distribution effect, more credit access would result in unambiguously deeper recessions and slower recoveries.

Table 10: Credit Expansion Before Recession: Credit Approval Rates Among Unemployed

\begin{tabular}{cccccccc}
\hline \multicolumn{6}{c}{ Credit Approval Rates Among Unemployed by } & Assets Carried Into Credit Market Search \\
\hline & $\mathrm{b} \leq-.2$ & $-0.2<\mathrm{b} \leq-0.05$ & $-0.05<\mathrm{b} \leq .1$ & $.1<\mathrm{b} \leq .25$ & $.25<\mathrm{b} \leq .4$ & $.4<\mathrm{b} \leq .55$ & $.55<\mathrm{b}$ \\
\hline Quarter Prior Recession & $19.61 \%$ & $16.79 \%$ & $13.59 \%$ & $13.79 \%$ & $14.24 \%$ & $14.87 \%$ & $16.63 \%$ \\
Average During Recession & $19.85 \%$ & $16.15 \%$ & $13.84 \%$ & $14.32 \%$ & $15.17 \%$ & $17.43 \%$ & $17.27 \%$ \\
Quarter After Recession & $19.79 \%$ & $15.59 \%$ & $13.71 \%$ & $13.53 \%$ & $14.12 \%$ & $14.73 \%$ & $16.09 \%$ \\
\hline
\end{tabular}


Figure 11: Credit Expansion Before Recession: Inputs
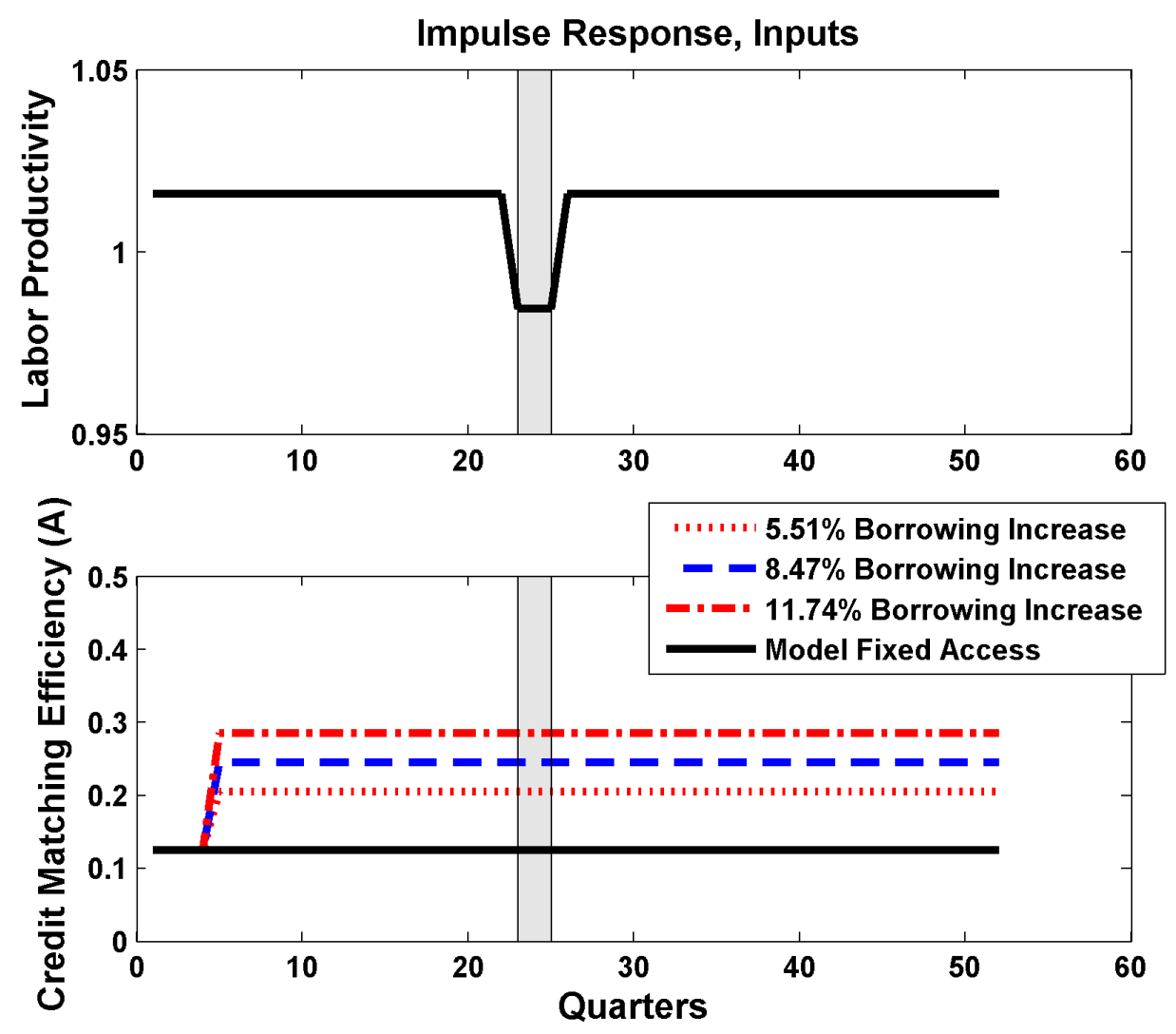

Figure 12: Credit Expansion Before Recession: Percentage Change in employment

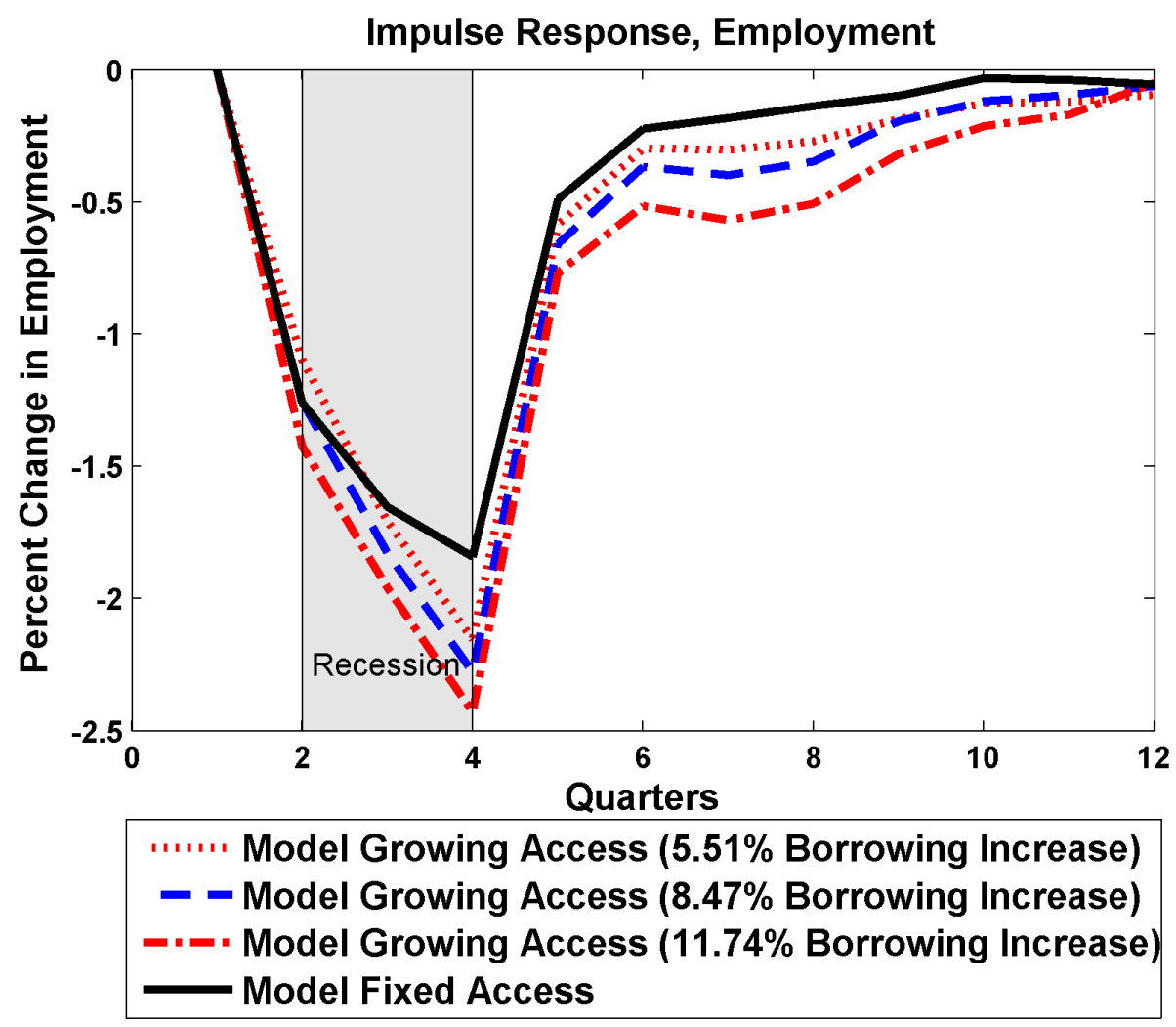


Figure 13: Credit Expansion Before Recession: Job Finding Rate

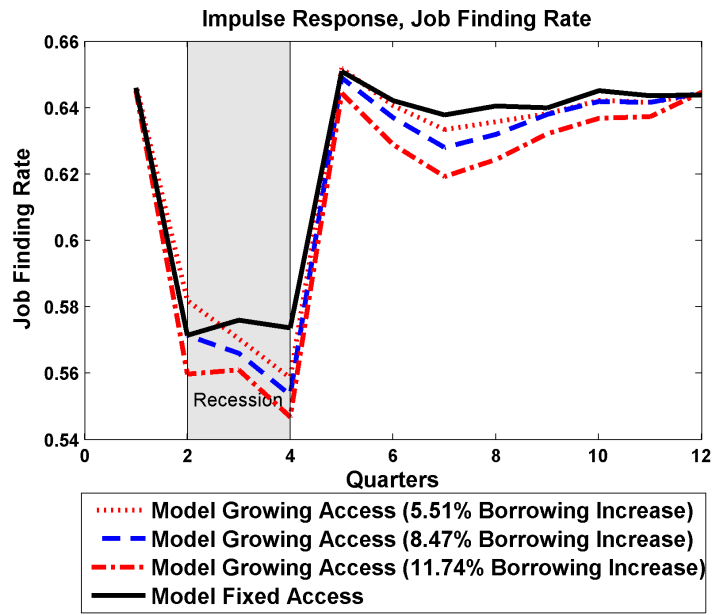

Figure 15: Credit Expansion Before Recession: Aggregate Liquid Assets and Unused Credit Per Capita

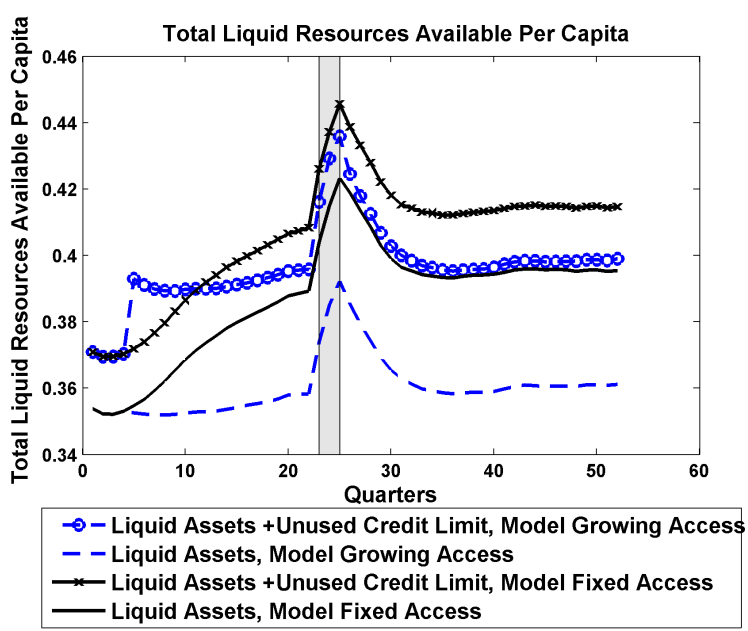

Figure 14: Credit Expansion Before Recession: Fraction of Unemployed Households Borrowing

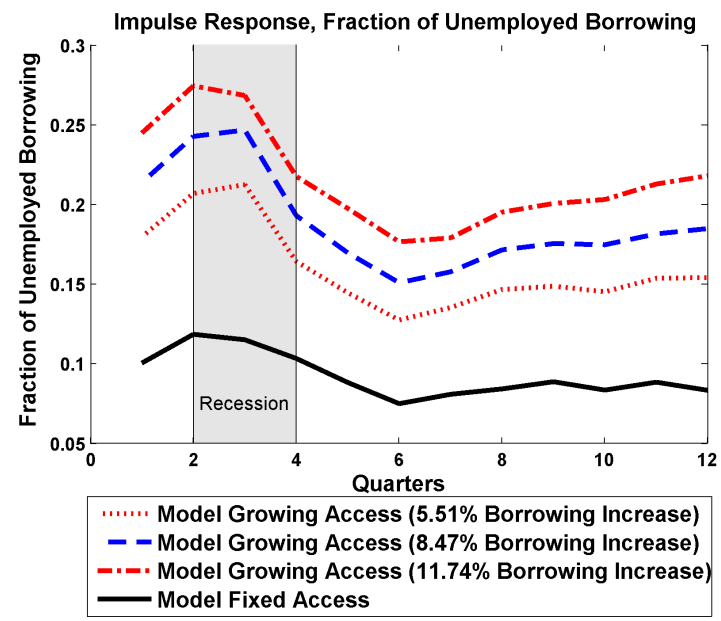

Figure 16: Credit Expansion Before Recession: Aggregate Liquid Assets and Unused Credit Per Capita in Fixed Access Economy Minus Growing Access Economy

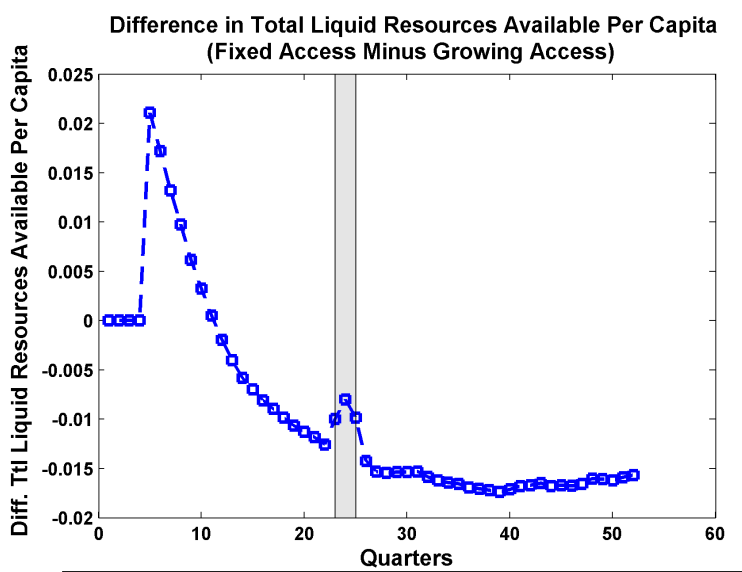

$\rightarrow$ Liquid Asset +Unused Credit Limit,

Model with Fixed Acces Minus Model with Growing Access 
Figure 17: Credit Expansion Before Recession: Comparing Job Finding Rates Allowing Wealth Distribution to Adjust

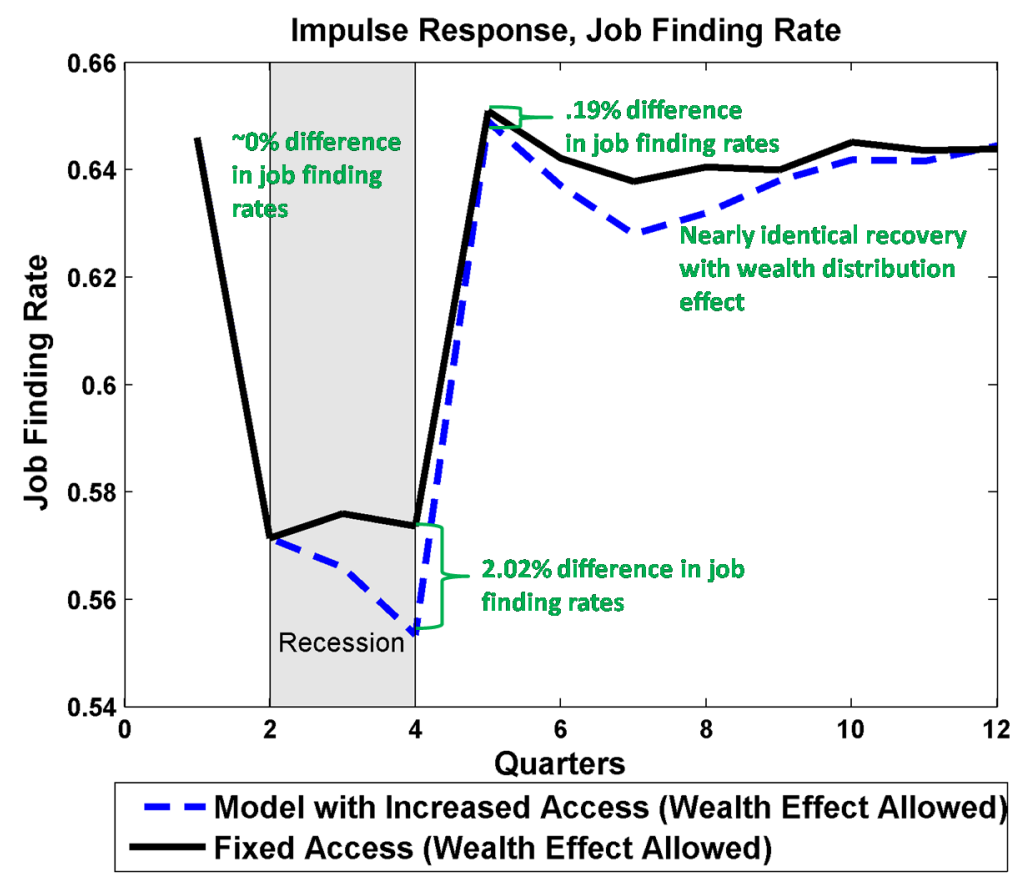

Figure 18: Credit Expansion Before Recession: Job Finding Rates Holding Wealth Distribution Fixed

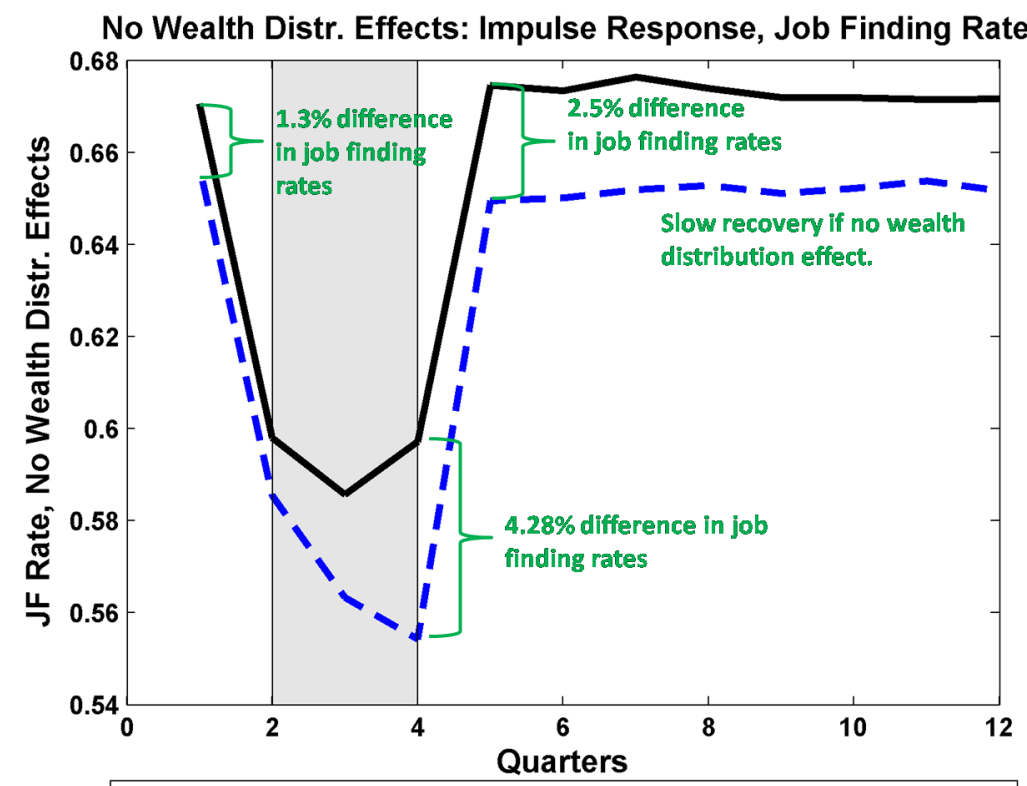

- - Model with Increased Access (No Wealth Distr. Shifts)

Fixed Access (No Wealth Distr. Shifts) 


\section{Transition Experiment}

While stochastic steady state analysis is useful to understand the basic mechanisms at work, it is not an accurate portrayal of the 1974-2012 time period which exhibited continual and persistent increases in credit. To better understand the business cycles during this time period, I compare labor market recoveries across two economies, one in which credit grows to 2010 levels and the other in which credit remains fixed at 1977 levels. The details are explained below:

i. Two identical economies are simulated for a large number of periods with productivity set to its non-stochastic mean and with aggregate credit matching efficiency set to $A_{1977}$.

ii. Both economies then receive actual labor productivity residuals from 1974-I to 2012-IV.

iii. Economy With Growing Access: Credit matching efficiency grows according to actual SCF data over the sample period, 1974-I to 2012-IV.

iv. Economy With Fixed Access: Credit matching efficiency remains fixed at $A_{1977}$ over the sample period, 1974-I to 2012-IV.

\subsection{Transition Experiment Calibration}

In order to match the SCF data on the fraction of unemployed households borrowing, I assume the aggregate credit matching efficiency process follows a 6-state markov chain taking the possible values $A_{1977}, A_{1985}, A_{1991}, A_{2002}, A_{2006}$, and $A_{2009} \cdot{ }^{29}$ I calibrate each aggregate credit matching efficiency $A_{j}$ to match the fraction of the unemployed borrowing in the SCF survey date closest to year $j$. For example, $A_{1991}$ is set to target the fraction of the unemployed who are borrowing in the 1992 SCF survey (the closest available date). The top panel of Figure 19 illustrates that the calibrated process matches the data quite well, correctly replicating the fraction of unemployed households borrowing in each targeted SCF

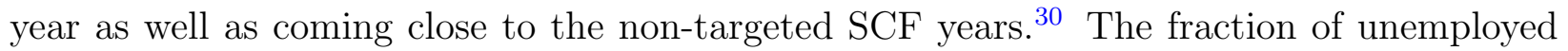
households borrowing in each targeted SCF year as well as the model's corresponding average over the target year are reported in Table 11.

Optimizing behavior endogenously generates a sharp reduction in borrowing during the 1990, 2001, and 2007 recessions as illustrated in the top panel of Figure 19. In order to match the observed levels of borrowing by the time of the 1992, 2004, and 2010 SCFs the model requires large credit expansions coming out of each recession as illustrated in the bottom panel of Figure 19. In the data, since credit moves pro-cyclically (see Table 12), I assume that these expansions occur following each of the 1990, 2001, and 2007 recession. For

\footnotetext{
${ }^{29}$ See the text and Appendix D for more on timing.

${ }^{30}$ The numeric naming convention is such that 1974.13 corresponds to $1974-\mathrm{Q} 1$
} 
Figure 19: Transition Experiment: Calibration Targets and Credit Matching Efficiency Time Path
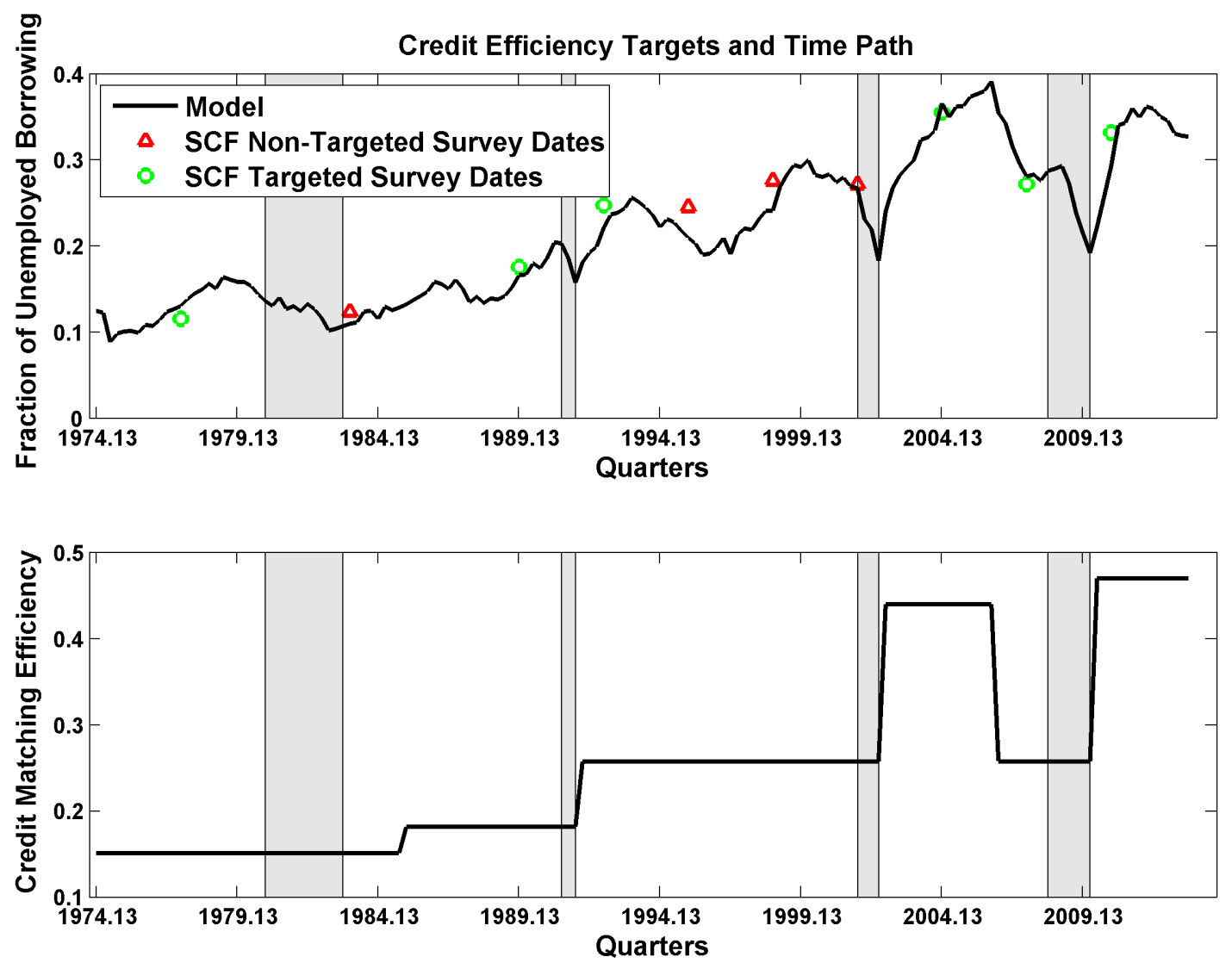

example, since the model implies a large borrowing contraction during the 1990 recession, at some point between 1991 and 1992 credit matching efficiency must grow in order for the model to replicate the observed fraction of households with access to credit in the $1992 \mathrm{SCF}$. I assume the expansion occurs immediately after the 1990 recession, and in Appendix D I explore alternate timing assumptions. The SCF data implies a credit contraction between 2004 and 2007, and so I allow for a contraction in 2006 which is the first year that mortgage originations began to decline.

The transition matrix governing the matching efficiencies, which is known by agents, is rational. For example, the transition probability governing the switch from $A_{1991}$ to $A_{2002}$ is set such that the expected time to transit from $A_{1991}$ to $A_{2002}$ is 11 years. This implies the 
transition matrix for aggregate credit matching efficiency $P_{A}$ below:

$$
P_{A}=\left[\begin{array}{cccccc}
0.9773 & 0.0227 & 0 & 0 & 0 & 0 \\
0 & 0.9583 & 0.0417 & 0 & 0 & 0 \\
0 & 0 & 0.9773 & 0.0227 & 0 & 0 \\
0 & 0 & 0 & 0.9375 & 0.0625 & 0 \\
0 & 0 & 0 & 0 & 0.9167 & 0.0833 \\
0 & 0 & 0 & 0 & 0 & 1
\end{array}\right]
$$

Table 11: Transition Experiment: Fraction of Unemployed Borrowing, Calibration Targets

\begin{tabular}{lllllll}
\hline \multicolumn{7}{c}{ Fraction of Unemployed Borrowing (Annual Avg.) } \\
\hline & $\underline{1977}$ & $\underline{1989}$ & $\underline{1992}$ & $\underline{2001}$ & $\underline{2007}$ & $\underline{2010}$ \\
Model & 0.115 & 0.181 & 0.244 & 0.347 & 0.276 & 0.334 \\
Data & 0.115 & 0.175 & 0.247 & 0.355 & 0.272 & 0.331 \\
$\begin{array}{l}\text { Credit Matching } \\
\text { Efficiency (A) }\end{array}$ & 0.151 & 0.182 & 0.258 & 0.439 & 0.258 & 0.470 \\
\hline
\end{tabular}

Table 12: Cyclical and Trend Correlation of Credit and Productivity

\begin{tabular}{|c|c|c|c|}
\hline \multicolumn{4}{|c|}{ Correlation Between Quarterly Credit Approval Rate and Labor Productivity } \\
\hline & Productivity $(\mathrm{t}-1)$ & Productivity $(\mathrm{t})$ & Productivity $(\mathrm{t}+1)$ \\
\hline Approval Rate Deviation $(\mathrm{t})$ & 0.54 & 0.40 & 0.18 \\
\hline Approval Rate Trend (t) & 0.44 & 0.31 & 0.11 \\
\hline
\end{tabular}

Notes: Band Pass Filtered (6,32). Sample period in model and data is 1999-II to 2012-I. Productivity is BLS Output Per Worker. Approval rate is fraction of credit inquirers with new credit line in Equifax.

\section{Results of the Transition Experiment}

After solving for the transition path of the two economies I find that (i) growth in credit access coming out of the 1990, 2001, and 2007 recessions results in moderately slower recoveries as compared to a world with fixed credit access, and the model predicts (ii) a large trend increase in defaults from 1974-2012 as well as (iii) a large trend decline in liquid asset holdings. The model also exhibits a decline in the relative standard deviation of consumption to income as well as a trend increase in unemployment durations, both of which are also seen in the data (Mukoyama and Şahin [2009] and Krueger and Perri [2006]). 


\subsection{Cyclical Response of Employment Along Transition Path}

While the full transition path is solved from 1974 to 2012, I will focus on several specific episodes along the transition path in the current section.

2001 Recession: Consider zooming in on the transition path to a window around the 2001 recession. Figure 20 illustrates what labor productivity and aggregate credit matching efficiency look like around the 2001 recession. As described in Section 7, band passed output per worker residuals are fed into the model as measured from the data, and credit matching efficiency growth is fed into the model to generate the same fraction of unemployed households borrowing as observed in the data (see Section 7.1 for more details).

Figure 21 plots the percentage change in employment across these two economies. The peak difference in employment deviations between the two economies is .63 percentage points and that occurs 7 quarters after the onset of the recession. Figure 21 shows that 16 quarters after the onset of the recession, the economy with fixed credit predicts a full recovery to prior peak employment levels; for the economy in which credit expands, employment is still .4 percentage points below the prior peak employment levels after 16 quarters. Figure 22 plots the job finding rate for the two economies. The lower job finding rate in the economy with growing credit access is a direct result of increased self-insurance afforded by the credit expansion (see Figure 23 which plots the fraction of unemployed agents who borrow). Those with the ability to borrow optimally take longer to find a job which was shown theoretically in Corollary 3.6. For those denied access to credit and carrying a large amount of debt into the present period, default provides the same type of safety net (see Section 8.5 for more on the insurance role of default).

1990 Recession: Now, consider zooming in on the transition path to a window around the 1990 recession. Figure 24 illustrates what labor productivity and aggregate credit matching efficiency look like around the 1990 experiment. Figure 25 reveals an interesting feature of the 1990 recession which is that the implied credit expansion is large enough that it shifts the trough of employment by one quarter later. Figure 25 also shows that the difference in employment deviations between the two economies peaks at .44 percentage points seven quarters after the onset of the recession.

2007 Recession: Again, consider zooming in on the transition path to a window around the 2007 recession. Figure 26 illustrates what labor productivity and aggregate credit matching efficiency look like around the 2007 recession. Similar to the 1990 recession, the implied credit expansion coming out of the 2007 recession shifts the trough of employment by 1 quarter. The difference in employment deviations peaks at 1.03 percentage points ten quarters after the onset of the recession. Moreover, this difference in employment deviations is still .82 percentage points sixteen quarters after the start of the recession.

In the model, the large endogenous decline in borrowing during the 2007 recession implies a large credit expansion to match the fraction of unemployed households borrowing in the 2010 SCF (see Figure 19). In the real world, where is this credit coming from? There has 
been a large subprime credit card expansion coming out of the 2009 recession, ${ }^{31}$ and, although only a limited fraction of student loans have a revolving feature, the United States' student loan programs have subsidized households to be non-labor force participants for extended periods of time and subsequently be choosier about wages upon reentry to the labor force. This is one the largest expansions of credit among the non-employed in US history.

Table 13 summarizes the percentage change in employment per capita 12 quarters after its prior peak for the 1990, 2001, and 2007 recessions. In each of these recessions, credit access results in moderately slower employment recoveries, with employment remaining depressed by .2 percentage points to .8 percentage points three years after the initial onset.

Table 13: Transition Experiment: Percentage Change in Employment 12 Quarters Since the Peak

\begin{tabular}{cccc}
\hline \multicolumn{4}{c}{ Percentage Change in Employment 12Q Since Peak } \\
\hline & Model with Fixed Access & Model with Access & Data \\
1990 & 1.09 & 0.86 & 0.12 \\
2001 & -1.02 & -1.42 & -1.85 \\
2007 & -0.13 & -0.94 & -5.59 \\
\hline
\end{tabular}

Notes. Data is Nonfarm Business Sector Employment. Percentage change formula: $100^{*}(\mathrm{E}(\mathrm{t}) / \mathrm{E}(0)-1)$ where $\mathrm{E}(0)$ is employment in period prior to NBER dated recession.

Table 14: Transition Experiment: Reduction in Employment Discrepancy Between Model and Data by Including Credit Matching Efficiency Expansions

Reduction in Employment Discrepancy Between Model and Data by Including Credit Matching Efficiency Expansions

\begin{tabular}{cclll}
\hline & 1990 & 2001 & 2007 & Average \\
8 Quarters from Peak & $-21 \%$ & $-189 \%$ & $-5 \%$ & $-71 \%$ \\
12 Quarters from Peak & $-24 \%$ & $-48 \%$ & $-15 \%$ & $-29 \%$ \\
\hline
\end{tabular}

Notes. Formula: (E(Fixed Access)-E(Access))/(E(Fixed Access)-E(Data)) where E(.) is employment.

The timing of the revolving credit boom and its effect on employment make it a potentially important component of the jobless recovery phenomenon. Take for instance the 2007 recession simulation. While productivity grows enormously from its trough during the 2007 recession, employment remains much lower in the economy with credit access. Table 14 shows that allowing for credit expansions can rationalize $29 \%$ of the gap between the model with fixed access and the data three years after the 1990, 2001, and 2007 recoveries,

\footnotetext{
31 "The Supply of Credit in the Card Market," by Andrew Davidson, Mintel Comperemedia, February 22nd, 2011.
} 
on average. Since productivity and output move one for one in the model, the model, to a certain degree, disconnects employment movements from output movements. Table 15 shows that the correlation between productivity and unemployment from 1974-2012 is -.77 in the model with credit growth and -.84 in the model with fixed credit. In the data there is considerable discrepancy over the size of the drop in the correlation between unemployment and productivity (see Hagedorn and Manovskii [2010] for more).

Table 15: Transition Experiment: Summary of Labor Market Moments

\begin{tabular}{|c|c|c|c|c|c|c|c|}
\hline \multicolumn{8}{|l|}{ Access } \\
\hline \multirow[t]{2}{*}{$x$} & $u_{1}$ & $v$ & $\theta$ & $y$ & $\tilde{w}$ & UE & Default \\
\hline & & & & & & Rate & Rate \\
\hline $\mathrm{SD}(\mathrm{x}) / \mathrm{SD}(\mathrm{y})$ & 12.59 & 3.39 & 5.41 & 1.00 & 0.58 & 5.23 & 0.002 \\
\hline Autocorr(x) & 0.93 & 0.60 & 0.87 & 0.85 & 0.85 & 0.89 & 0.081 \\
\hline \multicolumn{8}{|l|}{$\operatorname{Corr}(\cdot, \mathrm{x})$} \\
\hline$u_{1}$ & 1.00 & -0.37 & -0.94 & -0.77 & -0.76 & -0.98 & 0.09 \\
\hline \multicolumn{8}{|l|}{ No Access } \\
\hline \multirow[t]{2}{*}{$x$} & $u_{1}$ & $v$ & $\theta$ & $y$ & $\tilde{w}$ & UE & Default \\
\hline & & & & & & Rate & Rate \\
\hline $\mathrm{SD}(\mathrm{x}) / \mathrm{SD}(\mathrm{y})$ & 12.19 & 3.17 & 4.92 & 1.00 & 0.57 & 5.04 & 0.001 \\
\hline Autocorr(x) & 0.93 & 0.61 & 0.87 & 0.85 & 0.85 & 0.89 & -0.001 \\
\hline \multicolumn{8}{|l|}{$\operatorname{Corr}(\cdot, \mathrm{x})$} \\
\hline$u_{1}$ & 1.00 & -0.30 & -0.94 & -0.84 & -0.83 & -0.98 & 0.13 \\
\hline \multicolumn{8}{|l|}{ Data } \\
\hline \multirow[t]{2}{*}{$x$} & $u_{1}$ & $v$ & $\theta$ & $y$ & $\tilde{w}$ & $\mathrm{UE}$ & Default \\
\hline & & & & & & Rate & Rate* \\
\hline $\mathrm{SD}(\mathrm{x}) / \mathrm{SD}(\mathrm{y})$ & 9.50 & 10.10 & 19.10 & 1.00 & - & 5.90 & 6.07 \\
\hline $\begin{array}{l}\text { Autocorrelation } \\
\operatorname{Corr}(\cdot, x)\end{array}$ & 0.94 & 0.94 & 0.94 & 0.88 & - & 0.91 & 0.92 \\
\hline$u_{1}$ & 1.00 & -0.89 & -0.97 & -0.41 & - & -0.95 & 0.55 \\
\hline \multicolumn{8}{|c|}{$\begin{array}{l}\text { Notes: HP filtered with smoothing parameter } 10^{5} \text { to be consistent with Shimer [2005]. Data } \\
\text { are from Shimer }[2005] \text {, except }(*) \text { the default rate which is taken from Equifax }(1999-2012) \text {. } \\
\text { As in the data, } u_{1} \text { is calculated as the fraction of unemployed households at the end of a } \\
\text { quarter. } \theta=\frac{v}{u_{1}+u_{2}} \text { includes the measure of households that immediately found jobs }\left(u_{2}\right) \text {, } \\
\text { hence the low volatility as that mass is quite large and very stable. }\end{array}$} \\
\hline
\end{tabular}


Figure 20: Transition Experiment: Labor Productivity \& Credit Match Efficiency Inputs, 2001 Recession
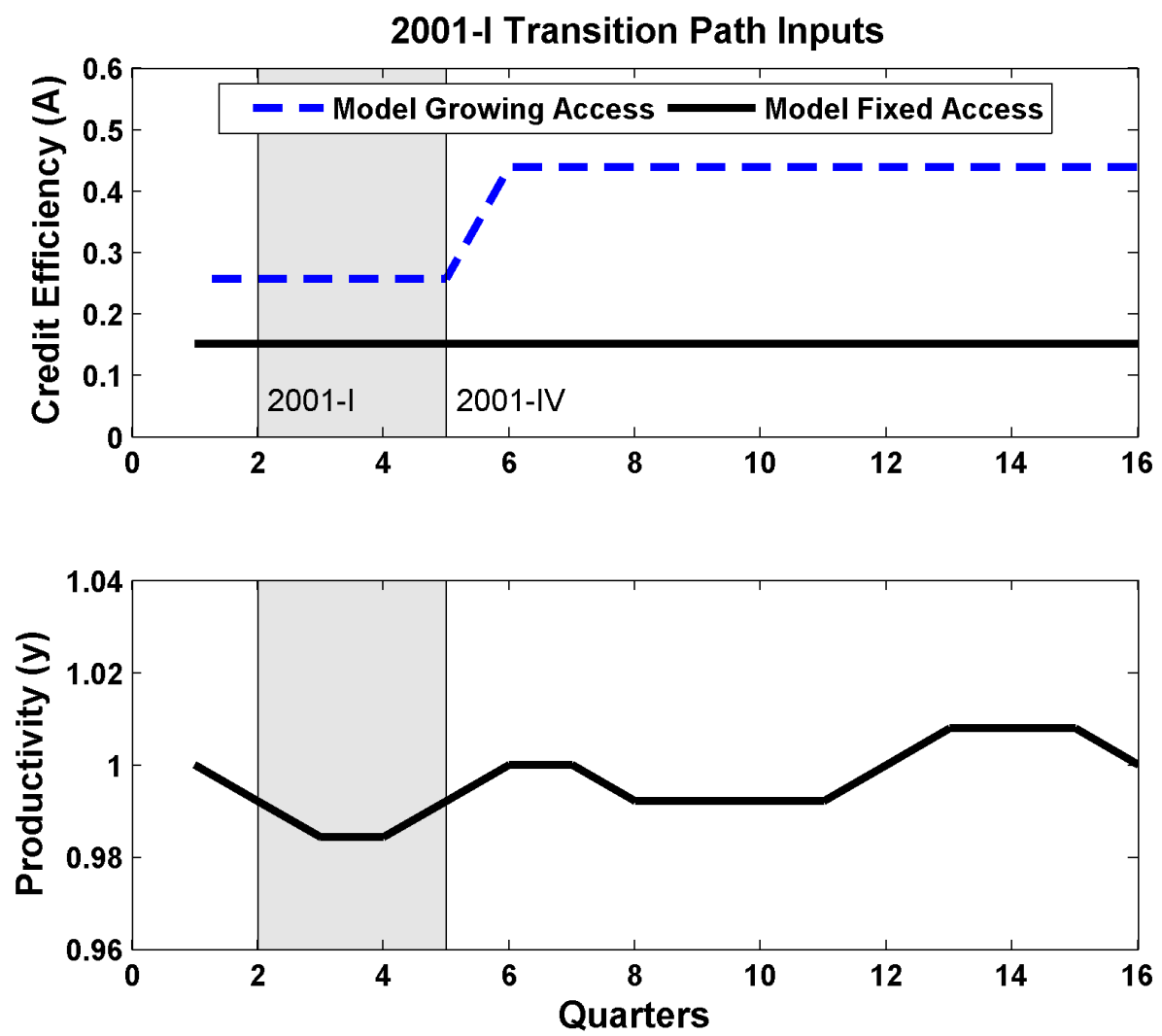

Figure 21: Percentage Change in employment, 2001 Recession

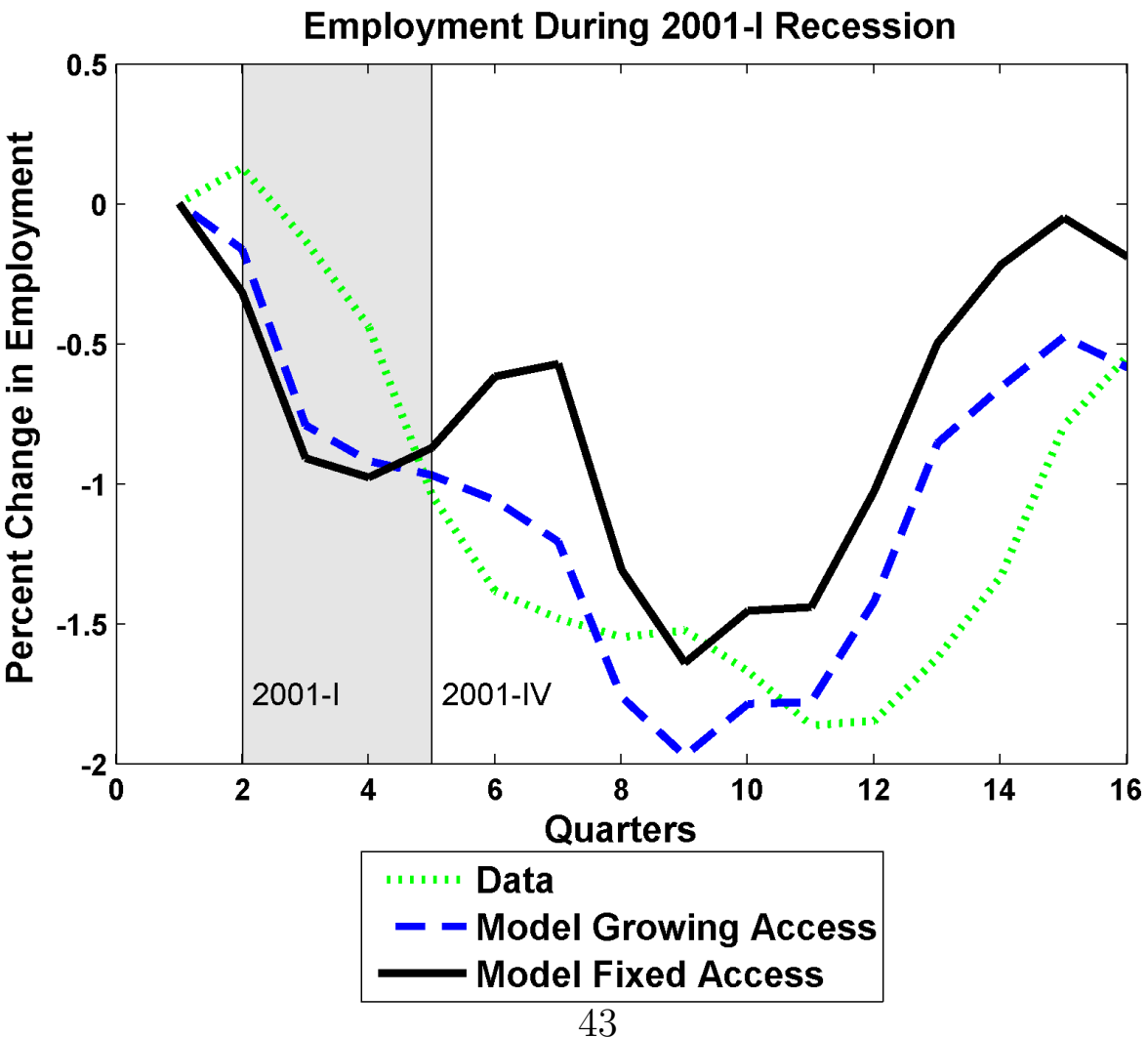


Figure 22: Transition Experiment: Job Finding Rate, 2001 Recession

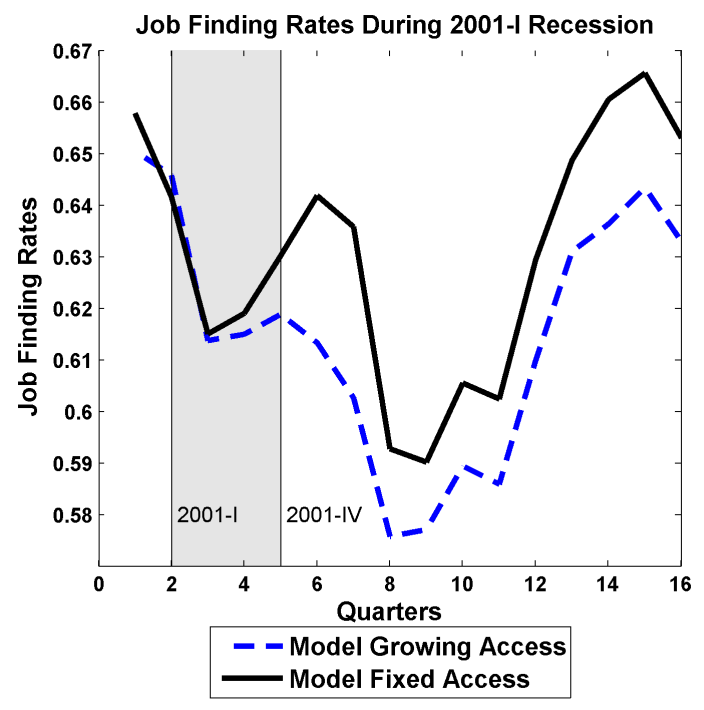

Figure 24: Transition Experiment: Labor Productivity and Credit Match Efficiency Inputs, 1990 Recession
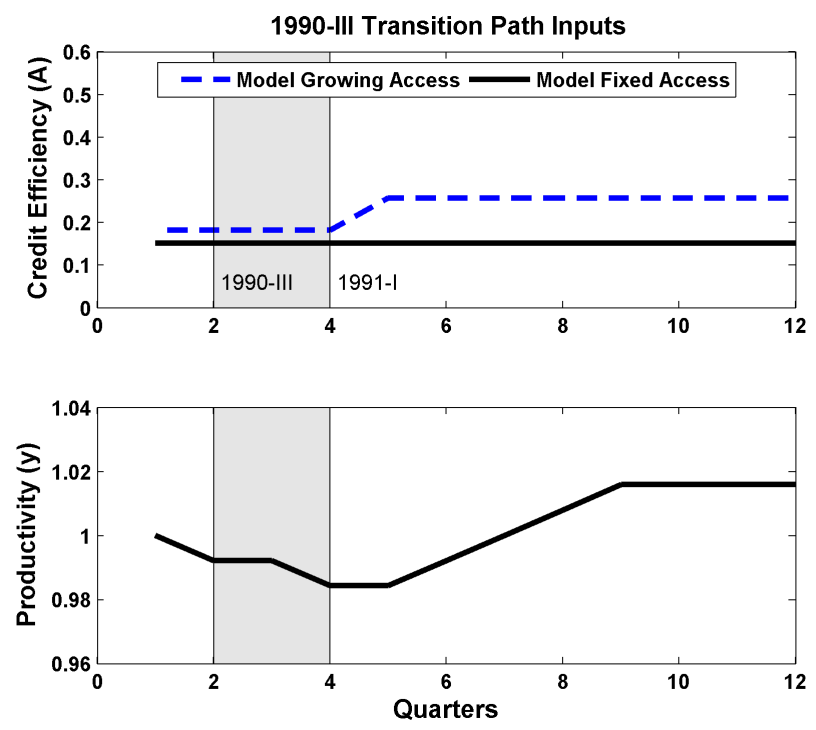

Figure 23: Fraction of Unemployed Borrowing, 2001 Recession

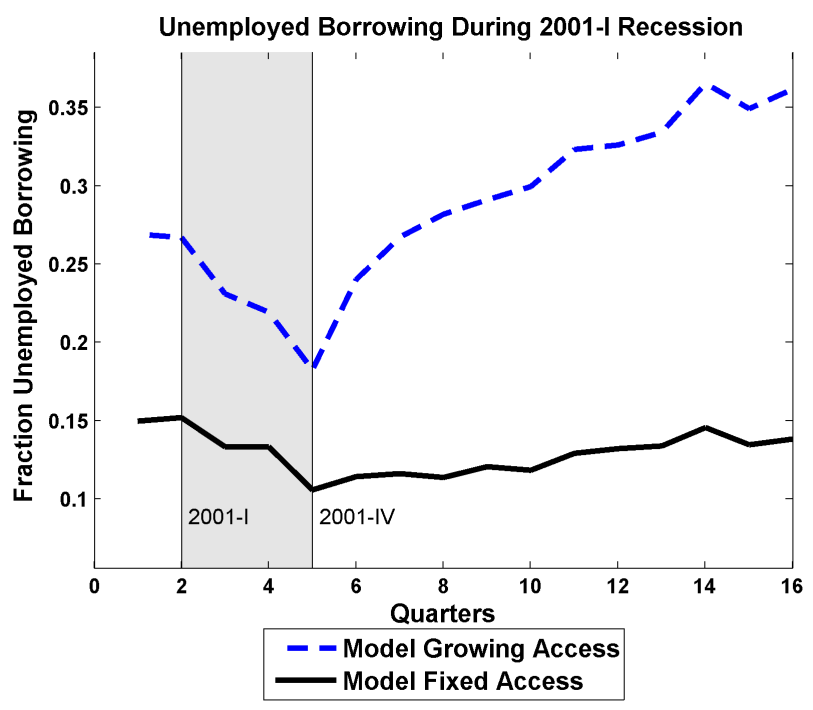

Figure 25: Transition Experiment: Percentage Change in employment, 1990 Recession

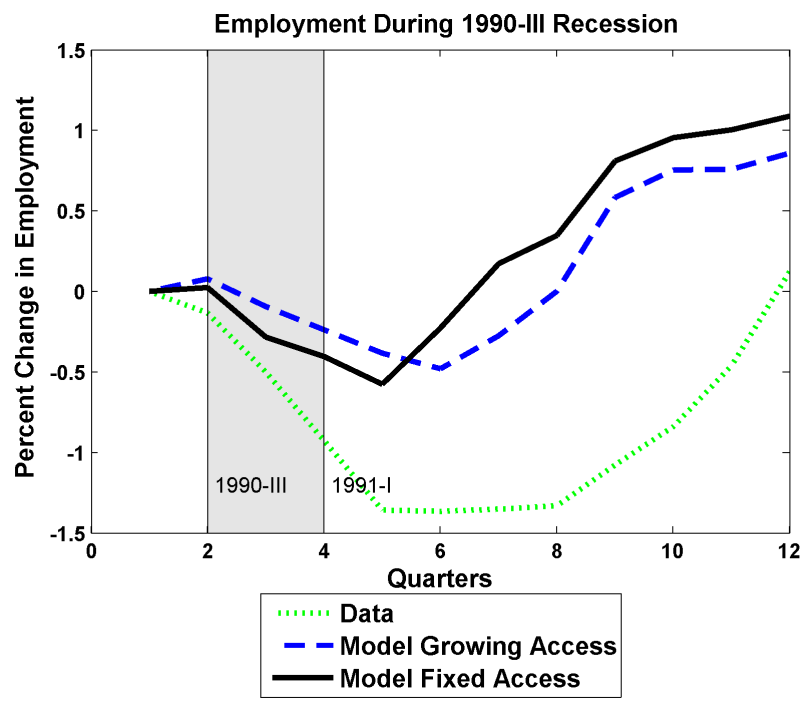


Figure 26: Transition Experiment: Labor Productivity and Credit Match Efficiency Inputs, 2007 Recession
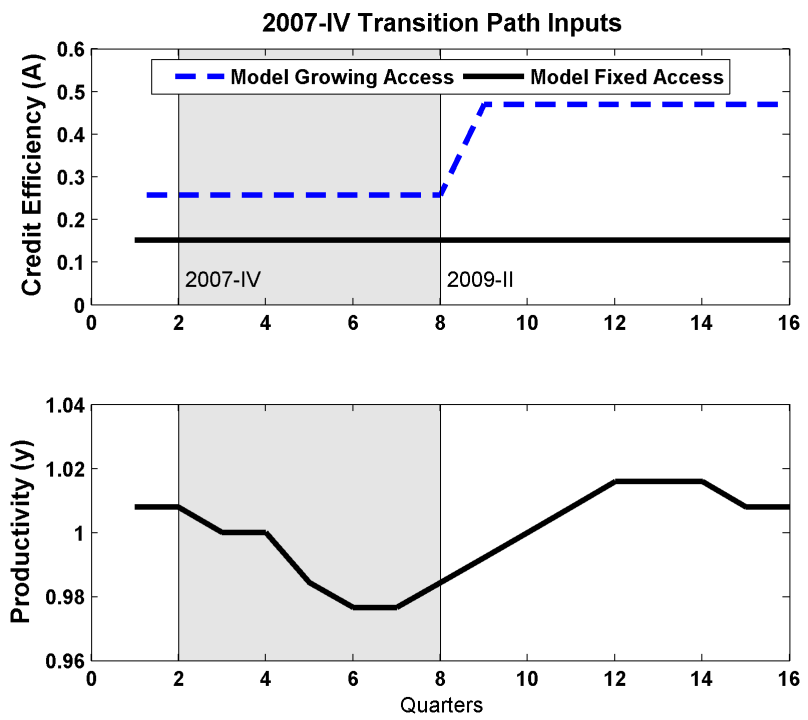

Figure 27: Transition Experiment: Percentage Change in employment, 2007 Recession

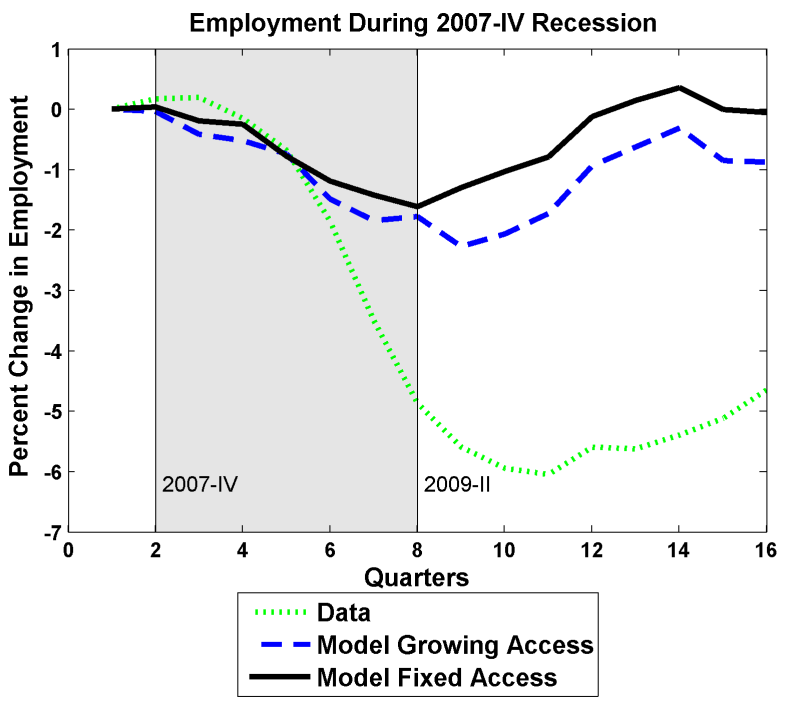




\subsection{Trends in Saving and Default}

The model does quite well at capturing the precipitous decline in the liquid asset holdings of households. Figure 28 plots the fraction of households with liquid assets to gross annual income less than 1\% (LQTI<1\%) from 1974-I to 2012-IV on the right hand axis (the solid line) versus the data on the left hand axis (the dashed line). ${ }^{32}$ In the model there is a secular decline in liquid savings such that the fraction of households with LQTI $<1 \%$ more than doubles, similar to the data (see Carroll et al. [2012] for more).

Figure 29 plots the model's annual trend in defaults per agent against the annual trend in bankruptcy per working age individual in the United States (the only default proxy available over the sample period). ${ }^{33}$ There is enormous growth in bankruptcies following the financial liberalization of the 1980s, and a pronounced increase in bankruptcies after bankruptcy reform (dashed red line). Similarly, the model predicts a large increase in defaults caused by the growth in credit access (solid black line). The model's default rate should, in theory, be 6 times larger than the bankruptcy rate (see Herkenhoff [2012] and Athreya et al. [2012]) but in the present calibration the model's default rate is an order of magnitude smaller than the data. Nonetheless, the model broadly captures the trend in default rates over the last 40 years.

Figure 28: Transition Experiment: Savings Rate

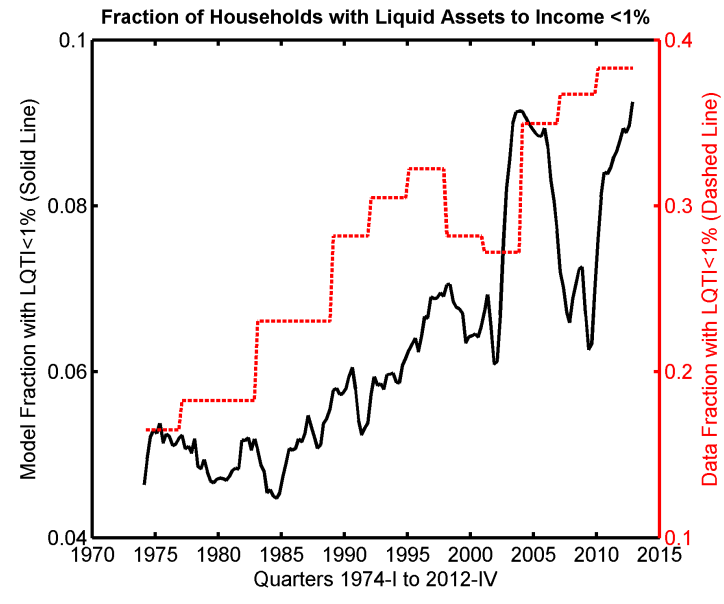

Figure 29: Transition Experiment: Default/Bankruptcy Rate

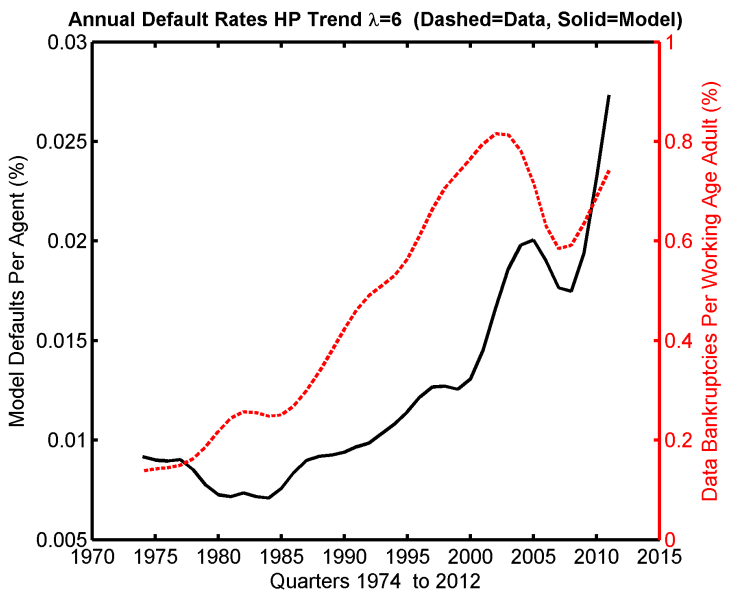

\footnotetext{
${ }^{32}$ The data is taken from the SCF (and it predecessor survey), and computed as the sum of cash, checking, money market funds, CDS, corporate bonds, government saving bonds, stocks, and mutual funds less credit card debt.

${ }^{33}$ The bankruptcy data is from the Historical Statistics of the United States Millennial Edition for the years 1948 to 1998 and the American Bankruptcy Institute for the years 1998 to 2012.
} 


\subsection{Trends in Income and Consumption Dispersion}

Figure 30 shows that income dispersion rises in the economy from 1974-2012 while consumption dispersion, depicted in Figure 31, actually falls. Credit access leads to more risky wage posting behavior by households which tends to fan out the income distribution. However, the ability to insure that risky behavior allows households to reduce consumption volatility. While the relative change in standard deviations is consistent with the data, the decline in consumption volatility is counterfactual.

When credit expands in 1985 and the wealth distribution is roughly constant in the short run, average consumption increases as shown in Figure 33. However, over time, households

save less and ultimately consume less. The mechanism is that credit access allows households to borrow while unemployed, but the loans must be repaid. On average, agents are willing to trade high consumption dispersion and higher average consumption for lower consumption dispersion with lower average consumption.

Income per capita depicted in Figure 32 behaves somewhat differently (here income is defined as the sum of wages and benefits over the number of agents in the model). When credit expands in the short term, households are out of jobs for longer which immediately lowers income per capita. If productivity remains above trend for a prolonged period of time, then income per capita in the economy with credit access expansions surpasses the economy with fixed credit due to the higher wages sought by better-insured households.

Table 16 compares the aggregate correlations between the model and data. After averaging across agents, the times series for aggregate consumption is slightly more volatile with credit access. From an agents perspective in the model, the benefit of credit is that the correlation between employment and consumption drops from .77 to .69, whereas in the data, the correlation between employment and consumption is .68.

\subsection{Cyclical Properties of the Credit Market}

As shown in Table 10, during a recession the model predicts increased credit access among relatively wealthy households and decreased credit access among households with moderate negative net worth. Table 17 shows what this micro-behavior implies for business cycle correlations between credit and other variables. In the model with access, because the exogenous credit access expansions occur during recoveries, the correlation between productivity and credit approval rates is .13, and in the model with fixed credit access this number is - 93 . In the data the correlation between productivity and credit approval rates (measured over 1999-2012) is .34, and so the credit expansions bring the model closer to the data. Table 16 also shows that the economy in which credit expands has a significantly higher volatility of credit access due to the exogenous movements in the credit matching efficiency, which also helps reconcile the model with the data. 


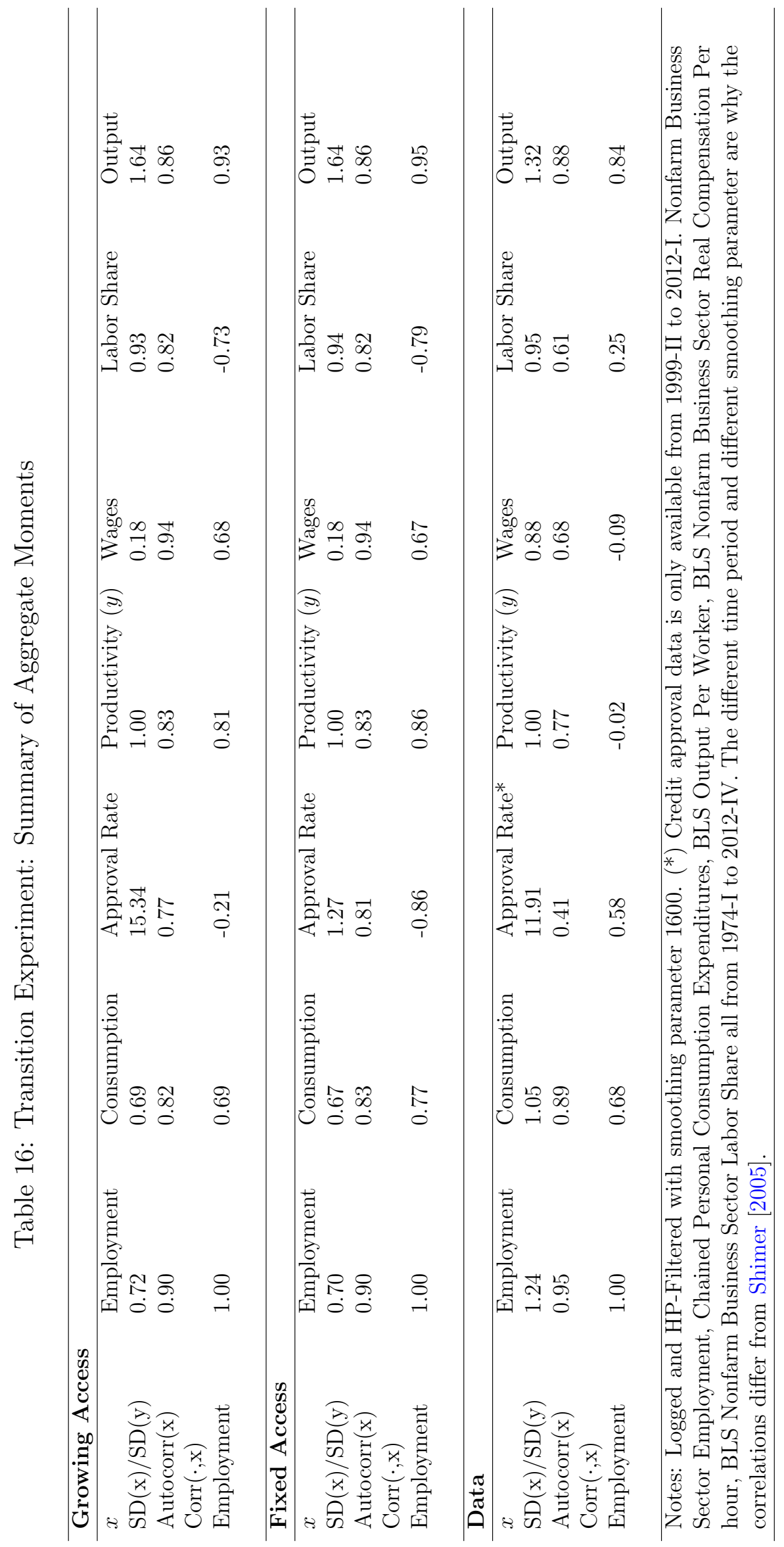


Figure 30: Transition Experiment: Income Dispersion

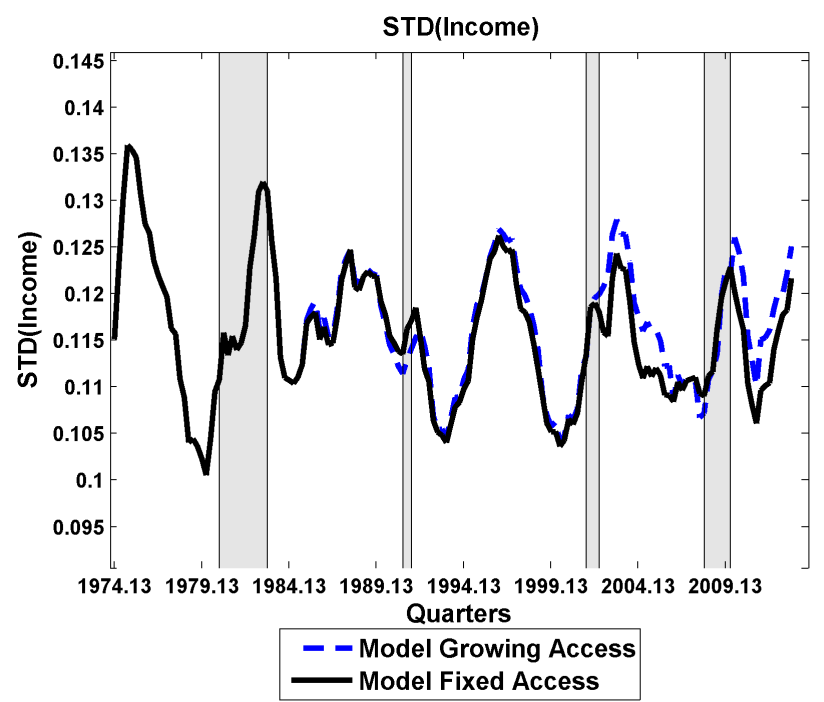

Figure 32: Transition Experiment: Income Per Capita

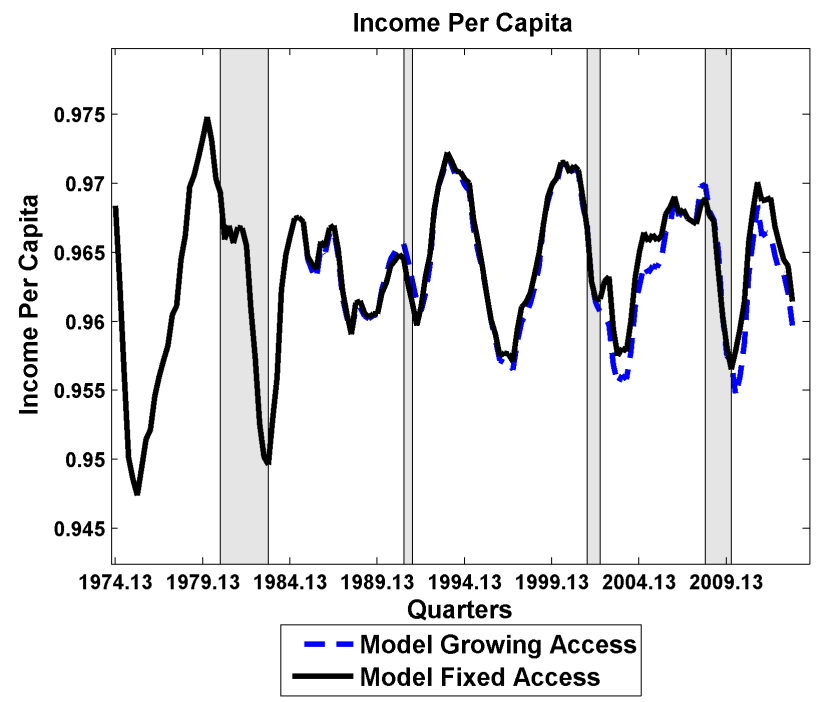

Figure 31: Transition Experiment: Consumption Dispersion

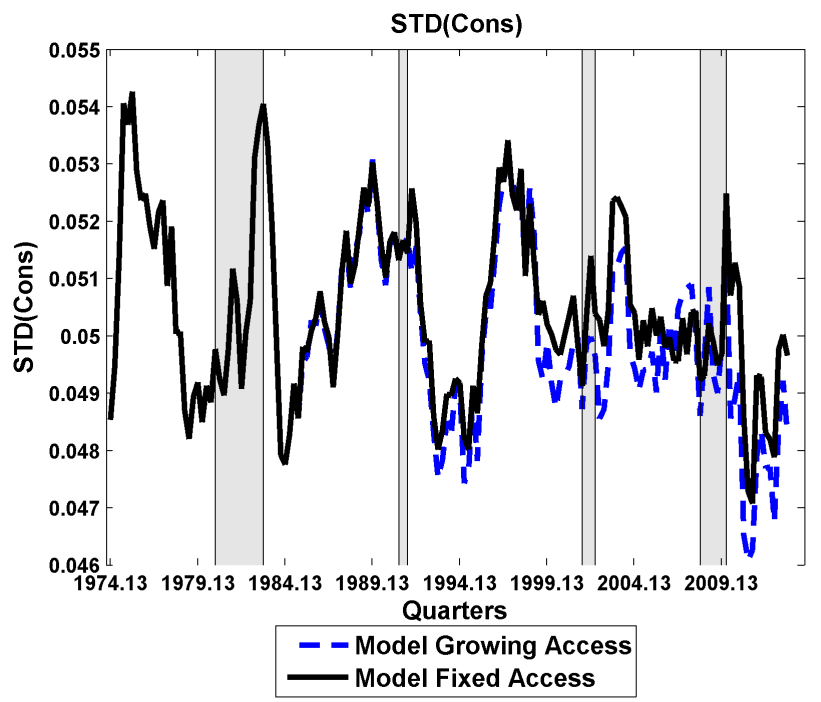

Figure 33: Transition Experiment: Consumption Per Capita

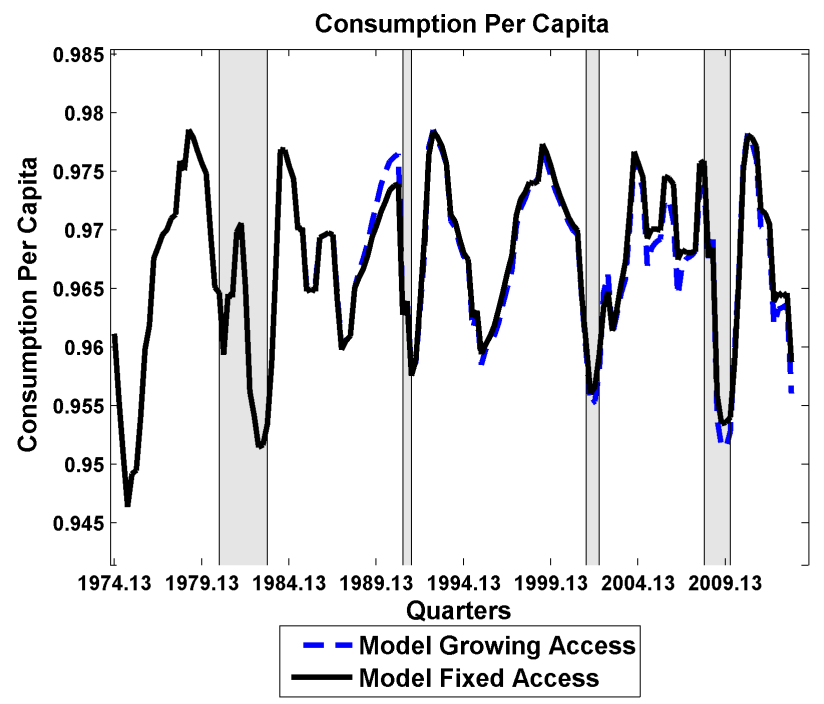

The model, however, does produce several counterfactual business cycle moments including a highly positive correlation between wages and employment. What would help remedy this problem is an idiosyncratic component of productivity (see Menzio and Shi [2011]), but such a modification is beyond the scope of this paper. 
Table 17: Transition Experiment: Business Cycle Correlations of Model's Credit Approval Rate vs. Data (1999-II to 2012-I)

\begin{tabular}{|c|c|c|c|c|c|c|}
\hline \multicolumn{7}{|l|}{ Growing Access } \\
\hline$x$ & Productivity & Consumption & Output & Employment & Wage Bill & Labor Share \\
\hline Corr(Credit Approval Rate, $x$ ) & 0.13 & 0.17 & -0.02 & -0.21 & -0.14 & -0.16 \\
\hline \multicolumn{7}{|l|}{ Fixed Access } \\
\hline$x$ & Productivity & Consumption & Output & Employment & Wage Bill & Labor Share \\
\hline Corr(Credit Approval Rate, $x$ ) & -0.93 & -0.81 & -0.93 & -0.86 & -0.58 & 0.88 \\
\hline \multicolumn{7}{|l|}{ Data } \\
\hline$x$ & Productivity & Consumption & Output & Employment & Wage Bill & Labor Share \\
\hline Corr(Credit Approval Rate, $x$ ) & 0.34 & 0.73 & 0.73 & 0.58 & 0.07 & 0.07 \\
\hline
\end{tabular}

Notes: Logged and HP-Filtered with smoothing parameter 1600. Sample period in model and data is 1999-II to 2012-I. Nonfarm Business Sector Employment, Chained Personal Consumption Expenditures, BLS Output Per Worker, BLS Nonfarm Business Sector Real Compensation Per hour, BLS Nonfarm Business Sector Labor Share all from 1974-I to 2012-IV.

Figure 34: Average Default Episode, Employment, Income, Repayment
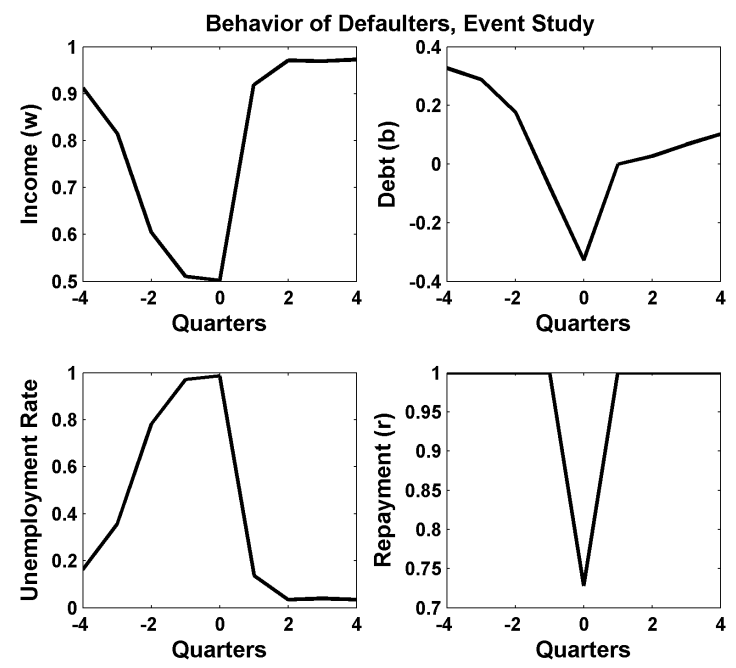

Figure 35: Average Default Episode, Credit Access

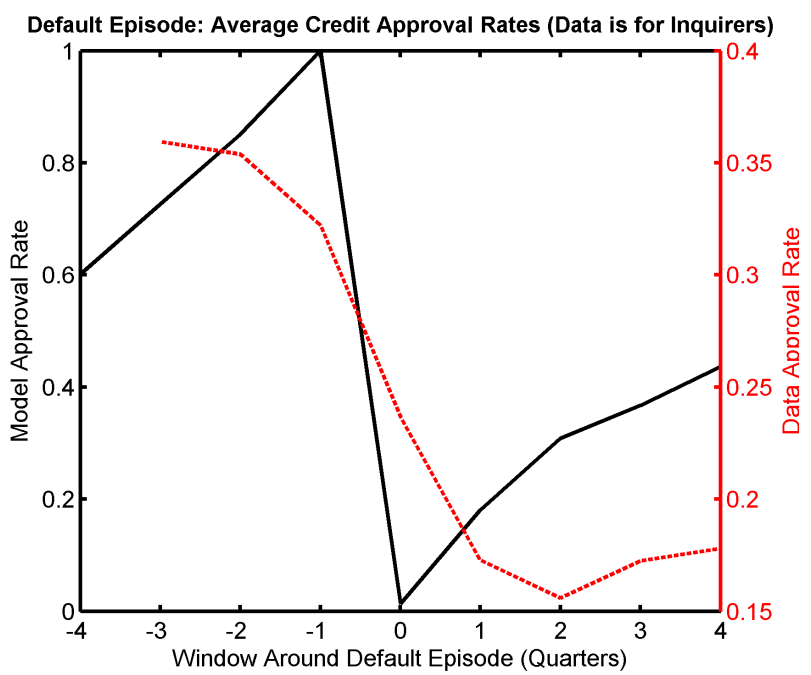

\subsection{Default as Unemployment Insurance}

In terms of default, Figure 34 illustrates what income, debt, employment, and repayment $(r=1-D)$ look like 4 quarters before and after the average default episode $(\mathrm{t}=0$ is the default event). ${ }^{34}$ In the period before default, almost every agent is unemployed (some may have borrowed 2 or 3 periods ago from a prior job loss) and levers up. After unsuccessfully

\footnotetext{
${ }^{34}$ Default is defined to be $90+$ days late in Equifax. Default is defined to be any partial repayment in the model. The figures were generated by simulating the economy, marking default episodes as date 0 , and
} 
finding a job, the agents default- nearly every agent is unemployed in the period of default (there are some employed agents who find jobs and default when credit access is irrelevant to them). This group of unemployed agents is using default as a pure insurance mechanism.

The model's semi-endogenous exclusion response to default shown in Figure 35 can also be compared with reaccess rates from the data. After default, the slow reintegration into credit markets is endogenous and determined by the creditors' willingness to lend to the household. Compared to Equifax credit approval rate data, the model produces approximately similar dynamics, with access remaining relatively low for the 4 quarters following default.

\section{Conclusions}

Unemployed households' access to unsecured revolving credit has grown remarkably over the last 3 decades, and existing studies have shown that such access is an empirically meaningful consumption smoothing mechanism for job losers. The objective of this paper has been to understand how this increased access to unsecured revolving credit affected business cycles.

The paper makes three contributions. Empirically, it presents time series for unemployed households' credit access and credit use from 1970 to 2010. Theoretically, it develops a general equilibrium search and matching model with defaultable debt. And quantitatively, it measures the mechanisms through which credit access impacts unemployment over the business cycle, detailing in a series of experiments the crucial role of credit access growth and its impact on employment recoveries from 1974 to 2012.

After calibrating to the times series on unsecured revolving credit use, the model's transition path shows that growth in households' access to credit markets coming out of the 1990, 2001, and 2007 recessions results in an additional .2 to .8 percentage point decline in employment 12 quarters after the initial downturn. In both the 1990 and 2007 recessions, the increased credit access delays the trough of employment by 1 quarter. The mechanism that generates this employment slowdown is that credit access growth coming out of a recession acts as a safety net allowing households to search for better-paying but harder-to-find jobs. Even though this mechanism protracts recessions and slows recoveries, households would be willing to sacrifice $.12 \%$ of lifetime consumption in order to be born in an economy with 2010 levels of credit access as opposed to an economy with 1970s levels of credit access.

This exercise produces many testable implications. The theory is shown to be consistent with several low frequency trends including the increase in defaults per capita from 1974 to 2012, the long run decline in liquid asset holdings, the rise in unemployment durations, and the decline in consumption dispersion relative to income dispersion.

In light of these findings, there remain several unanswered questions that I plan to pursue

looking at behavior 4 quarters before the default and 4 quarters after the default. I then took averages across people to build the measures (to be consistent, I did the same for the Equifax data). 
in future work. How has default protection changed over this time frame? Has that influenced self-insurance opportunities? Does credit access interact with unemployment benefits? And if so, should the government use loan programs in place of unemployment insurance or is there an optimal mix?

\section{References}

Katharine G Abraham and Robert Shimer. Changes in unemployment duration and labor force attachment. Technical report, National Bureau of Economic Research, 2001.

Daron Acemoglu and Robert Shimer. Efficient unemployment insurance. Technical report, National Bureau of Economic Research, 1998.

R.S Aiyagari. Nonmonetary steady states in stationary overlapping generations models with long lived agents and discounting: Multiplicity, optimality, and consumption smoothing. Journal of Economic Theory, 45 (1):102-127, 1988.

A. Araujo and B. Funchal. How much debtors' punishment? Fundação Getulio Vargas, 2006.

K. Athreya, J.M. Sanchez, X. Tam, and E. Young. A model of credit card delinquency. 2012.

K.B. Athreya and N.B. Simpson. Unsecured debt with public insurance: From bad to worse. Journal of Monetary economics, 53(4):797-825, 2006.

David Autor and David Dorn. Inequality and specialization: the growth of low-skill service jobs in the United States. National Bureau of Economic Research, 2009.

Ruediger Bachmann. Understanding jobless recoveries. University of Michigan, manuscript, 2009.

Yves Balasko and Karl Shell. The overlapping generations model, i: The case of pure exchange without money. Journal of Economic Theory, 23(3):281-306, 1980.

Allen N Berger, Anil K Kashyap, and J.M. Scalise. The transformation of the us banking industry: What a long, strange trip it's been. Brookings papers on economic activity, 1995(2):55-218, 1995.

David Berger. Countercyclical restructuring and jobless recoveries. Manuscript, Yale, 2012.

Zach Bethune, Guillaume Rocheteau, and Peter Rupert. Aggregate unemployment and household unsecured debt. 2013.

Stephen Boyd and Lieven Vandenberghe. Convex optimization. Cambridge university press, 2004.

Kenneth Burdett and Kenneth L Judd. Equilibrium price dispersion. Econometrica: Journal of the Econometric Society, pages 955-969, 1983.

Guillermo A Calvo, Alejandro Izquierdo, and Ernesto Talvi. Phoenix miracles in emerging markets: recovering without credit from systemic financial crises. Technical report, National Bureau of Economic Research, 2006.

Christopher Carroll, Jiri Slacalek, and Martin Sommer. Dissecting saving dynamics: Measuring wealth, precautionary and credit effects. 2012.

S. Chatterjee, D. Corbae, M. Nakajima, and J.V. Ríos-Rull. A quantitative theory of unsecured consumer credit with risk of default. Econometrica, 75(6):1525-1589, 2007.

D. Chen. Impact of personal bankruptcy on labor supply decisions. Technical report, mimeo, 2012.

R. Chetty. Moral hazard vs. liquidity and optimal unemployment insurance. Technical report, National Bureau of Economic Research, 2008.

Thomas F Crossley and Hamish Low. Borrowing constraints, the cost of precautionary saving, and unemployment insurance. Hamilton, Ont., 2005.

Will Dobbie and Jae Song. Debt relief and debtor outcomes: Measuring the effects of consumer bankruptcy protection. Technical report, working paper, 2013.

Lukasz A Drozd and Jaromir B Nosal. Competing for customers: A search model of the market for unsecured credit. Unpublished Manuscript, University of Wisconsin, 2008.

Lukasz A Drozd and Ricardo Serrano-Padial. Dynamic poaching in credit card lending. 2012. 
P. Dubey, J. Geanakoplos, and M. Shubik. Default and efficiency in a general equilibrium model with incomplete markets. Research paper, (879R):915, 1990.

P. Dubey, J. Geanakoplos, and M. Shubik. Default and punishment in general equilibrium1. econometrica, 73(1):1-37, 2005.

J. Eaton and M. Gersovitz. Debt with potential repudiation: Theoretical and empirical analysis. The Review of Economic Studies, pages 289-309, 1981.

M. Furletti. Consumer bankruptcy: how unsecured lenders fare. Technical report, Federal Reserve Bank of Philadelphia, 2003.

G. Gordon. Evaluating default policy: The business cycle matters. 2011.

Veronica Guerrieri and Guido Lorenzoni. Credit crises, precautionary savings, and the liquidity trap. Technical report, National Bureau of Economic Research, 2011.

W.J. Haan, G. Ramey, and J. Watson. Job destruction and propagation of shocks. Technical report, National Bureau of Economic Research, 1997.

Marcus Hagedorn and Iourii Manovskii. Productivity and the labor market: Co-movement over the business cycle. 2010.

Marcus Hagedorn, Fatih Karahan, Iourii Manovskii, and Kurt Mitman. Unemployment benefits and unemployment in the great recession: the role of macro effects. Economics working paper, University of Pennsylvania, 2013.

Song Han and Wenli Li. Fresh start or head start? the effects of filing for personal bankruptcy on work effort. Journal of Financial Services Research, 31(2-3):123-152, 2007.

Gary D Hansen and Ayşe İmrohoroğlu. The role of unemployment insurance in an economy with liquidity constraints and moral hazard. Journal of political economy, pages 118-142, 1992.

K.F. Herkenhoff. Informal unemployment insurance and labor market dynamics. Federal Reserve Bank of St. Louis Working Paper 2012-057A, 2012.

K.F. Herkenhoff and L.E. Ohanian. Labor market dysfunction during the great recession. Technical report, National Bureau of Economic Research, 2011.

K.F. Herkenhoff and L.E. Ohanian. Foreclosure delay and us unemployment. Federal Reserve Bank of St. Louis Working Paper 2012-017A, 2012.

Hugo A Hopenhayn and Juan Pablo Nicolini. Optimal unemployment insurance. Journal of political economy, 105(2):412-438, 1997.

Michael D Hurd and Susann Rohwedder. Effects of the financial crisis and great recession on american households. Technical report, National Bureau of Economic Research, 2010.

E. Hurst and F. Stafford. Home is where the equity is: mortgage refinancing and household consumption. Journal of Money, Credit and Banking, pages 985-1014, 2004.

Louis S Jacobson, Robert J LaLonde, and Daniel G Sullivan. Earnings losses of displaced workers. The American Economic Review, pages 685-709, 1993.

Nir Jaimovich and Henry E Siu. The trend is the cycle: Job polarization and jobless recoveries. Technical report, National Bureau of Economic Research, 2012.

Tullio Jappelli and Marco Pagano. Saving, growth, and liquidity constraints. The Quarterly Journal of Economics, 109(1):83-109, 1994.

F. Karahan and S. Rhee. Housing and the labor market: The role of migration on aggregate unemployment. University of Pennsylvania, mimeo, 2011.

Lawrence F Katz and Bruce D Meyer. Unemployment insurance, recall expectations, and unemployment outcomes. The Quarterly Journal of Economics, 105(4):973-1002, 1990.

Dirk Krueger and Fabrizio Perri. Does income inequality lead to consumption inequality? evidence and theory. The Review of Economic Studies, 73(1):163-193, 2006.

Per Krusell, Toshihiko Mukoyama, and Ayşegül Şahin. Labour-market matching with precautionary savings and aggregate fluctuations. The Review of Economic Studies, 77(4):1477-1507, 2010.

David K Levine. Infinite horizon equilibrium with incomplete markets. Journal of Mathematical Economics, 18(4):357-376, 1989. 
I. Livshits, J. MacGee, and M. Tertilt. Consumer bankruptcy: A fresh start. The American Economic Review, 97(1):402-418, 2007.

L. Ljungqvist and T.J. Sargent. The european unemployment dilemma. Journal of Political Economy, 106 (3):514-550, 1998.

Robert E Lucas. Models of business cycles, volume 26. Basil Blackwell Oxford, 1987.

G. Menzio and S. Shi. Efficient search on the job and the business cycle. Technical report, National Bureau of Economic Research, 2009.

G. Menzio and S. Shi. Block recursive equilibria for stochastic models of search on the job. Journal of Economic Theory, 145(4):1453-1494, 2010.

G. Menzio and S. Shi. Efficient search on the job and the business cycle. Journal of Political Economy, 119 (3):468-510, 2011.

Guido Menzio, Irina A Telyukova, and Ludo Visschers. Directed search over the life cycle. Technical report, National Bureau of Economic Research, 2012.

Loretta J Mester. What's the point of credit scoring? Business review, 3:3-16, 1997.

Kurt Mitman and Stanislav Rabinovich. Do changes in unemployment insurance explain the emergence of jobless recoveries? 2012.

Espen R Moen. Competitive search equilibrium. Journal of Political Economy, 105(2):385-411, 1997.

Dale T Mortensen. Unemployment insurance and job search decisions. Indus. \&5 Lab. Rel. Rev., 30:505, 1976.

D.T. Mortensen and C.A. Pissarides. Job creation and job destruction in the theory of unemployment. The review of economic studies, 61(3):397-415, 1994.

Toshihiko Mukoyama and Ayşegül Şahin. Why did the average duration of unemployment become so much longer? Journal of Monetary Economics, 56(2):200-209, 2009.

Casey B Mulligan. The redistribution recession, 2012.

C.B. Mulligan. A depressing scenario: Mortgage debt becomes unemployment insurance. Technical report, National Bureau of Economic Research, 2008.

Makoto Nakajima. Business cycles in the equilibrium model of labor market search and self-insurance*. International Economic Review, 53(2):399-432, 2012.

Nicolas Petrosky-Nadeau. Credit, vacancies and unemployment fluctuations. Available at SSRN 1508503, 2009.

Nicolas Petrosky-Nadeau and Etienne Wasmer. The cyclical volatility of labor markets under frictional financial markets. American Economic Journal: Macroeconomics, 5(1):193-221, 2013.

Silvio Rendon. Job search and asset accumulation under borrowing constraints. International Economic Review, 47(1):233-263, 2006.

J. Rothstein. Unemployment insurance and job search in the great recession. Technical report, National Bureau of Economic Research, 2011.

Edouard Schaal. Uncertainty, productivity and unemployment in the great recession. Federal Reserve Bank of Minneapolis, mimeo, 2012.

Stacey L Schreft and Aarti Singh. A closer look at jobless recoveries. Economic Review-Federal Reserve Bank of Kansas City, 88(2):45-73, 2003.

R. Shimer. The cyclical behavior of equilibrium unemployment and vacancies. American economic review, pages 25-49, 2005.

Robert Shimer. Wage rigidities and jobless recoveries. Department of Economics, University of Chicago, Working Paper, 2010.

K. Storesletten, C.I. Telmer, and A. Yaron. Cyclical dynamics in idiosyncratic labor market risk. Journal of Political Economy, 112(3):695-717, 2004.

J.X. Sullivan. Borrowing during unemployment. Journal of Human Resources, 43(2):383-412, 2008.

Etienne Wasmer and Philippe Weil. The macroeconomics of labor and credit market imperfections. 2000.

W.R. Zame. Efficiency and the role of default when security markets are incomplete. The American Economic Review, pages 1142-1164, 1993. 


\section{A Proofs for Theoretic Characterization}

\section{A.1 Finite Life Span Economy}

To characterize the model analytically, I must make several basic Assumptions:

\section{A.i Boundedness:}

(a) $w \in \mathcal{W} \equiv[\underline{w}, \bar{w}] \subseteq \mathbb{R}_{+}$

(b) $z \in \mathcal{Z} \equiv[\gamma \underline{w}, \gamma \bar{w}] \subseteq \mathbb{R}_{+}$where $\gamma \in(0,1)$

(c) $b \in \mathcal{B} \equiv[\underline{b}, \bar{b}] \subseteq \mathbb{R}$

(d) $y \in \mathcal{Y} \in[\underline{y}, \bar{y}] \subseteq \mathbb{R}_{+}$

(e) $A \in \mathcal{A} \in[\underline{A}, \bar{A}] \subseteq \mathbb{R}_{+}$

(f) $\mu:\{W, U\} \times\{C, N\} \times \mathcal{W} \times \mathcal{B} \times \mathbb{N}_{T} \rightarrow[0,1]$ (the distribution now includes a distribution over ages $t \in \mathbb{N}_{T}$ )

\section{A.ii Inada Conditions:}

(a) The utility function is twice continuously differentiable, $u^{\prime \prime}<0, u^{\prime}>0, \lim _{c \rightarrow 0} u^{\prime}(c)=+\infty$, and $\lim _{c \rightarrow+\infty} u^{\prime}(c)=0$.

(b) The penalty function is also twice continuously differentiable $x^{\prime \prime}>0, x^{\prime}>0, \lim _{D \rightarrow \bar{D}} x^{\prime}(D)=\infty$, $\lim _{D \rightarrow 0} x^{\prime}(D)=0$.

Restatement of Lemma 3.1: Under the Inada conditions outlined in assumption A.ii (see Appendix A.1), for initial debt levels such that $b \in \mathcal{B}$ and $b<0$, (1) the optimal choice of $D$ is continuously differentiable over the set $[\underline{b}, \epsilon]$ for arbitrarily small $\epsilon<0$ (2) the fraction of debt defaulted upon is monotone increasing in the initial debt position $|b|, b<0$ and (3) the fraction of debt defaulted upon is monotone decreasing in resources borrowed $\left|q_{e, t}\left(w, b^{\prime} ; \Omega\right) b^{\prime}\right|, b^{\prime}<0$ across all ages.

Proof. Claim (1): Under the hypothesis, first order conditions suffice to characterize $D$ when $b \in \mathcal{B}$ and $b<0$ :

$$
-u^{\prime}\left(w+(1-D) b-q_{e, t}\left(w, b^{\prime} ; \Omega\right) b^{\prime}\right) b=x^{\prime}(D)
$$

Definition: Define the continuously differentiable function $\nu:[0,1] \times \mathcal{B} \rightarrow \mathbb{R}$ as follows:

$$
\nu(D, b)=-u^{\prime}\left(w+(1-D) b-q_{e, t}\left(w, b^{\prime} ; \Omega\right) b^{\prime}\right) b-x^{\prime}(D)
$$

Jacobian: The Jacobian of the function $\nu(D, b)$ is shown below for any coordinates such that $\nu\left(D_{0}, b_{0}\right)=0$ and $\left(D_{0}, b_{0}\right) \in[0,1] \times \mathcal{B}_{--}$where $\mathcal{B}_{--}$are all the elements $b \in \mathcal{B}, b<0$,

$$
\begin{aligned}
(D \nu)\left(D_{0}, b_{0}\right)= & {\left[\frac{\partial \nu}{\partial D}\left(D_{0}, b_{0}\right) \mid \frac{\partial \nu}{\partial b}\left(D_{0}, b_{0}\right)\right] } \\
= & {\left[u^{\prime \prime}\left(w+(1-D) b-q_{e, t}\left(w, b^{\prime} ; \Omega\right) b^{\prime}\right) b^{2}-x^{\prime \prime}(D) \mid\right.} \\
& \left.-u^{\prime \prime}\left(w+(1-D) b-q_{e, t}\left(w, b^{\prime} ; \Omega\right) b^{\prime}\right)(1-D) b-u^{\prime}\left(w+(1-D) b-q_{e, t}\left(w, b^{\prime} ; \Omega\right) b^{\prime}\right)\right]
\end{aligned}
$$


Since $u^{\prime \prime}<0$ and $x^{\prime \prime}>0$, the first element of the Jacobian is non-zero so long as the initial state is such that $b \in \mathcal{B}$ and $b<0$. Thus there exists an open set containing $D_{0}, D_{\epsilon}=N_{\epsilon}\left(D_{0}\right)$, an open set containing $b_{0}, B_{\epsilon}=N_{\epsilon}\left(b_{0}\right)$, and a unique continuously differentiable function $D^{*}: B_{\epsilon} \rightarrow D_{\epsilon}$.

Claim (2): Applying the envelope theorem, the expression for the optimal default fraction is given below:

$\frac{d D}{d b}=\left.\frac{u^{\prime \prime}\left(w+(1-D) b-q_{e, t}(w, \hat{b} ; \Omega) \hat{b}\right) b(1-D)+u^{\prime}\left(w+(1-D) b-q_{e, t}(w, \hat{b} ; \Omega) \hat{b}\right)}{u^{\prime \prime}\left(w+(1-D) b-q_{e, t}(w, \hat{b} ; \Omega) \hat{b}\right) b^{2}-x^{\prime \prime}(D)}\right|_{\hat{b}=b_{e, t}^{\prime *}(w, b ; \Omega)} \quad<0 \quad \forall b \in \mathcal{B}, b<0$

If $b<0$ (the only case in which a household would default) then since $u^{\prime \prime}<0, u^{\prime}>0$, and $x^{\prime \prime}>0$, then $\frac{\partial D}{\partial b}<0$. This means that if households begin the period with a small positive perturbation of debt (i.e. $b$ is slightly more negative) they will default on a larger fraction of that debt position.

Claim (3): Let $R=q_{e, t}\left(w, b^{\prime} ; \Omega\right) b^{\prime}<0(>0)$ denote total resources borrowed (saved) in the present period.

$$
\frac{\partial D}{\partial R}=\frac{-u^{\prime \prime}\left(w+(1-D) b-q_{e, t}\left(w, b^{\prime} ; \Omega\right) b^{\prime}\right) b}{u^{\prime \prime}\left(w+(1-D) b-q_{e, t}\left(w, b^{\prime} ; \Omega\right) b^{\prime}\right) b^{2}-x^{\prime \prime}(D)}>0 \quad \forall b \in \mathcal{B}, b<0
$$

This expression says that the fraction of debt defaulted upon is weakly increasing in the amount of resources borrowed. Thus, if $R$ is perturbed to be slightly more negative (i.e. the household has access to more resources), then the household will repay more of the present debt.

Restatement of Corollary 3.2: Under the Inada conditions outlined in assumption A.ii (see Appendix A.1), for initial debt levels such that $b \in \mathcal{B}$ and $b<0$, (1) the equilibrium bond price is continuously differentiable over the interval $[\underline{b}, \epsilon], \epsilon<0$, (2) the equilibrium bond price is monotone decreasing in resources lent and (3) the equilibrium bond price is monotone increasing in subsequent resources borrowed across all ages.

Proof. This is a direct implication of Lemma 3.1 in combination with the equilibrium pricing equation 2.

Restatement of Proposition 3.3: Under the boundedness conditions and Inada conditions outlined in assumptions A.i and A.ii, a Block Recursive Equilibrium exists for the T-span economy.

Proof. Solution Method for T-span Economy: For any given lifespan, it is possible to construct an equilibrium following Menzio et al. [2012].

i. In the last period of life, $q_{e, T}(w, b ; A, y)=0 \quad \forall b \in \mathcal{B}_{-}$(anyone that borrows in their last period of life will not repay anything next period because they will be dead). Thus, $\theta_{e, T}^{C}(w, b ; A, y)=0$ and no one gets credit in the last period. Neither object depends on the distribution.

ii. Obtain the default rule $D_{e, T}^{*, a}(z, b ; A, y)$ and the degenerate asset accumulation rule $b_{e, T}^{\prime *, a}(z, b ; A, y)$ from the household problem at date $T$ :

$$
\begin{gathered}
W_{T}^{C}(w, b)=\max _{D \in[0,1], b^{\prime} \geq 0} u(w+(1-D) b)-x(D) \\
U_{T}^{C}(z, b)=\max _{D \in[0,1], b^{\prime} \geq 0} u(z+(1-D) b)-x(D)+\eta
\end{gathered}
$$


iii. Obtain the labor market tightness $\theta_{T}^{L}(w ; y)$ from the free entry condition and using the fact that $J_{T}(w ; \Omega)=J_{T}(w ; y)=y-w .^{35}$

$$
\theta_{T}^{L}(w ; y)=q^{-1}\left(\frac{\kappa_{L}}{J_{T}(w ; y)}\right)
$$

iv. Given the household default rule $D_{e, T}^{*, a}(z, b ; A, y)$ and the fact that it never makes sense to lend to someone in their last period of life $\left(\theta_{e, T}^{C}(w, b ; A, y)=0\right)$, the household makes new take-it-or-leave-it bond proposals $q_{e, T-1}(w, b ; y, A)$ based on the date $\mathrm{T}$ default policies.

v. Solve HH problem at date $T-1:^{36}$

$$
W_{T-1}^{C}(w, b ; A, y)=\max _{b^{\prime} \in \mathcal{B}, D \in[0,1]} u(c)-x(D)+\beta \mathbb{E}\left[\left(1-\delta\left(w ; y^{\prime}\right)\right) W_{T}\left(w, b^{\prime} ; A^{\prime}, y^{\prime}\right)+\delta\left(w ; y^{\prime}\right) U_{T}\left(\gamma w, b^{\prime} ; A^{\prime}, y^{\prime}\right)\right]
$$

Such that:

$$
\begin{gathered}
c+q_{W, T-1}\left(w, b^{\prime} ; A, y\right) b^{\prime} \leq w+(1-D) b \\
y^{\prime} \sim F\left(y^{\prime} \mid y\right) \\
A^{\prime} \sim G\left(A^{\prime} \mid A\right) \\
U_{T-1}^{C}(z, b ; A, y)=\max _{b^{\prime} \in \mathcal{B}, D \in[0,1]} u(c)-x(D)+\eta+\beta \mathbb{E}\left[\max _{\tilde{w} \in \mathcal{W}} p\left(\theta_{T}^{L}\left(\tilde{w} ; A^{\prime}, y^{\prime}\right)\right) W_{T}\left(\tilde{w}, b^{\prime} ; A^{\prime}, y^{\prime}\right)\right. \\
\left.+\left(1-p\left(\theta_{T}^{L}\left(\tilde{w} ; A^{\prime}, y^{\prime}\right)\right)\right) \widehat{U}_{T}\left(z, b^{\prime} ; A^{\prime}, y^{\prime}\right)\right]
\end{gathered}
$$

Such that:

$$
\begin{aligned}
c+q_{U, T-1}\left(z, b^{\prime} ; \Omega\right) b^{\prime} \leq z+(1-D) b \\
y^{\prime} \sim F\left(y^{\prime} \mid y\right) \\
A^{\prime} \sim G\left(A^{\prime} \mid A\right)
\end{aligned}
$$

and

$$
\widehat{U}_{T}\left(z, b^{\prime} ; A^{\prime}, y^{\prime}\right)=p_{z} U_{T}\left(\underline{z}, b^{\prime} ; A^{\prime}, y^{\prime}\right)+\left(1-p_{z}\right) U_{T}\left(z, b^{\prime} ; A^{\prime}, y^{\prime}\right)
$$

These problems imply optimal rules for default $D_{e, T-1}^{*, a}(z, b ; A, y)$, assets $b_{e, T-1}^{* *, a}(z, b ; A, y)$, and, in the case of the unemployed, the optimal wage posting rule $\tilde{w}_{T-1}^{*}(w, b ; A, y)$. In general, under assumptions A.ii, $D_{e, T-1}^{*, a}(z, b ; A, y)$ is unique; however, $b_{e, T-1}^{\prime *, a}(z, b ; A, y)$ may not be unique. The objective function is continuous and the choice set $\mathcal{B}$ is by assumption compact, thus the objective is bounded and the maximum and minimum are obtained over $\mathcal{B}$ (i.e. the Weierstrass extreme value theorem attains). While this guarantees $a$ solution, the objective function might attain the maximum at two or more different points in the state space. This is irrelevant for the proof that follows, but in section A.2, I prove that for a certain class of matching functions and penalty functions, the asset policy function is unique.

${ }^{35}$ This object is only well defined if $J_{T}>0$ which is discussed below. In general $J_{T}>0$ since $\delta(y, w)=1$ if $y \leq w$, and $J_{T} \geq \min _{i, j}$ s.t. $y(i)>w(j)\{y(i)-w(j)\}$. Notice that the tightness does not depend on credit conditions but the weighted average tightness of visited submarkets will fluctuate with credit access.

${ }^{36}$ For the purposes of reducing clutter, I assume laid off workers must wait one period for search. The same proof works without this assumption. 
vi. Now move back to $T-1$ for the firm to obtain $J_{T-1}(w ; y)$ :

$$
J_{T-1}(w ; y)=y-w+\beta E\left[\left(1-\delta_{T-1}\left(w, y^{\prime}\right)\right) J_{T}\left(w ; y^{\prime}\right)\right]
$$

Such that

$$
\delta_{t}\left(w, y^{\prime}\right)= \begin{cases}1 & \text { if } t>T \text { or } y<w \\ \bar{\delta} & \text { otherwise }\end{cases}
$$

and the shock follows the process

$$
y^{\prime} \sim F\left(y^{\prime} \mid y\right)
$$

vii. Obtain the labor market tightness $\theta_{T-1}^{L}(w ; y)$ from the free entry condition:

$$
\theta_{T-1}^{L}(w ; y)=q^{-1}\left(\frac{\kappa_{L}}{J_{T-1}(w ; y)}\right)
$$

viii. Given $q_{T-1}(w, b ; A, y)$, use $D_{e, T-1}^{*, a}(z, b ; A, y), b_{e, T-1}^{\prime, a}(z, b ; A, y)$ to solve for $Q_{T-1}(e, w, b ; A, y)$. The free entry condition can then be inverted to obtain the credit market tightness:

$$
\theta_{e, T-1}^{C}(w, b ; A, y)=\phi^{-1}\left(\frac{\kappa_{C}}{A \cdot Q_{T-1}(e, w, b ; A, y)}\right)
$$

ix. Repeat this process for $\mathrm{t}=T-2, \cdots, 1$ to obtain a sequence of equilibrium prices that does not depend on the distribution.

This process results in a vector of equilibrium prices for agents aged 1 through $\mathrm{T}$.

\section{A.2 Uniqueness of Finite Life Span Equilibrium}

For certain functional forms, the equilibrium is shown to exist and be unique.

Restatement of Lemma 3.4: Suppose that $x(0)=0$ and $x(D) \rightarrow \infty \forall D>0, M(u, v)=\min \{u, v\}$ and $M_{C}\left(u_{C}, v_{C}\right)=v_{C}^{\alpha_{C}} u_{C}^{1-\alpha_{C}}$ with $\alpha_{C} \rightarrow 0$ (i.e. constant arrival rate of credit offers). Under assumptions A.i-A.ii there exists a unique Competitive Equilibrium that is also Block Recursive.

Proof. (1) Asset Policy Uniqueness: By hypothesis, the bond price is given by $q=\frac{1}{1+r_{f}}$ for $b \geq 0$ and $q=\frac{1}{1+r_{f}+\tau}$ for $b<0$ and the arrival rate of credit is given by a constant $p\left(\theta^{C}\right)=A$.

Let $\mathcal{B}_{-}=\{b \mid b \in \mathcal{B} \cap b \leq 0\}$ be the lending contract space and $\mathcal{B}_{+}=\{b \mid b \in \mathcal{B} \cap b>0\}$ be the saving contract space. Define the strictly concave functions (inherited from $u$ by hypothesis) $u_{j}: \mathcal{B} \rightarrow \mathbb{R}$ for $j \in\{+,-\}$ such that:

i. $u_{-}\left(b^{\prime}\right)=u\left(w+b+\frac{b^{\prime}}{1+r_{f}+\tau}\right)$ which corresponds to the actual utility function $\forall b^{\prime} \in \mathcal{B}_{-}$.

ii. $u_{+}\left(b^{\prime}\right)=u\left(w+b+\frac{b^{\prime}}{1+r_{f}}\right)$ which corresponds to the actual utility function $\forall b^{\prime} \in \mathcal{B}_{+}$.

Define $u^{*}\left(b^{\prime}\right)=\min _{j}\left\{u_{j}\left(b^{\prime}\right)\right\}$. By construction, this is the objective function of the household's dynamic programming problem. The minimum of continuous functions is continuous and the minimum of strictly concave functions is strictly concave (see Boyd and Vandenberghe [2004]), but may not be differentiable. 
However, since the theorem of the maximum does not require differentiability, there exists a unique policy function $b^{* *}$ and the resulting objective function is strictly concave in $b$. Iterating backwards from $t=$ $T, T-1, \ldots, 1$, the objective function is strictly concave in net assets and there exists a unique net asset policy function for each age.

(2) Wage Policy Uniqueness: Iterating backwards from $t=T, T-1, \ldots, 1$, the objective function is strictly concave and differentiable with respect to the wage. In the last period of life, trivially $W_{T}^{j}\left(w, b^{\prime} ; \Omega\right)$ for $j \in\{C, N\}$ is strictly concave and differentiable in the wage.

For ease of exposition, consider the case where $y$ is non-stochastic and job destruction is constant $\bar{\delta}{ }^{37}$ Under these assumptions, the value of a firm is given by:

$$
J_{t}(w ; y)=\frac{y-w}{1-\beta(1-\bar{\delta})}-\beta^{T-t}(1-\bar{\delta})^{T-t} \frac{y-w}{1-\beta(1-\bar{\delta})}
$$

Using the matching function and the free entry condition, it is possible to solve for the job finding rate of households:

$$
p\left(\theta_{t}^{L}(w ; y)\right)=\theta_{t}^{L}(w ; y)=\frac{\kappa_{L}}{A J_{t}(w ; y)} \propto c_{0}(t) w+c_{1}(t) y
$$

with $c_{0}(t)<0$ and $c_{1}(t)>0$ for all $t \in\{1, \ldots, T\}$. It is straightforward to show that for any strictly concave function $f(x)$, the function $(a x+b) \cdot f(x)+(1-(a x+b)) \cdot \bar{u}$ is strictly concave and differentiable for any constant $\bar{u}$ so long as $a<0$ and $a x+b>0$. Therefore, the objective function of households in the labor market is strictly concave and differentiable with respect to wages:

$$
\max _{\tilde{w}} p\left(\theta_{t}^{L}(\tilde{w} ; y)\right) W_{t}^{j}\left(\tilde{w}, b^{\prime} ; \Omega\right)+\left(1-p\left(\theta_{t}^{L}(\tilde{w} ; y)\right)\right) U_{t}^{j}\left(z, b^{\prime} ; \Omega\right)
$$

Thus starting from $T$ and working backward and repeatedly applying the theorem of the maximum, a unique $\tilde{w}^{*}$ exists and the resulting objective function is strictly concave in $w$.

Restatement of Corollary 3.6: Under the assumptions of Lemma 3.4, the wage policy function of the household is increasing in credit access.

Proof. Suppressing states to conserve space, the optimal wage is chosen such that:

$$
\frac{\partial p_{t}}{\partial \theta_{t}} \frac{\partial \theta_{t}}{\partial \tilde{w}}\left(W_{t}-U_{t}\right) \leq-p_{t} \frac{\partial W_{t}}{\partial \tilde{w}} \quad(\text { with equality if } w \in(\underline{w}, \bar{w}))
$$

Use the functional form assumption for $M(u, v)$ and the fact that $p_{t}=\theta_{t}>0$ to obtain the following criteria for an interior wage choice:

$$
\begin{aligned}
& \frac{c_{0}(t)}{p_{t}}\left(W_{t}-U_{t}\right)=-\frac{\partial W_{t}}{\partial \tilde{w}} \\
& L H S=\underbrace{\frac{c_{0}(t)}{p_{t}}}_{(-), \text {grows more neg as w incr. }} \times \underbrace{\left(W_{t}-U_{t}\right)}_{(+), \text {grows more pos as w incr. }}
\end{aligned}
$$

\footnotetext{
${ }^{37}$ All of the following results are attainable with a Markovian assumption for $y$ and no restrictions on the job destruction rate. An N-state Markov process allows one to solve for $J_{t}\left(w ; y_{N}\right)$ analytically, similar to what is done here.
} 


$$
R H S=\underbrace{-\frac{\partial W_{t}}{\partial \tilde{w}}}_{(-), \text {grows less neg as w incr. }}
$$

An increase in credit access increases the value of unemployment $U_{t}$ relative to working $W_{t}$. Thus, the increase in credit access tends to make the LHS of Equation 5 (the incremental value of waiting) less negative at every point in the wage choice set. Equality is restored by increasing the reservation wage to make the RHS of Equation 5 (the incremental value of taking a job) less negative. Following such a credit access perturbation, the resulting reservation wage is strictly greater than the initial reservation wage if the agent begins with an interior initial wage. Figure 36 illustrates this graphically.

Figure 36: Comparative Statics: Increase Access to Unsecured Credit, Increase the Reservation wage from $\mathrm{w}$ to $\mathrm{w}$ '

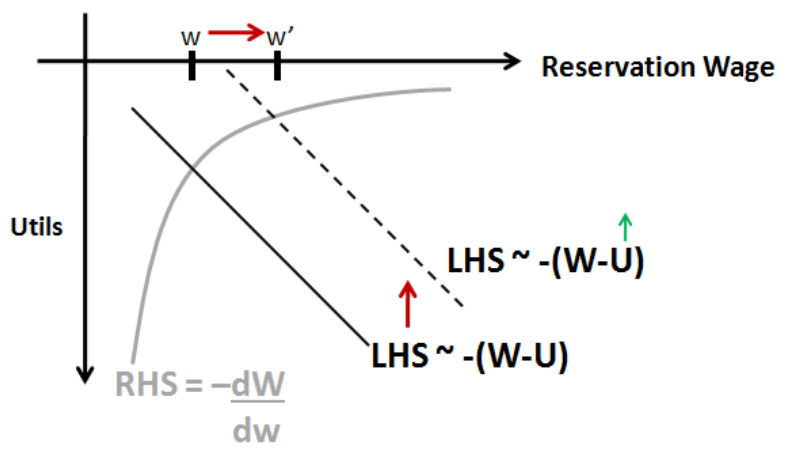

\section{A.3 Infinite Life Span Existence}

I will use arguments similar to Balasko and Shell [1980] and Levine [1989] in order to establish existence. The basic premise of the proof is as follows.

i. Solve for the finite T-lifespan set of equilibrium prices using backward induction as in Proposition 3.3. The solution should be independent of the distribution of households across states.

ii. This price vector is compact and non-empty. ${ }^{38}$

iii. Now increase the lifespan by 1 year. Repeat the above steps. The new price vector is compact and non-empty, but more importantly, it is nested in the previous price vector.

iv. As the life span tends to infinity, the limiting price vector is the intersection of these nested compact non-empty sets, and is therefore non-empty.

Fix the lifespan at $T$ years and apply the backward induction steps of Section A.1. This process results in a vector of equilibrium prices for agents aged 1 through $\mathrm{T}$. I will call these prices the determinate prices.

\footnotetext{
${ }^{38}$ Conditions to ensure all potential t-span prices lie in a compact space are given below. Technically, as will be explained below, the price vector is also defined to include the irrelevant ages from $-1,-2,-3$, and onward.
} 
For technical reasons, I must define indeterminate prices for ages $-1,-2, \ldots$ Even though these prices are irrelevant for the t-span economy, I must define these prices in a way such that they take values in compact intervals that are consistent with $\mathrm{t}+\mathrm{n}$-span economies, $n \in \mathbb{N}_{+}$arbitrary. For these reasons, I must make several additional assumptions:

\section{Assumptions to Ensure Equilibrium Prices Contained in Compact Set:}

B.i Labor Tightness: I will assume that zero profit matches are destroyed with probability 1:

$$
\delta_{t}(w ; y)= \begin{cases}1 & \text { if } t>T \text { or } y<w \\ \bar{\delta} & \text { if } y>w\end{cases}
$$

Define $J_{\text {max }}=1 /(1-\beta) J_{\text {min }}=\min _{i, j}$ s.t. $y(i)>w(j)\{y(i)-w(j)\}$ Then labor market tightness lies in a closed and bounded interval.

$$
\theta_{t}^{L}(w ; y) \in \Theta^{L} \equiv[\underline{\theta}, \bar{\theta}]=\left[q^{-1}\left(\frac{\kappa_{L}}{J_{\min }}\right), q^{-1}\left(\frac{\kappa_{L}}{J_{\max }}\right)\right] \forall t
$$

B.ii Credit Tightness: Assume there is a minimum loan size $\mathcal{B}=\left[\underline{b},-\epsilon_{b}\right] \cup[0, \bar{b}]$ and further assume that repayment is strictly positive $D \leq \epsilon_{D}<1$, but small enough that even the worst-off unemployed agents with expired benefits can obtain positive consumption $(-1)\left(1-\epsilon_{D}\right) \underline{b}<\underline{z}$. Define $Q_{\max }=\frac{\tau}{1+r_{f}} \bar{b}$ and $Q_{\min }=\frac{\tau}{1+r_{f}} \epsilon_{b} \cdot\left(1-\epsilon_{D}\right)$ Then the credit market tightness lies in a closed and bounded interval, $A \in[\underline{A}, \bar{A}]$.

$$
\theta_{t}^{C}(w ; y, A) \in \Theta^{C} \equiv[\underline{\theta}, \bar{\theta}]=\left[\phi^{-1}\left(\frac{\kappa_{C}}{\underline{A} Q_{\min }}\right), \phi^{-1}\left(\frac{\kappa_{C}}{\bar{A} Q_{\max }}\right)\right] \forall t
$$

B.iii Bond Price: Since $D \in\left[0, \epsilon_{D}\right]$ and $\epsilon_{D}>0$ it must be the case that $q \in\left[\frac{1-\epsilon_{D}}{1+r_{f}}, \frac{1}{1+r_{f}}\right] \equiv \mathcal{Q}$.

Consider equilibrium prices vectors that extend from $-\infty$ to $T$, where bond prices lie in their respective compact intervals outlined above $q_{0, e}(w, b ; A, y), q_{-1, e}(w, b ; A, y), \ldots \in \mathcal{Q}$, labor market tightnesses lie in their respective compact intervals outlined above $\theta_{0}(w, b ; A, y), \theta_{-1, e}^{L}(w, b ; A, y), \ldots \in \Theta^{L}$, and credit market tightnesses lie in their respective compact intervals outlined above $\theta_{0, e}^{C}(w, b ; A, y), \theta_{-1, e}^{C}(w, b ; A, y), \ldots \in \Theta^{C}$. The price vector is thus given below: ${ }^{39}$

$$
p_{T, e}(w, b ; A, y)=\left[\begin{array}{ccc|ccc}
\cdots & q_{-1, e}(w, b ; A, y) & q_{0, e}(w, b ; A, y) & q_{1, e}(w, b ; A, y) & \cdots & q_{T, e}(w, b ; A, y) \\
\cdots & \theta_{-1, e}^{L}(w, b ; A, y) & \theta_{0}^{L}(w, b ; A, y) & \theta_{1}^{L}(w, b ; A, y) & \cdots & \theta_{T}^{L}(w, b ; A, y) \\
\cdots & \theta_{-1, e}^{C}(w, b ; A, y) & \theta_{0, e}^{C}(w, b ; A, y) & \theta_{1, e}^{C}(w, b ; A, y) & \cdots & \theta_{T, e}^{C}(w, b ; A, y)
\end{array}\right]
$$

Define $p_{T}^{+}$as the sub matrix of equilibrium prices for ages 1 through T. This vector is unique and pinned down using the solution method outlined above.

$$
p_{T, e}^{+}(w, b ; \Omega)=\left[\begin{array}{ccc}
q_{1, e}(w, b ; A, y) & \cdots & q_{T, e}(w, b ; A, y) \\
\theta_{1}^{L}(w, b ; A, y) & \cdots & \theta_{T}^{L}(w, b ; A, y) \\
\theta_{1, e}^{C}(w, b ; A, y) & \cdots & \theta_{T, e}^{C}(w, b ; A, y)
\end{array}\right]
$$

\footnotetext{
${ }^{39}$ I have partitioned the matrix in a particular way to isolate the determinate portion from the indeterminate portion.
} 
Define $p_{T}^{-}$as the sub matrix of ages less than or equal to zero. In a T-period economy, the vector of prices for ages less than 1 are arbitrary so long as they live in the compact intervals implied by assumption A.i-A.iii:

$$
p_{T, e}^{-}(w, b ; \Omega)=\left[\begin{array}{ccc}
\cdots & q_{-1, e}(w, b ; A, y) & q_{0, e}(w, b ; A, y) \\
\cdots & \theta_{-1, e}^{L}(w, b ; A, y) & \theta_{0}^{L}(w, b ; A, y) \\
\cdots & \theta_{-1, e}^{C}(w, b ; A, y) & \theta_{0, e}^{C}(w, b ; A, y)
\end{array}\right]
$$

Suppose instead consumers live until age $T+1$. The price vector for the $T+1$ economy is given below:

$$
p_{T+1, e}(w, b ; A, y)=\left[\begin{array}{cc|cccc}
\cdots & q_{0, e}(w, b ; A, y) & q_{1, e}(w, b ; A, y) & \cdots & q_{T, e}(w, b ; A, y) & q_{T+1, e}(w, b ; A, y) \\
\cdots & \theta_{0}^{L}(w, b ; A, y) & \theta_{1}^{L}(w, b ; A, y) & \cdots & \theta_{T}^{L}(w, b ; A, y) & \theta_{T}^{L}(w, b ; A, y) \\
\cdots & \theta_{0, e}^{C}(w, b ; A, y) & \theta_{1, e}^{C}(w, b ; A, y) & \cdots & \theta_{T, e}^{C}(w, b ; A, y) & \theta_{T+1, e}^{C}(w, b ; A, y)
\end{array}\right]
$$

Relabel the elements such that $\tilde{T}=T+1$ (it is always possible to relabel the elements such that $\tilde{T}=T+N$ as $N \rightarrow \infty)$. Define $p_{\tilde{T}}^{+}$as the sub matrix for agents whose transformed age is between 1 and $\tilde{T}$.

Based on the equilibrium construction method, $p_{\tilde{T}}^{+}=p_{T}^{+}$. In other words, the prices implied by solving the model in the last period of life are the same across different life spans. It does not matter if the life span is 10 years or 20 years, in the last period of life the problem is always the same.

Now notice that when $\tilde{T}<1$, the implied prices $\left.\left(q_{\tilde{T}, e}(w, b ; A, y), \theta_{\tilde{T}}^{L}(w, b ; A, y), \theta_{\tilde{T}, e}^{C}(w, b ; A, y)\right)\right) \in \mathcal{Q} \times$ $\Theta^{L} \times \theta^{C}$ must lie in the compact intervals outlined in assumptions A.i-A.iii. Thus, the equilibrium price vectors are nested since the elements of $p_{T}^{-}$can assume any value in the set $\mathcal{Q} \times \Theta^{L} \times \theta^{C}$.

Definition: Let $\mathcal{P}(t)$ be the equilibrium vector of prices for an economy in which agents live t periods:

$\mathcal{P}(t)=\left\{p_{t} \mid p_{t}^{+}\right.$solves equilibrium conditions age 1 to age $\mathrm{t}$ and all elements of $\left.p_{t}^{-} \in \mathcal{Q} \times \Theta^{L} \times \theta^{C}\right\}$

As outlined above, $p_{t}=\left(q, \theta^{L}, \theta^{C}\right)^{\prime}$ summarizes the age specific equilibrium prices and $p_{t}^{+}$a determinate vector of the sub-coordinates of $p_{t}$ for attainable ages.

Lemma A.1. Under assumptions A.i-A.ii and B.i-B.iii, $\mathcal{P}(t)$ is non-empty and compact.

Proof. Non-emptiness: The above solution method yields a unique vector for $p_{t}^{+}$. Let $p_{t}^{-}$have arbitrary elements selected from the set $\mathcal{Q} \times \Theta^{L} \times \theta^{C}$. Then $p=\left[p_{t}^{-}, p_{t}^{+}\right] \in \mathcal{P}(t)$ is an equilibrium price vector.

Compactness: Under assumptions B.i-B.iii, all possible t-span equilibrium price vectors have elements that reside in the compact set $\mathcal{Q} \times \Theta^{L} \times \theta^{C}$.

$p_{t}^{+}$is uniquely defined thus, those coordinates are compact. The arbitrary price vector $p_{t}^{-}$is forced to live in a closed and bounded interval. Thus $\mathcal{P}(t)$ is compact for every $t=0,1,2, \cdots$.

Lemma A.2. The equilibrium price vectors are nested such that $\mathcal{P}(t+1) \subset \mathcal{P}(t) \quad \forall i>1$

Proof. Implied by construction.

Restatement of Proposition 3.5: Under assumptions A.i-A.ii and B.i-B.iii, there exists an equilibrium sequence of prices for an infinitely lived agent economy where the equilibrium sequence of prices is independent of the distribution across states. 
Proof. Following Balasko and Shell [1980] it is sufficient to show that $\mathcal{P}(\infty)$ is non-empty to establish existence. Note that $\mathcal{P}(\infty)=\cap_{t=1}^{\infty} \mathcal{P}(t)$ by construction. Since $\mathcal{P}(\infty)$ is the intersection of nested, nonempty, compact intervals, $\mathcal{P}(\infty)$ is non-empty.

\section{B Long Lived Credit Relationships: Lending Institu- tions}

When there are long lived credit relationships, the lender's problem is no longer static and must be solved via dynamic programming. I assume that the relationship is broken up endogenously in the case of a default and for exogenous reasons with probability $\bar{s}$. To operationalize endogenous separation, lenders use a universal default rule.

Universal Default Assumption: Default results in the immediate severance of all lending relationships (summarized by $\Xi(D)$ ).

In the period of default, no credit is made available to the household within the period, and the credit relationship is destroyed with probability one. Let $\Xi(D)$ summarize this universal default rule, where $\Xi(D)=$ 0 if there is a default.

$$
\Xi(D)= \begin{cases}0 & \text { if } D>\underline{D} \\ 1 & \text { if } D=\underline{D}\end{cases}
$$

As before, households make take it or leave it bond price proposals to lenders taking into account the proportional minimum servicing fee. This assumption guarantees lenders the proportional minimum servicing fee $\tau$ on a per-period basis and allows me to express the bond pricing function in a familiar form. Let $D_{e^{\prime}, t+1}^{a^{\prime}}\left(w^{\prime}, \hat{b} ; \Omega^{\prime}\right)$ be the policy function implied by the household's problem, then the bond price can be written as,

$$
q_{e, t}(w, \hat{b}, \hat{D} ; \Omega)= \begin{cases}\frac{\bar{s} \cdot \mathbb{E}\left[\left(1-D_{e^{\prime}, t+1}^{a^{\prime}}\left(w^{\prime}, \hat{b} ; \Omega^{\prime}\right)\right)\right]+(1-\bar{s}) \mathbb{E}\left[\cdot\left(1-D_{e^{\prime}, t+1}^{C}\left(w^{\prime}, \hat{b} ; \Omega^{\prime}\right)\right)\right]}{\left(1+r_{f}+\tau\right)}, & \hat{b} \in \mathcal{B}_{-}, \quad \hat{D}=\underline{D} \\ 0, & \hat{b} \in \mathcal{B}_{-}, \quad \hat{D}>\underline{D} \\ \frac{1}{\left(1+r_{f}\right)}, & \hat{b} \in \mathcal{B}_{+}\end{cases}
$$

The net present value of profits accruing to the lender must now reflect the future service revenue flows which depend on household policy functions. As such, the lender must forecast future household decisions which is summarized by the recursive equation below:

$$
\begin{aligned}
Q_{t}(e, w, b ; \Omega)=(1-\Xi(\hat{D}))\{ & q_{e, t}(w, \hat{b}, \hat{D} ; \Omega) \hat{b}-\bar{s} \cdot \frac{1}{1+r_{f}} \mathbb{E}\left[\left(1-D_{e^{\prime}, t+1}^{a^{\prime}}\left(w^{\prime}, \hat{b} ; \Omega^{\prime}\right)\right) \cdot \hat{b}\right]-(1-\bar{s}) \cdot \frac{1}{1+r_{f}} \mathbb{E}\left[\left(1-D_{e^{\prime}, t+1}^{\mathbf{C}}\left(w^{\prime}, \hat{b} ; \Omega^{\prime}\right)\right) \cdot \hat{b}\right] \\
& \left.+(1-\bar{s}) \frac{1}{1+r_{f}} \mathbb{E}\left[Q_{t+1}\left(e^{\prime}, w^{\prime}, \hat{b} ; \Omega^{\prime}\right)\right]\right\}\left.\right|_{\hat{b}=b_{e, t}^{\prime *}(w, b ; \Omega), \quad \hat{D}=D_{e, t}^{C}(w, b ; \Omega), \quad e \in\{W, U\}, \quad b \in \mathcal{B}}
\end{aligned}
$$

\section{On The Job Search Extension}

Let $\lambda$ be the probability of a worker conducting on-the-job-search. Firms must know the entire state vector of the household in order to forecast future job changes and form expectations. In this extension, firms are 
allowed to condition job offers on the proposed wage $w \in \mathcal{W}$, the assets of the applicant $b \in \mathcal{B}$, the current credit access of the applicant $a \in\{C, N\}$ (in the case of long lived credit relationships, this is a relevant state), the age of the applicant $t$, and the aggregate state $\Omega=(\mu, y, A)$.

The submarket tightness is therefore given by $\theta_{t}^{L}(a, w, b ; \Omega)=\frac{v_{t}(a, w, b ; \Omega)}{u_{t}(a, w, b ; \Omega)}$ where $v_{t}(a, w, b ; \Omega)$ is the number of vacancies posted in the $(a, w, b, t ; \Omega)$ submarket and $u_{t}(a, w, b ; \Omega)$ is the number of unemployed people in that submarket. The corresponding vacancy-filling rate in that submarket is $f\left(\theta_{t}^{L}(a, w, b ; \Omega)\right)$. Let $J_{t}^{a}(w, b ; \Omega)$ be the continuation value of a firm matched with a household state vector $(a, w, b, t ; \Omega)$. With this notation, the value of posting a vacancy in submarket $(a, w, b ; \Omega)$ is given by,

$$
V_{t}(a, w, b ; \Omega)=-\kappa_{L}+f\left(\theta_{t}^{L}(a, w, b ; \Omega)\right) J_{t}^{a}(w, b ; \Omega)
$$

With free entry it must be the case that profits are competed away. Thus, the market tightness is given by,

$$
\theta_{t}^{L}(a, w, b ; \Omega)=f^{-1}\left(\frac{\kappa_{L}}{J_{t}^{a}(w, b ; \Omega)}\right) \text { if } \theta_{t}^{L}(a, w, b ; \Omega)>0
$$

The firm takes as given (i) $\tilde{w}_{C}^{*}=\tilde{w}_{W, t+1}^{C}(w, b ; \Omega)$ which is the optimal 'on-the-job-search' policy function for households with credit, (ii) $\tilde{w}_{N}^{*}=\tilde{w}_{W, t+1}^{N}(w, b ; \Omega)$ which is the optimal on-the-job-search policy for households without credit, (iii) $D^{*}=D_{W, t}^{C *}(w, b ; \Omega)$ which is the optimal default policy function for employed households with credit, and (iv) $b^{*}=b_{W, t}^{* * C}(w, b ; \Omega)$ which is the optimal asset accumulation policy function for households with credit. Taking the household policy functions as given, the value of an ongoing match to a firm with an age $t$ worker with credit access (C), wage $w$, and assets $b$ is given below:

$$
\begin{array}{r}
J_{t}^{C}(w, b ; \Omega)=y-w+\left(1-s\left(D^{*}\right)\right) \beta \mathbb{E}_{\Omega^{\prime}}\left[\left(1-\lambda p\left(\theta_{t+1}^{L}\left(C, \tilde{w}_{C}^{*}, b^{*} ; \Omega^{\prime}\right)\right)\right) \cdot\left(1-\delta_{t+1}\left(w ; y^{\prime}\right)\right) \cdot J_{t+1}^{C}\left(w, b^{*} ; \Omega^{\prime}\right)\right] \\
+s\left(D^{*}\right) \beta \mathbb{E}_{\Omega^{\prime}}\left[\left(1-\lambda p\left(\theta_{t+1}^{L}\left(N, \tilde{w}_{N}^{*}, b^{\prime} ; \Omega^{\prime}\right)\right)\right) \cdot\left(1-\delta_{t+1}\left(w ; y^{\prime}\right)\right) \cdot J_{t+1}\left(w, b^{\prime *} ; \Omega^{\prime}\right)\right]
\end{array}
$$

such that firms take the aggregate law of motion as given (the equations are given by (1)) and the evolution of the credit status of the employee is taken into account,

$$
J_{t}(w, b ; \Omega)=A \psi\left(\theta_{W, t}^{C}(w, b ; \Omega)\right) J_{t}^{C}(w, b ; \Omega)+\left(1-A \psi\left(\theta_{W, t}^{C}(w, b ; \Omega)\right)\right) J_{t}^{N}(w, b ; \Omega)
$$

A similar set of equations hold for a firm matched with a household that does not have credit access. These equations are in the online appendix.

\section{C.0.1 On the Job Search: Household Problem}

With on-the-job-search and long term credit relationships, the household problem must reflect the probability that a credit relationship is destroyed $(s(D))$ along with the opportunity to engage in on-the-job-search. ${ }^{40}$

\footnotetext{
${ }^{40}$ For the purposes of reducing clutter, I assume laid off workers must wait one period to search. The simulations shown below add back this feature.
} 
For an employed agent (W) with credit access (C), their dynamic programming problem is given by,

$$
\begin{aligned}
W_{t}^{C}(w, b ; \Omega)=\max _{b^{\prime} \in \mathcal{B}, D \in[0,1]} u(c)-x(D)+s(D) & \cdot \beta \mathbb{E}\left[( 1 - \delta _ { t + 1 } ( w ; y ^ { \prime } ) ) \left\{\max _{\tilde{w} \in \mathcal{W}} \lambda p\left(\theta_{t+1}^{L}\left(N, \tilde{w}, b^{\prime} ; \Omega^{\prime}\right)\right) W_{t+1}\left(\tilde{w}, b^{\prime} ; \Omega^{\prime}\right)\right.\right. \\
& \left.\left.+\left(1-\lambda p\left(\theta_{t+1}^{L}\left(N, \tilde{w}, b^{\prime} ; \Omega^{\prime}\right)\right)\right) W_{t+1}\left(w, b^{\prime} ; \Omega^{\prime}\right)\right\}+\delta_{t+1}\left(w ; y^{\prime}\right) U_{t+1}\left(\gamma w, b^{\prime} ; \Omega^{\prime}\right)\right] \\
+(1-s(D)) \cdot \beta \mathbb{E}[ & \left(1-\delta_{t+1}\left(w ; y^{\prime}\right)\right)\left\{\max _{\tilde{w} \in \mathcal{W}} \lambda p\left(\theta_{t+1}^{L}\left(C, \tilde{w}, b^{\prime} ; \Omega^{\prime}\right)\right) W_{t+1}^{C}\left(\tilde{w}, b^{\prime} ; \Omega^{\prime}\right)\right. \\
& \left.\left.+\left(1-\lambda p\left(\theta_{t+1}^{L}\left(C, \tilde{w}, b^{\prime} ; \Omega^{\prime}\right)\right)\right) W_{t+1}^{C}\left(w, b^{\prime} ; \Omega^{\prime}\right)\right\}+\delta_{t+1}\left(w ; y^{\prime}\right) U_{t+1}^{C}\left(\gamma w, b^{\prime} ; \Omega^{\prime}\right)\right]
\end{aligned}
$$

Such that the law of motion for aggregates holds (the equations are given by (1)) and the budget constraint is satisfied:

$$
c+q_{W, t}\left(w, b^{\prime}, D ; \Omega\right) b^{\prime} \leq w+(1-D) b
$$

\section{C.0.2 On the Job Search: Lending Institutions}

The profit function is the same as before, the only difference is the expectation over $w^{\prime}$ now takes into account that there is on-the-job-search. The recursive statement of the profit function is given below:

$$
\begin{aligned}
Q_{t}(e, w, b ; \Omega)=(1-\Xi(\hat{D}))\{ & q_{e, t}(w, \hat{b}, \hat{D} ; \Omega) \hat{b}-\bar{d} \cdot \frac{1}{1+r_{f}} \mathbb{E}\left[\left(1-D_{e^{\prime}, t+1}^{a^{\prime}}\left(w^{\prime}, \hat{b} ; \Omega^{\prime}\right)\right) \cdot \hat{b}\right]-(1-\bar{d}) \cdot \frac{1}{1+r_{f}} \mathbb{E}\left[\left(1-D_{e^{\prime}, t+1}^{\mathbf{C}}\left(w^{\prime}, \hat{b} ; \Omega^{\prime}\right)\right) \cdot \hat{b}\right] \\
& \left.+(1-\bar{d}) \frac{1}{1+r_{f}} \mathbb{E}\left[Q_{t+1}\left(e^{\prime}, w^{\prime}, \hat{b} ; \Omega^{\prime}\right)\right]\right\}\left.\right|_{\hat{b}=b_{e, t}^{\prime}(w, b ; \Omega), \quad \hat{D}=D_{e, t}^{C}(w, b ; \Omega), \quad e \in\{W, U\}, \quad b \in \mathcal{B}}
\end{aligned}
$$

such that the universal default rule is given by,

$$
\Xi(\hat{D})= \begin{cases}1 & \text { if } \hat{D}>\underline{D} \\ 0 & \text { if } \hat{D}=\underline{D}\end{cases}
$$

and the bond price is given by,

$$
q_{e, t}(w, \hat{b}, \hat{D} ; \Omega)= \begin{cases}\frac{\bar{d} \cdot \mathbb{E}\left[\left(1-D_{e^{\prime}, t+1}^{a^{\prime}}\left(w^{\prime}, \hat{b} ; \Omega^{\prime}\right)\right)\right]+(1-\bar{d}) \mathbb{E}\left[\cdot\left(1-D_{e^{\prime}, t+1}^{C}\left(w^{\prime}, \hat{b} ; \Omega^{\prime}\right)\right)\right]}{\left(1+r_{f}+\tau\right)}, & \hat{b} \in \mathcal{B}_{-}, \quad \hat{D}=\underline{D} \\ 0, & \hat{b} \in \mathcal{B}_{-}, \quad \hat{D}>\underline{D} \\ \frac{1}{\left(1+r_{f}\right)}, & \hat{b} \in \mathcal{B}_{+}\end{cases}
$$

\section{C.1 Transition Experiment: On the Job Search}

Figure 37 illustrates the same 2007 recession experiment along the transition path with on-the-job-search (OJS). All parameters were kept fixed, except there is now a positive probability of conducting OJS given by $\lambda=.1$. Menzio and Shi [2011] use a much larger value of $\lambda=.73$ in order to entirely correct for the counterfactual Beveridge curve generated by models with directed search and no on-the-job-search. ${ }^{41}$ However, such a high probability of on-the-job-search induces counterfactual wage ladders. ${ }^{42}$ On-the-jobsearch alters wage search and acceptance decisions, prompting workers to take the first available job and

\footnotetext{
${ }^{41}$ In down times, firms post lots of vacancies since they will "lock-in" the low wages workers are willing to work for. With on-the-job-search, there is no "lock-in."

${ }^{42}$ See Jacobson et al. [1993] for more on earnings losses after job displacement during recessions.
} 
Figure 37: On the Job Search, 2007 Recession

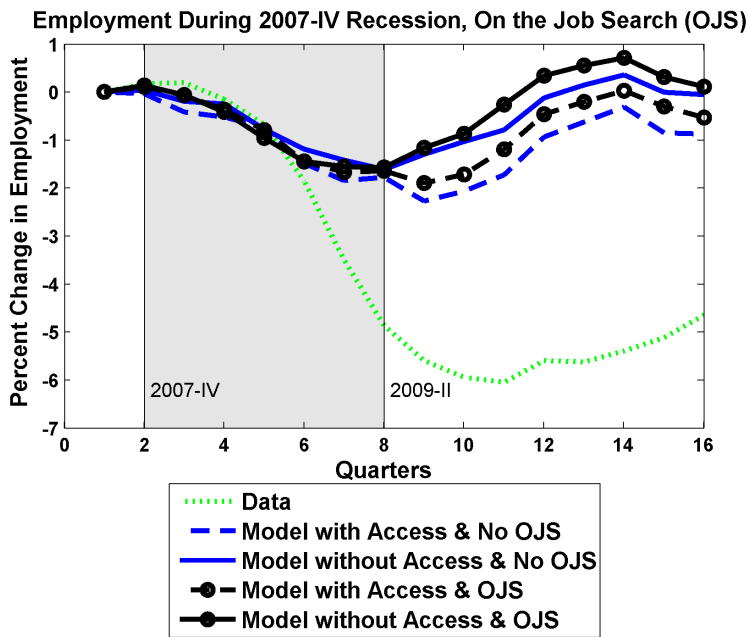

then transit to higher paying jobs later. The gap then between the economy with access and the economy without is smaller with on-the-job-search since the insurance mechanisms are weaker. In some sense, there is an OJS insurance plan which is to take a poorly paying job and then work up the wage ladder. Overall, however, the introduction of on the job search does not change the general quantitative message.

\section{Robustness Checks: Timing}

As a robustness check to the timing of the credit expansions used in the transition path, I consider several different timing assumptions. Holding all other parameters constant, I recalibrate the credit matching efficiency expansions to occur 2 quarters after the trough of the recession and 4 quarters after the trough of the recession. For the 2001 recession, Figure 38 shows the new credit matching efficiency inputs, and Figure 39 demonstrates that the employment deviations 3 years after the 2001 recession remains virtually unchanged. The same holds true for the 1990 and 2007 recessions.

\section{E Estimation of Credit Matching Function}

Annual data from Synovate on the number of direct mail credit card offers from 1990-2007 $\left(v_{c, t}\right)$ were combined with the fraction of SCF respondents in 1995, 1998, 2001, 2004, and 2007 that applied to credit, weighted to reflect the population $\left(f_{c, t}\right) \cdot{ }^{43}$ I also collected data on the CPS civilian working age population

${ }^{43}$ Direct mail credit card orders have been in decline for several years as internet offers have risen, but Synovate estimates that $60 \%$ of the offers direct respondents online to apply. The SCF credit application question is worded as follows: "Have you and your (husband/wife/partner) applied for any type of credit or loan in the last five years? Include Pre-Approved Credit that Respondent Accepted." I aggregate all time series to reflect the 5 year interval in the estimation that follows. 
Figure 38: Alternate Credit Expansion Timing: Credit Match Efficiency Inputs, 2001 Recession

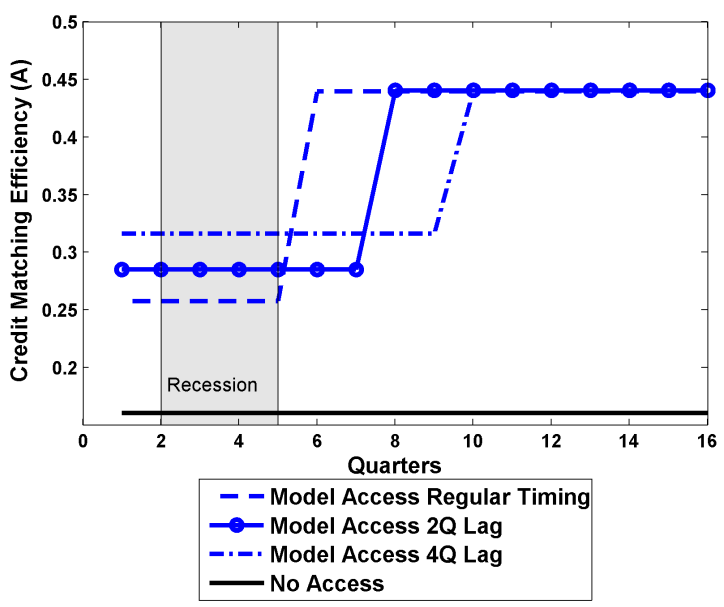

Figure 39: Alternate Credit Expansion Timing: Percentage Change in employment, 2001 Recession

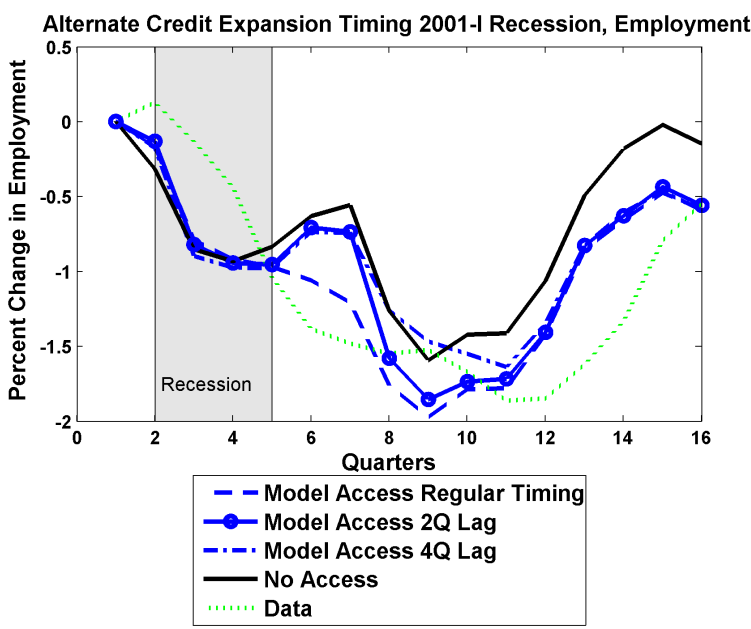

$\left(p o p_{t}\right)$. From this data, it is possible to estimate the number of households that applied for credit $\left(u_{c t}=\right.$ $\left.\operatorname{pop}_{t} \cdot f_{c, t}\right)$. I also used the SCF question regarding credit denial to obtain the probability a household received credit $p_{c, t} \cdot{ }^{44}$ Define $\theta_{c, t}=\frac{v_{c, t}}{u_{c, t}}$ Using the assumed functional form, I estimated $\gamma$ using non-linear least squares:

$$
\begin{aligned}
& A_{c} M\left(u_{c}, v_{c}\right)=A_{c} \frac{u_{c} \cdot v_{c}}{\left(u_{c}^{\gamma}+v_{c}^{\gamma}\right)^{1 / \gamma}} \in[0,1) \\
& \underbrace{A_{c} p(\theta)}_{\text {rerved Match Probability } p_{c, t}}=A_{c} \theta \cdot\left(1+\theta^{\gamma}\right)^{\frac{-1}{\gamma}}
\end{aligned}
$$

The equation that I estimate is given below:

$$
p_{c, t}=A_{c} \theta_{c, t}\left(1+\theta_{c, t}^{\gamma}\right)^{\frac{-1}{\gamma}}+\epsilon_{t}
$$

Estimation yields $A_{c}=.974$ (significant at $1 \%$ ), $\gamma=.383$ (significant at 1\%), with a goodness of fit of .99 . The relatively few observations $(\mathrm{N}=5)$ provided by the SCF limit my ability to estimate $A_{c}$ dynamically, let alone as a static parameter. Estimating the match elasticity after imposing $A_{c}=1$ implies $\gamma=.372$ (significant at $1 \%$ ) with a goodness of fit of .99 .

\section{F Unemployment Duration}

The model predicts an increase in unemployment durations of approximately $\frac{1}{2}$ week relative to an economy with fixed access (see Figure 40). In the data, there is an increase in trend unemployment durations of nearly 3.9 weeks. Thus the model is broadly consistent with the rise in unemployment durations shown in

\footnotetext{
44 The credit denial question is given below: In the past five years, has a particular lender or creditor turned down any request you or your (husband/wife/partner) made for credit, or not given you as much credit as you applied for?
} 
Figure 40: Mean Unemployment Duration, Model 1974-2012

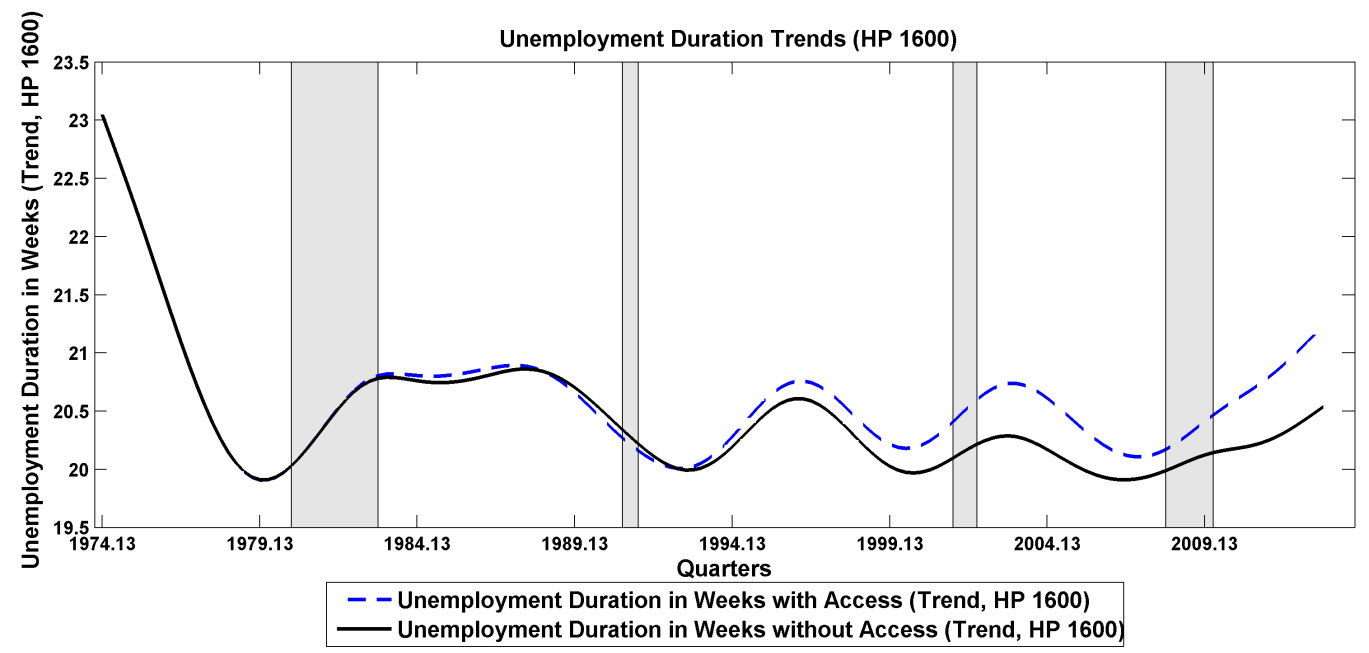

Figures 41 and 42 . Table 18 shows that unemployment durations went up significantly since the 1980s at a low frequency whether or not the 2007-2009 recession is included in the sample.

Figure 41: Mean Unemployment Duration, 1948-2012 (Source: CPS)

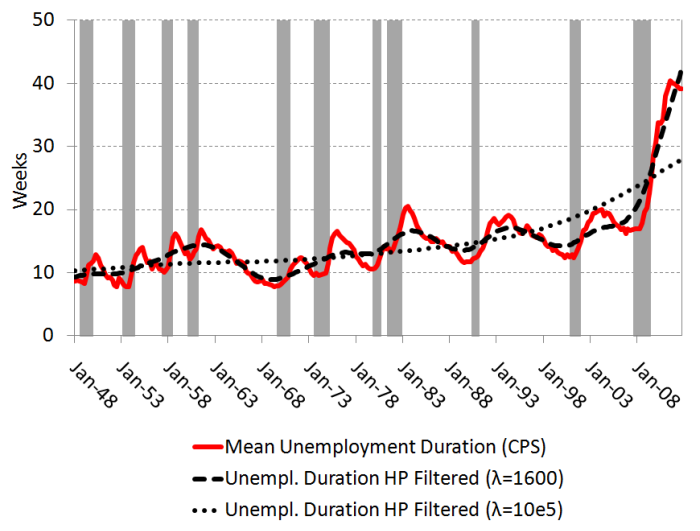

Figure 42: Mean Unemployment Duration, 1948-2007 (Source: CPS)

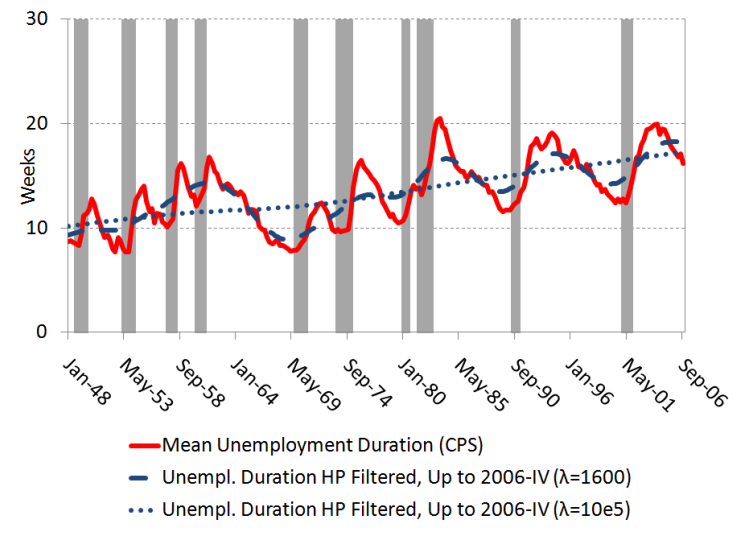

Table 18: Unemployment Durations

\begin{tabular}{|c|c|c|c|c|c|}
\hline $\begin{array}{l}\text { Recession } \\
\text { Trough }\end{array}$ & $\begin{array}{l}\text { Average Unemploy- } \\
\text { ment Duration }\end{array}$ & $\begin{array}{l}\text { Unempl. Duration HP } \\
\text { Filtered }(\lambda=1600)\end{array}$ & $\begin{array}{l}\text { Unempl. Duration HP } \\
\text { Filtered, Up to } 2006- \\
\text { IV }(\lambda=1600)\end{array}$ & $\begin{array}{l}\text { Unempl. Duration HP } \\
\text { Filtered }(\lambda=10 \mathrm{e} 5)\end{array}$ & $\begin{array}{l}\text { Unempl. Duration HP } \\
\text { Filtered, Up to 2006- } \\
\text { IV }(\lambda=10 \mathrm{e} 5)\end{array}$ \\
\hline $1975-\mathrm{I}$ & 11.4 & 12.5 & 12.5 & 12.3 & 12.7 \\
\hline 1991-I & 12.6 & 14.4 & 14.4 & 14.8 & 15.1 \\
\hline 2001-IV & 14.0 & 15.2 & 15.4 & 19.1 & 16.6 \\
\hline 2009-II & 22.6 & 25.2 & NA & 24.8 & NA \\
\hline
\end{tabular}

